\title{
The intragastric bacterial flora in relation to gastric malignancy : methodological and clinical studies
}

Citation for published version (APA):

Jonkers, D. M. A. E. (1997). The intragastric bacterial flora in relation to gastric malignancy:

methodological and clinical studies. [Doctoral Thesis, Maastricht University]. Maastricht University. https://doi.org/10.26481/dis.19970618dj

Document status and date:

Published: 01/01/1997

DOI:

10.26481/dis.19970618dj

Document Version:

Publisher's PDF, also known as Version of record

\section{Please check the document version of this publication:}

- A submitted manuscript is the version of the article upon submission and before peer-review. There can be important differences between the submitted version and the official published version of record.

People interested in the research are advised to contact the author for the final version of the publication, or visit the DOI to the publisher's website.

- The final author version and the galley proof are versions of the publication after peer review.

- The final published version features the final layout of the paper including the volume, issue and page numbers.

Link to publication

\footnotetext{
General rights rights.

- You may freely distribute the URL identifying the publication in the public portal. please follow below link for the End User Agreement:

www.umlib.nl/taverne-license

Take down policy

If you believe that this document breaches copyright please contact us at:

repository@maastrichtuniversity.nl

providing details and we will investigate your claim.
}

Copyright and moral rights for the publications made accessible in the public portal are retained by the authors and/or other copyright owners and it is a condition of accessing publications that users recognise and abide by the legal requirements associated with these

- Users may download and print one copy of any publication from the public portal for the purpose of private study or research.

- You may not further distribute the material or use it for any profit-making activity or commercial gain

If the publication is distributed under the terms of Article $25 \mathrm{fa}$ of the Dutch Copyright Act, indicated by the "Taverne" license above, 


\section{The intragastric bacterial flora in relation to gastric malignancy}

methodological and clinical studies 
- Jonkers, Dorethea Maria Agnes Elisa ISBN 90-9010627-8

Printing of this thesis was financially supported by Astra Pharmaceutica BV and Imphos BV. 


\section{The intragastric bacterial flora in relation to gastric malignancy}

methodological and clinical studies

\section{PROEFSCHRIFT}

ter verkrijging van de graad van doctor aan de Universiteit Maastricht,

op gezag van de Rector Magnificus, Prof. Mr. M.J. Cohen, volgens thet besluit van het College van Decanen,

in het openbaar te verdedigen

op woensdag 18 juni 1997 om 14.00 uur

door

D M A Jonkers

geboren op 02-12-1968 te Nederween 
Promotor

Prof dr RW Stockbrügger

\section{Co-promotores}

Dr EE Stobberingh

Dr AP de Bruine

\section{Beoordelingscommissie}

Prof dr EFM Wouters (voorzitter)

Prof dr CPA van Bowen (Rijksuniversiteit Leiden)

Prof dr MP van Dieijen-Visser

Prof dr SGM Meuwissen (Vrije Universiteit Amsterdam)

Prof dr MF von Meyenfeldt 
Aan: mijn ouders Karel 


\section{Contents}

Chapter I: Introduction 9

Aims of the study 44

Chapter II: Influence of oropharyngeal flora and specimen pretreatment on the recovery of Helicobacter pylori $\mathbf{4 5}$

Chapter III: Evaluation of immunohistochemistry for the detection of Helicobacter pylori in gastric mucosal biopsies $\mathbf{5 7}$

Chapter IV: Ongoing gastric acid inhibition is a confounding factor in Helicobacter pylori diagnosis 69

Chapter V: The gastroduodenal distribution of Helicobacter pylori in patients with duodenal and gastric ulcer: relation to inflammatory changes, mucosal atrophy and intestinal metaplasia in the stomach and gastric metaplasia in the duodenum $\mathbf{8 1}$

Chapter VI: Helicobacter pylori and non-Helicobacter pylori bacterial flora in gastric mucosal and tumour specimens of patients with primary gastric lymphoma 97

Chapter VII: The role of Helicobacter pylori and non-Helicobacter pylori intragastric bacterial flora in gastric cancer: a study in 39 newly diagnosed patients 113

Chapter VIII: General discussion 131

Chapter IX: Summary 141

Chapter X: Samenvatting 147

Dankwoord 153

Curriculum vitae 157

Publications 159 


\section{Chapter I}

\section{Introduction and aims of the study}




\section{Introduction}

The Helicobacter pylori (H.pylori) is associated with gastric and duodenal ulceration and with an increased risk of gastric cancer and gastric mucosaassociated lymphoid tissue (MALT) lymphoma. However, the exact role of H.pylori in these diseases is not yet clear and other factors, like host and environmental factors, may also be involved. Moreover, other bacteria, in this study called the non-H.pylori bacterial flora, can also be present in the stomach depending on the intragastric $\mathrm{pH}$. Their presence is associated with several clinical lesions in which H.pylori can also be found.

\section{Helicobacter pylori}

The first report about the presence of spiral bacteria in the stomach of animals results from Bizzozero in $1893^{1}$. The first study in humans was performed by Doenges $^{2}$ who found spirochaetes in the gastric glands of $43 \%$ of human stomachs exarnined in routine autopsies. In 1983, Warren and Marshall $1^{3}$ described the presence of unidentified curved bacilli on gastric epithelium in active chronic gastritis and were the first to culture the organism. The bacterium was identified as Campylobacter pyloridis ${ }^{4}$ and was later given the name Helicobacter pylori.

\section{Microbiology}

H.pylori is a Gram-negative S-shaped rod measuring $0.5 \times 3.0 \mu \mathrm{m}$ with four to six sheathed flagella attached to one pole ${ }^{5-7}$. The bacterium is highly motile and possesses enzymes including oxidase, catalase, alkaline phosphatase, and a high urease activity ${ }^{5.8 .9}$ but does not reduce nitrate, hydrolyse hippurate, or metabolize glucose ${ }^{5,6}$. H.pylori grows under micro-aerophilic conditions and produces small (1 $\mathrm{mm}$ ) translucent colonies within 3 to 4 days at $37^{\circ} \mathrm{C}^{3,10}$. This fastidiously growing microorganism requires fresh media made with fresh blood or serum and maintenance of an adequate humidity throughout the incubation ${ }^{0,11,12}$. Bacterial cells in older cultures or exposed to oxygen may give rise to coccoid forms ${ }^{6,9}$. The viability of these coccoid forms is still under debate.

The H.pylori urease has a low Michaelis constant permitting the enzyme to operate with a high efficiency at low urea concentrations ${ }^{13}$. By its extreme urease activity, H.pylori can convert urea into ammonium and bicarbonate ${ }^{7}$. Ammonia is an $\mathrm{H}^{+}$acceptor leading to a local rise in $\mathrm{pH}^{14}$, thus creating an alkaline microenvironment that protects H.pylori from the intragastric acidity. 
H.pylori has been adapted to the gastric micro-environment by the potent urease activity, its micro-aerophilism, the spiral shape and high motility. These last two characteristics enable the bacterium to move through the gastric mucus towards the gastric epithelium ${ }^{9}$, probably attracted by chemotaxins and/or growth factors ${ }^{15}$.

\section{Epidemiology}

H.pylori infection occurs worldwide. The prevalence of infection varies between geographical regions ${ }^{16}$. The incidence of $H$.pylori has been declining over time. H.pylori infection starts in childhood ${ }^{17,18}$. The prevalence increases with age ${ }^{17,19,30}$ from about $10 \%-20 \%$ in the age of $18-29$ years to $50 \%-70 \%$ in the age of $60-69$ years ${ }^{21.22}$. In developing countries the H.pylori prevalences are very high ${ }^{23.25}$ and a majority of children become infected ${ }^{16,26}$. In adults in industrialized countries, the incidence of new H.pylori infections is $0.5-1.0 \%$ per year while in developing countries the incidence varies between $3 \%$ and $10 \%$ per year ${ }^{18}$. H.pylori infection usually persists for many years and the spontaneous eradication rate appears to be $\operatorname{low}^{16.27}$,

An increased risk for H.pylori infection is associated with non-white race and low socio-economic status ${ }^{17-20,22,28}$. No association could be found with use of NSAIDs, alcohol or current smoking ${ }^{19.21}$. The source of H.pylori infection has not been found yet but evidence for person-to-person transmission results from studies showing a high H.pylori prevalence in institutions ${ }^{29,30}$, clustering of H.pylori within families ${ }^{17,31-33}$, and linkage of H.pylori with conditions associated with residential crowding and poor hygiene ${ }^{17,20}$. Furthermore, some studies found evidence for a role of waterborne transmission ${ }^{26}$, and also a correlation of H.pylori infection with the consumption of uncooked vegetables has been reported ${ }^{24}$.

Two routes for person-to-person transmission have been described: the faecaloral and the oral-oral route. Findings of H.pylori in stool ${ }^{34,35}$ and in dental plaque or saliva ${ }^{36-38}$ support these routes. Person-to-person transmission is also demonstrated by a high H.pylori prevalence in gastroenterologists and endoscopists, especially in those who do not wear gloves ${ }^{19,39-41}$. H.pylori may spread from contaminated instruments or speci-mens ${ }^{19}$.

\section{Helicobacter pylori-associated gastritis}

H.pylori is strongly associated with the presence of gastritis ${ }^{3,42-44}$. The bacteria are only rarely found in the histologically normal mucosa and are almost always accompanied by active chronic gastritis characterized by a neutrophil infiltrate ${ }^{45-48}$. H.pylori is associated with type B antral gastritis which subsequently may spread out to the corpus ${ }^{49}$.

A causal role for H.pylori in gastritis is supported by two studies of healthy 
volunteers showing an acute antral inflammation and $H$.pylori colonization after ingestion of H.pylori ${ }^{49,50}$. Furthermore, eradication of H.pylon results in an improvement or disappearance of the gastritis ${ }^{51-53}$.

H.pylori will colonize the "normal" gastric mucosa and cause gastritis and will not preferably colonize an inflamed gastric mucosa as the prevalence of H.pylori is low in patients with gastritis associated with pernicious anaemia ${ }^{54.55}$, eosinophilic gastritis ${ }^{56}$ and Ménétrier's disease ${ }^{56}$.

On long term, chronic H.pylori-associated gastritis can progress towards atrophic gastritis and intestinal metaplasia ${ }^{48,57,58}$. With increasing mucosal atrophy and intestinal metaplasia, the colonization of H.pylori in the stomach decreases ${ }^{59,600}$.

\section{Peptic ulcer disease}

H.pylori is associated with both duodenal and gastric ulcers. H.pylori prevalences range from $78 \%-100 \%$ in patients with duodenal ulcer disease ${ }^{42,61-65}$ and from $60 \%$ $100 \%$ in patients with gastric ulcer disease ${ }^{62,63,66,67}$.

Nomura et al. ${ }^{68}$ showed after a follow up period of 20 years that H.pylori positive subjects are at higher risk to develop peptic ulcer disease than H.pylori negative controls. In cross-sectional and follow-up studies, peptic ulcer disease was found in $2.8 \%-20 \%$ of H.pylori positive subjects ${ }^{21,69,70}$. A higher prevalence was found for duodenal than for gastric ulcer disease. Duodenal ulcer patients are generally associated with antral-predominant H.pylori colonization and gastritis, a high intragastric acidity and the presence of gastric metaplasia in the duodenal bulb. Gastric ulcer patients are often found to be older with a more wide-spread H.pylori colonization and gastritis in both antrum and corpus, a decreased intragastric acidity and higher prevalences of atrophic gastritis than in duodenal ulcer patients ${ }^{71.73}$. Recurrence of peptic ulcers has been prevented by eradication of H.pylori in both duodenal ${ }^{65,74-76}$ and gastric ulcer patients ${ }^{75,77,78}$.

In general, acquisition of H.pylori is already mentioned to occur in childhood ${ }^{17,48}$. The development of a gastric ulcer appears to be especially related to an infection with H.pylori acquired at a young age while duodenal ulceration will develop from a H.pylori infection acquired at a later age $\mathrm{e}^{79,80}$.

A majority of subjects infected with H.pylori will not develop a peptic ulcer. Mechanisms in peptic ulcer pathogenesis and differences in pathogenesis of duodenal or gastric ulcer formation are not completely understood. Differences in host response, H.pylori strains, and environmental factors may play a role in the differential development of peptic ulcer disease of infected subjects. Environmental factors include diet, smoking and stress. Host response may differ with regard to the parietal cell mass, basal acid secretory capacity, gastrin levels, and mucus resistance $^{72}$. A great genetic diversity in H.pylori strains has been shown ${ }^{81-83}$. 
Recently, the presence of vacA and cagA positive strains has gained much interest. The vacA gene encodes a vacuolizing cytotoxic protein. Almost all strains appear to possess the vacA gene which is only expressed in the presence of the cytotoxinassociated gene (cagA) ${ }^{44}$. Several studies report an association between the presence of peptic ulcer disease and a cag A positive $\operatorname{strain}^{85,86}$.

\section{Gastric cancer}

Two types of gastric cancer can be distinguished according to the classification by Laurén ${ }^{87}$ : the intestinal and the diffuse type. Although the incidence of gastric cancer is declining over time, it is stijl associated with a high mortality ${ }^{88-90}$. The decline is attributable to a decrease of tumours located in the distal stomach, while the incidence of cancer in the gastric cardia increases ${ }^{88.91}$. The intestinal type is more often found in the distal stomach while the diffuse type develops throughout the stomach but especially in the gastric cardia ${ }^{92}$.

There is a wide geographical variation in the incidence of gastric cancer with high incidences in blacks and males ${ }^{90-93}$. Furthermore gastric cancer has been found to cluster within families and is associated with a low socio-economic status ${ }^{90,92,93}$. These epidemiological findings of gastric cancer resemble those for the prevalence of H.pylori. Histological ${ }^{94-97}$ and serological studies ${ }^{98-102}$ find an association of H.pylori with gastric cancer. Serological studies indicate a three-to-sixfold higher risk for H.pylori positive subjects to develop gastric cancer ${ }^{98-100}$. High odds ratios are especially found in young H.pylori positive subjects below 40 years of age ${ }^{103.104}$.

The mode in which H.pylori contributes to the development of gastric cancer is still unknown. H.pylori associated gastritis may progress towards gastric mucosal atrophy and intestinal metaplasia which are known to be possible precancerous lesions, especially for the intestinal type of gastric cancer ${ }^{105-107}$. H.pylori may mainly play an initiating role in the histological cascade towards gastric cancer by causing a chronic gastritis, as subsequently H.pylori colonization is known to decrease in atrophic gastritis and intestinal metaplasia, and is even absent in the gastric tumour tissue itself. Although some studies report H.pylori to be more often present in the intestinal type of gastric cancer ${ }^{95-97}$, others find similar H.pylori prevalences in both the intestinal and the diffuse type ${ }^{108-110}$.

Although some epidemiological studies find a similar distribution of H.pylori and gastric cancer ${ }^{111}$, others find high H.pylori prevalences in gastric cancer patients in countries with low gastric cancer incidences ${ }^{112}$. Recently, neither Kuipers et al. ${ }^{113}$ nor Webb et al. ${ }^{114}$ could support a role of H.pylori in gastric carcinogenesis.

Besides H.pylori, other factors have to be involved in gastric cancer: the 
presence of nitrite and $\mathrm{N}$-nitroso compounds in diet, low intake of vitamin $\mathrm{C}$ and $\mathrm{E}$, and a high salt intake are associated with an increased risk of gastric cancer $^{90,92,93}$. Furthermore clinical conditions such as partial gastrectomy ${ }^{15.116}$, achlorhydric atrophic gastritis with or without pernicious anaemia ${ }^{17-121}$, intestinal metaplasia ${ }^{105}$, and use of $\mathrm{H}_{2}$-receptor antagonists ${ }^{122}$ are associated with an increased risk of gastric cancer.

\section{Primary gastric lymphoma}

Primary gastric lymphoma account for $1-5 \%$ of all gastric malignancies ${ }^{123}$. Normally lymphoid tissue is not found in the stomach but it is reported to be acquired in response to a H.pylori infection ${ }^{124,125}$. The presence of lymphoid follicles and aggregates is found to correlate with the degree and activity of antral gastritis and the density of H.pylori colonization ${ }^{125}$. In a clinical case study, Carlson et al. ${ }^{126}$ followed a patient with $H$.pylori-associated gastritis that progressed to lymphoid hyperplasia and subsequently to the development of a monoclonal Bcell lymphoma. The presence of acquired mucosa-associated lymphoid tissue (MALT) may precede to the development of primary gastric lymphoma.

A serological nested case-control study by Parsonnet et al. ${ }^{127}$ showed that patients with primary gastric lymphoma are more likely to have evidence of a previous H.pylori infection (odds ratio 6.3). An association is also found between the incidence of non-Hodgkin's lymphoma and the rate of H.pylori infection in an epidemiological study by Doglioni et al. ${ }^{128}$. A high prevalence of $\mathrm{H}$.pylori $(80 \%$ $92 \%$ ) has been found by histology in non-tumorous gastric mucosa of patients with primary gastric lymphoma of MALT origin ${ }^{123,124}$ and eradication of H.pylori has been shown to lead to a regression of the lymphoma ${ }^{129-131}$. However, also lower H.pylori prevalences in gastric lymphoma (about 50\%) are reported by others ${ }^{132,133}$.

\section{Pathogenesis}

H.pylori is primarily associated with gastric epithelium, including areas of gastric metaplasia. The bacterium is found in the gastric mucus as well as in close proximity of the epithelial cells, mainly near the tight-junctions ${ }^{15,134-137}$.

H.pylori is able to colonize the gastric mucosa by the extreme urease activity: H.pylori is surrounded by an alkaline cloud which protects the bacterium from the gastric acid ${ }^{13,15,137}$. Urease plays an important role in infection as urease-negative H.pylori strains are not able to induce gastritis in gnotobiotic piglets ${ }^{138}$. Furthermore, urea can be used as a nitrogen source ${ }^{13.137}$ and urease elicits an immune response ${ }^{139}$.

In the mucus layer, the $\mathrm{pH}$ is near to neutral ${ }^{135}$. H.pylori is adapted to the viscous milieu of the mucus by the high motility mediated by the flagella, the spiral 
shape $e^{15.135}$ and the production of protease which degrades mucin moleculles ${ }^{15.137}$.

H.pylori can adhere to the gastric epithelial cells via non-specific factors like surface charges and hydrophobic interactions and more specific via lectins and adhesins $^{15}$. Ultrastructural studies have shown the presence of adhesion pedestals between H.pylori and gastric mucosal cells ${ }^{140}$. Adhesion results in depletion of microvilli and distortion of the cytoskelet ${ }^{15,135,137}$.

The initial response to H.pylori infection is accompanied by a period of achlorhydria ${ }^{141}$. H.pylori produces a protein inhibitor of gastric acid secretion ${ }^{137}$. Also higher basal- and meal-stimulated gastrin values are reported in H.pylori positive DU patients ${ }^{142-144}$.

H.pylori elicits a local and systemic immune response: inflammatory cells migrate into the epithelium of the infected mucosa ${ }^{15.137}$ and $\operatorname{IgG}, \operatorname{IgA}$ and $\operatorname{IgM}$ antibodies against H.pylori can be detected both in the gastric mucosa ${ }^{145}$ and in the

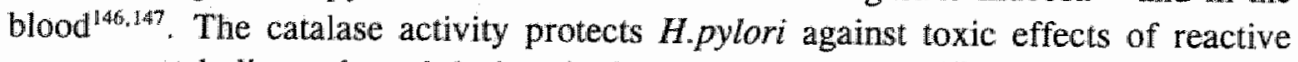
oxygen metabolites released during the inflammatory process ${ }^{148}$.

$H$.pylori can induce tissue damage by the production of several factors that damage the gastric mucosal integrity ${ }^{13.137 .139 .149}$. H.pylori can degrade the mucosal integrity by lipase and phospholipase activity ${ }^{137}$, by inhibition of the binding of laminin ${ }^{150}$, and by induction of pepsinogen secretion ${ }^{137,149}$. Furthermore, ammonia is cytotoxic, especially by ammonium hydroxide ${ }^{139}$ and certain $H$.pylori strains exert a vacuolating activity (vacA) which is associated with the presence of the cytotoxinassociated gene (cagA) ${ }^{84}$. This cytotoxic activity is found in $50 \%-60 \%$ of H.pylori strains ${ }^{149,15 !}$, and shows a higher prevalence in H.pylori positive duodenal ulcer patients compared to those without peptic ulcer disease ${ }^{86.152,153}$. Patients infected with a cagA positive strain, are at higher risk to develop atrophic gastritis and intestinal metaplasia ${ }^{154}$ and a high cagA prevalence is found in gastric cancer patients $^{155}$. Finally, an increased oxidative DNA damage is shown in the H.pyloriinfected human gastric mucosa ${ }^{156}$ and H.pylori and its immune response result in an increased proliferation of the gastric epithelial cells ${ }^{157}$.

\section{Eradication therapy for Helicobacter pylori}

After eradication of H.pylori, gastritis diminishes or resolves and recurrence of both gastric and duodenal ulcers markedly decrease. Furthermore a regression of gastric MALT-lymphoma has been demonstrated after H.pylori eradication therapy.

Good results with more than $80 \%$ eradication ${ }^{158}$ are obtained with a triple therapy of bismuth, metronidazole and amoxycillin or tetracycline, but side effects are frequently reported and there is no good compliance of the patients ${ }^{159}$.

The incidence of side-effects is lower using a two-week dual therapy consisting of the proton-pump inhibitor omeprazole in combination with amoxycillin or 
clarithromycin ${ }^{160}$. However, eradication rates are generally lower and show a wide variation $^{159.161}$. In a meta-analysis, eradication rates range from $53 \%$ to $72 \%$ with different antibiotics used ${ }^{161}$.

Better results are obtained using omeprazole with a combination of two antibiotics out of amoxycillin, clarithromycin or metronidazole ${ }^{162}$. Combining several studies, Tytgat ${ }^{158}$ reports an eradication percentage of $87.5 \%$ using clarithromycin and metronidazole and $95.0 \%$ using clarithromycin and amoxycillin. A success rate of $85 \%$ to $90 \%$ was obtained by only one week treatment ${ }^{163}$.

A recently introduced and very effective therapy is the quadruple therapy consisting of omeprazole, bismuth, metronidazole and tetracyclin for one week ${ }^{164}$.

The results of the eradication regimens depend on the compliance of the patients and the antibiotic susceptibility of $H$.pylori. A penicillin-allergy has been reported in $5 \%-10 \%$ of the population which can therefore not use amoxycillin ${ }^{165}$. Metronidazole resistant strains are reported in $10 \%-20 \%$ of patients in developed countries and up to $80 \%$ in developing countries ${ }^{159}$. Metronidazole resistance can be overcome in vivo when given in combination with omeprazole ${ }^{166}$. Also resistance against clarithromycin ${ }^{167,158}$ and tetracycline ${ }^{169,170}$ have been described. 


\section{Non-Helicobacter pylori intragastric bacterial flora}

\section{Role of intragastric acidity}

The parietal cells are located over the entire wall of the body and fundus of the stomach except parts of the lesser curvature, and secrete hydrochloric acid and intrinsic factor ${ }^{171,72}$. Gastric acid plays a role in the digestion of food by the conversion of pepsinogen into the active proteolytic enzyme pepsin, and activates the duodenal hormones secretin and cholecystokinin which stimulate the pancreatic secretion of bicarbonate and contraction of the gall-bladder, respectively ${ }^{171}$. Furthermore, gastric acidity inhibits the antral release of gastrin in a feedback mechanism. However, the main function of gastric acid is disinfection of the gastric content.

The number of bacteria present in the gastric juice correlates to the acidity of the gastric juice ${ }^{1 / 3-176}$. An intragastric pH below 3 to 4 is bactericidal ${ }^{175-178}$. Above $\mathrm{pH} 4$, mainly Lactobacilli spp. and Streptococci spp. will proliferate, and above $\mathrm{pH}$ 5 a more complex flora is able to proliferate ${ }^{178}$. In these situations mostly oropharyngeal bacteria, including viridans Streptococci, Staphylococci spp., Micrococci spp., Neisseria spp., Haemophili spp. and Lactobacilli spp. ${ }^{176,279,180,}$ faecal streptococci and Bacteroides spp. can be found, and sometimes Enterobacteriaceae are present ${ }^{174,176,178}$.

During a food intake the gastric $\mathrm{pH}$ rises and bacterial growth can occur. Feeding also increases the number of bacteria in the upper small intestine ${ }^{175}$. However, a fall in $\mathrm{pH}$ below 4.0 for more than two hours each day will prevent colonization $^{178}$. In subjects with a continuously reduced intragastric acidity, bacterial overgrowth can occur.

\section{Clinical conditions associated with reduced intragastric acidity and bacterial overgrowth}

In most parts of Asia, Africa, South and Central America and even in Eastern and Southern Europe, a remarkable proportion of young adults are found to be achlorhydric 178 . This may result from protein malnutrition, virus infections or high salt intake ${ }^{178}$. Also aging is associated with a decline in gastric acid output ${ }^{181,182}$, Furthermore, some major clinical conditions are associated with reduced intragastric acidity and subsequent bacterial overgrowth.

Firstly, the intragastric $\mathrm{pH}$ is associated with the histological grade of gastritis ${ }^{183}$ : a reduced intragastric acidity with bacterial overgrowth can be found in patients with atrophic gastritis with or without pernicious anaemia. Stockbrügger et al. ${ }^{184}$ found at least $10^{5} \mathrm{cfu} / \mathrm{ml}$ upper respiratory tract flora in all 22 patients with pernicious anaemia and in 14 of 22 patients also faecal-type bacteria were found. In 
another group of pernicious anaemia patients, bacteria were cultured from gastric juice of 14 of 18 patients ${ }^{185}$. The flora was found to be identical in gastric juice and in duodenal juice or biopsies ${ }^{184{ }^{185}}$. Dolby et al ${ }^{186}$ showed that bacterial overgrowth could be demonstrated in both gastric juice and gastric mucosal biopsies of patients with pernicious anaemia and found compa-rable concentrations of bacteria in both the gastric juice and the gastric mucosal biopsies.

Secondly, intragastric bacterial overgrowth has been demonstrated in patients after gastric surgery ${ }^{179,187,188}$. For example, Keighley et al. ${ }^{189}$ found bacterial counts to increase with the intragastric $\mathrm{pH}$ in patients after partial or total vagotomy with or without a partial gastrectomy. Carboni et al. ${ }^{190}$ compared patients with a partial gastrectomy (Billroth I or Billroth II) with normal controls and found a higher $\mathrm{pH}$, higher total viable counts and higher concentrations nitrate-reducing bacteria in the patients compared to the controls with the highest values after a Billroth II resection. Besides, the bacterial flora in the stomach of these patients will also be influenced by alterations in motility ${ }^{190,191}$ and/or the presence of blind loops ${ }^{17 \%}$.

A final important clinical cause of hypochlorhydria and achlorhydria is the use of gastric acid inhibitory drugs. Bacterial counts are negatively correlated to basal acid output after short term treatment with antimuscarinic drugs where both oropharyngeal and faecal-type bacteria were found ${ }^{192}$. Also after treatment with $\mathbf{H}_{2^{-}}$ antagonists a rise in total intragastric and in nitrate-reducing bacteria was observed $^{188,193-195}$. Similar results of bacterial overgrowth are obtained after treatment with omeprazole ${ }^{196-198}$. In ambulatory patients treated with omeprazole, bacterial overgrowth of both oral and faecal-type bacteria is also found in the duodenum ${ }^{199}$. Houben et al. ${ }^{200}$ compared the effects of 2 weeks treatment with placebo, ranitidine $300 \mathrm{mg}$, omeprazole 20 and omeprazole $40 \mathrm{mg}$ and found a similar increase in bacterial growth after each form of acid-inhibition although different median 24-hour $\mathrm{pH}$ values are obtained. Also Muscroft et al. ${ }^{176}$ could not find consistent viable bacterial counts per $\mathrm{pH}$-value. Others however, found a close association between the bacterial counts and the intragastric $\mathrm{pH}^{189.199}$.

\section{Consequences of intragastric bacterial overgrowth}

Bacterial overgrowth in the stomach can be associated with some short- and longterm consequences. Firstly, patients with achlorhydria and bacterial overgrowth have a higher risk for gastrointestinal infections ${ }^{201}$. A higher risk for bacterial gastrointestinal infections has been shown after gastric surgery ${ }^{202-203}$, and in patients taking acid-suppressive drugs ${ }^{203,204}$. In a review, Cook ${ }^{205}$ summarized studies on the consequences of hypochlorhydria on gastrointestinal infections and reported increased risks for bacterial infections such as Salmonella, Campylobacter, Shigella and Cholera but also a higher predisposition for parasitic infections such as giardiasis 
and strongyloidiasis. Finally a reduced intragastric acidity is linked to candidiasisis 2062 .

A second consequence of bacterial overgrowth is the risk of a bacterial overgrowth syndrome ${ }^{208}$. Especially small bowel bacterial overgrowth may interfere with the metabolism of nutrients, vitamins and minerals. This may result in a bacterial overgrowth syndrome characterized by malabsorption, and complications resulting from bacterial deconjugation of bilesalts ${ }^{209}$. Bilesalts can cause histological and ultrastructural damage to the gastric and intestinal mucosa $a^{210}$ and thereby cause malabsorption of nutrients, lactose intolerance and protein malabsorption ${ }^{178}$. Bile salt degradation results in an impaired fat absorption and steatorrhoea. On longterm there may develop a deficiency in fat-soluble vitamins. The bacterial flora can also interfere with the absorption of vitamin B12 and folate ${ }^{178}$. In addition, bacterial overgrowth following acid-inhibitory drugs can interact with the absorption of iron, calcium, vitamin $\mathrm{B} 12$ and phosphate ${ }^{211}$.

Sherwood et al. ${ }^{173}$ describe a marginal fat-malabsorption in half of the patients with pernicious anaemia. In a retrospective study, Stockbrügger et al. ${ }^{184}$ find a history of malabsorption and/or chronic intermittent diarrhoea in one third of patients with pernicious anaemia with intragastric and intestinal bacterial overgrowth. This occurred more frequently in patients with duodenitis. In another study no signs of a bacterial overgrowth syndrome are found ${ }^{185}$.

A major consequence of intragastric bacterial overgrowth is the production of nitrite and $\mathrm{N}$-nitroso compounds (NNOC's). NNOC's are formed by $\mathrm{N}$-nitrosation between various secondary and tertiary amines and nitrite or other nitrosating agents $^{212}$. The total human exposure of NNOC's consist of exogenous and endogenous components. Exogenous NNOC's mainly result from tobacco products, nitrite-cured meat, medicinal drugs and by occupational exposure ${ }^{213}$. In addition, humans are also exposed to many nitrogen compounds and nitrosating agents from tobacco smoke, diet and drinking water ${ }^{213}$.

Ingested nitrate is absorbed in the small intestine and excreted in the arine $(65-70 \%)$ and the raeces $(3-10 \%)^{214}$. Nitrate is secreted in salliva, gastric juice, tears, sweat and probably in the large bowel and the vagina ${ }^{215}$. In all sites where nitrate and bacteria are present, nitrite can be formed. About a quarter is taken up from the circulation by the salivary glands and a small percentage is converted to nitrite in the oral cavity ${ }^{214.215}$. Nitrate reduction can further occur in the achlorhydric stomach but also in the large bowel, the infected urinary bladder and the infected cervix ${ }^{214.215}$.

NNOC's can be formed endogenously by acid-catalyzed formation, by bacteria, and by activated macrophages during inflammation ${ }^{213,216}$. The endogenous 
$\mathrm{N}$-nitrosation is controlled by the intragastric $\mathrm{pH}$, concentrations of nitrite and nitrosatable nitrogen, and the incubation time $\mathrm{e}^{216}$. Furthermore, the concentration and bacterial species present play a role in the bacterial nitrosation ${ }^{216}$. Acidcatalyzed nitrosation occurs at a low $\mathrm{pH}(2-3)$ while bacterial nitrosation occurs at a $\mathrm{pH}$ of $6-8^{217}$.

With an increase of the $\mathrm{pH}$ in the stomach, increases of both total bacterial counts and numbers of nitrate-reducing bacteria are observed in achlorhydric patients with pernicious anaemia, after gastric surgery and after gastric inhibitory therapy ${ }^{176,180,188,190,193,195}$. Nitrate-reducing bacteria found in achlorhydric patients may include Micrococci spp., Staphylococcus aureus, Haemophili spp., Veillonella spp. and Escherichia coli ${ }^{176,180}$. In gastric juice of achlorhydric patients, also increased levels of nitrite ${ }^{184,190}$ and of both nitrite and NNOC's have been demonstrated ${ }^{195,196,218}$. Some studies found only an increase in nitrite but not in NNOC' $s^{188,189}$. Verdu et al. ${ }^{197}$ and Houben et al. ${ }^{200}$ did not find any significant increases in nitrate, nitrite or NNOC's after short-term treatment with omeprazole and ranitidine. The role of the intragastric $\mathrm{pH}$ in the nitrosation may partially explain differences in nitrite and NNOC concentrations found in diverse studies on achlorhydric patients. Furthermore, the measurements of NNOC's can be influenced by instability of NNOC's, the time between sampling and the assay, and the relative lack of specificity in certain assays $\mathrm{s}^{219,220}$.

NNOC's are found to be toxic in humans ${ }^{212}$ and the use of various nitrosourea derivates in treatment regimens of some human forms of cancer provide evidence that they may cause cancer themselves ${ }^{221}$. Furthermore, an association with cancer is demonstrated in several animal studies ${ }^{222}$. Further evidence for a carcinogenic role of NNOC's comes from epidemiological and clinical studies which find an association between nitrate and nitrite rich diet or drinking water and an increased risk of gastric cancer ${ }^{213,223}$. A role of NNOC's in the aetiology of gastric cancer is also supported by a study of Li et al. ${ }^{224}$, where a higher NNOC synthesis measured by the NPRO test, was found for inhabitants of high versus low risk areas of gastric cancer.

Also in clinical situations associated with bacterial overgrowth and high levels of nitrite and NNOC's in the stomach, an increased risk of gastric cancer is found ${ }^{115-118,120,122,225,226}$. In gastric cancer patients an increased $\mathrm{pH}$ and high nitrite concentrations are reported ${ }^{227}$. All these findings support the possibility of a carcinogenic role of NNOC's in the pathogenesis of gastric cancer. 


\section{Detection of the intragastric bacterial flora}

\section{Helicobacter pylori}

Various tests have been described for the detection of $H$.pylori in the upper gastrointestinal tract and can be divided into invasive and non-invasive tests. Invasive tests require biopsy specimens obtained during upper gastrointestinal endoscopy and include culture, histology, biopsy urease test, and polymerase chain reaction (PCR). To avoid a sampling error, at least two biopsies should be taken of both antrum and corpus ${ }^{228-230}$. Non-invasive tests include serology and breath tests. These will not be influenced by the patchy distribution of the bacterial flora.

\section{Histology}

For the histological detection of H.pylori, non-specific staining methods are widely applied such as haematoxylin-eosin stain (HE), and the modified Giemsa stain $(\mathrm{MG})^{231}$. The Warthin-Starry silver stain (WS) is more specific ${ }^{232}$. In the HE stain, the bacteria are only faintly visible and the sensitivity is low compared to Gram stain and WS $\operatorname{stain}^{233}$. The fact that this bacterium has not been noticed for several decades supports the low sensitivity of the HE $\operatorname{stain}^{233.234}$. The WS stain improves the recognition of $H$.pylori because the organisms appear larger than they are ${ }^{228.233}$. However, this stain is expensive and difficult to perform. The MG stain is easy to perform, inexpensive, and has a high sensitivity ${ }^{233.235 .236}$. Some find no difference between the MG stain and the WS $\operatorname{stain}^{231}$, while others find a higher sensitivity for the MG $\operatorname{stain}^{235,237,238}$. Also the acridine orange stain is very effective but fluorescent microscopy is required ${ }^{239,240}$.

As an advantage of histology, the presence of gastritis can be assessed simultaneously but the quality of the biopsy can influence the histological detection of the bacteria ${ }^{230,236}$. Using non-specific staining techniques, the H.pylori organism has to be identified by its appearance and typical location within or beneath the gastric mucus layer ${ }^{228,233}$. Other coccoid, rod-like or spiral shaped bacteria can be present in the stomach which may be difficult to differentiate from H.pylori. Both sensitivity and specificity of non-specific histological staining methods for the detection of H.pylori, will depend on the experience and critical view of the obser$\mathrm{ver}^{230}$ and can only assess the presence of H.pylori-like organisms.

\section{Culture}

Culture is very specific for the detection of H.pylori but is not always found to be as sensitive as histology, although good results can be achieved when the specimens 
are rapidly and correctly transported and processed on appropriate mediaa ${ }^{241}$. Saline is a convenient transport medium provided that the specimens are cultured within four hours and kept at $4^{\circ} \mathrm{C}^{236,242}$. Use of fresh media with fresh blood a moist micro-aerophilic atmosphere and incubation periods of 4-7 days are required $^{233,236,242}$. Heavier growth is obtained when biopsy specimens are ground compared to smearing them over the culture medium ${ }^{236}$. The presence of other bacteria in a biopsy specimens can disturb the detection of H.pylori and can be reduced by use of selective media ${ }^{243}$. Those bacteria mainly consist of oropharyngeal flora and Gram negative rods found in patients with impaired gastric acid secretion. Selective media with antibiotic combinations consisting of vancomycin, trimethoprim and polymyxin $B$ or a combination of vancomycin, nalidixic acid and amphotericin $B$ have been applied. However nalidixic acid ${ }^{244}$ and polymyxin $\mathrm{B}^{245}$ sensitivity has been described for H.pylori. These antibiotics can be replaced by cefsulodin. The advantage of culture is that antibiotic sensitivity can be assessed simultaneously. This can be very valuable when eradication therapy for H.pylori has failed ${ }^{229}$.

\section{Biopsy urease test}

A very quick invasive method is the biopsy urease test. This test is based on the high urease activity of H.pylori: Urea will be hydrolysed leading to the production. of ammonia and carbonate both producing an increase of the $\mathrm{pH}$. This increase can be visualized using a pH indicator in the medium. Most urease tests have a good specificity but a wide range of sensitivity is described ${ }^{241}$. Sensitivity depends on the number of bacteria present in the specimens: a quantity below $10^{4}$ microorganisms may result in a negative urease test ${ }^{241}$. The sensitivity will decrease when patients are treated with antibiotics or gastric acid inhibitors ${ }^{241}$. The biopsy-urease tests will be very specific but not very sensitive when read after 1 hour. Sensitivity will increase but specificity will decrease when the test is read after 24 hours $^{246}$. Especially after 24 hours, false positive results occur by the presence of contaminating bacteria with a lower urease activity ${ }^{246}$. However, others do not find false positives when the test is read after 24 hours $^{247}$. In short, the sensitivity and specificity of this test is strongly dependent on the media used and the incubation time $233,241,245,2466$.

\section{Polymerase Chain Reaction}

In recent years, the polymerase chain reaction (PCR) is widely applied for the detection of H.pylori in gastric biopsy specimens. PCR can for example be based on the urease A gene ${ }^{248.249}$ or $16 \mathrm{~s} \mathrm{rRNA}^{250,251}$. A high sensitivity and specificity was found performing PCR on several clinical isolates of H.pylori in comparison with 
many other bacterial strains ${ }^{245}, 249,252$. Furthermore, several studies found PCR to be superior to culture, histology $y^{248,250,251}$, the urea breath test ${ }^{253}$, the biopsy urease test and serological Western blotting ${ }^{23}$. As an additional advantage, PCR can be used for the detection of H.pylori in gastric juice ${ }^{244}$, dental plaque ${ }^{37.38}$, faecal samples ${ }^{34}$ and on endoscopes ${ }^{254}$.

\section{Urea breath test}

The urea breath test is also based on the fact that the urease enzyme hydrolyses urea producing carbon dioxide which subsequently diffuses into the blood and thereafter is partly excreted by the lungs ${ }^{255}$. In the test ${ }^{13} \mathrm{C}$ (non-radioactive) or ${ }^{14} \mathrm{C}$ (radioactive) labelled urea is given orally and later detected in the breath. A high energy test meal has to be given to delay gastric emptying ${ }^{255}$. This will result in a prolonged exposure of urea to the gastric bacteria and may prevent the substrate from reaching the colon were colonic bacteria could release carbon dioxide ${ }^{236}$.

In general the urea breath test is well tolerated, without risk when using nonradioactive tracers $\left({ }^{13} \mathrm{C}\right)$ and does not require experienced operators ${ }^{255}$. Good results are obtained with sensitivities from $90 \%-100 \%$ and specificities from $78 \%-100 \%$ in clinical situations ${ }^{255,256}$. The urea breath test can only detect an active H.pylori infection. False negative results can occur after treatment with antibiotics, bismuth or omeprazole ${ }^{255,256}$. Therefore, testing has to occur at least one month after the end of treatment ${ }^{255}$. As a disadvantage, the urea breath test does not measure bacterial load, and obviously no macroscopic and microscopic information of the stomach is obtained.

\section{Serology}

Chronic H.pylori infection elicits a local and systemic immune response ${ }^{22 \%}$. The presence of serum antibodies against $H$.pylori are found to correlate with $H$.pylori associated gastritis ${ }^{236,257}$. The accuracy of serological tests may vary with the antigens used and the population tested ${ }^{237.258}$. Using ELISA assays, the definition of the cut-off value is important and a grey zone has to be determined where results are indeterminate 258 . The assay should be validated in a local reference population $^{259}$ as the antibody titre may differ with ethnicity and age $258,260,261$. Furthermore an ELISA assay is less accurate in patients using NSAIDs ${ }^{262}$.

Patients may have a positive serology but negative histology or culture as they can have had a previous infection leaving a serological scar. This can occur after H.pylori eradication or on the basis of developing gastric mucosal atrophy or intestinal metaplasia which both are hostile to H.pylori ${ }^{260}$.

The antigens used in an ELISA assay are not allowed to be present in other bacteria such as Campylobacter jejuni, Campylobacter fetus or Escherichia 
coli $^{236,263}$ and antibodies against different $H$ pylori strains have to be applied to improve both the sensitivity and specificity of the assays. The antibody titres decrease slowly after eradication therapy for H.pylori ${ }^{228.236}$. For checking eradication of H.pylori, antibodies have to be determined before and not earlier than three months after treatment to find a sensitivity and specificity in an acceptable range ${ }^{264}$.

\section{Non-Helicobacter pylori bacterial overgrowth}

\section{Culture}

Gastric and duodenal juice and biopsies can be obtained for culture of the total aerobic and anaerobic bacterial flora using both selective and non-selective agarplates. In intestinal aspirate, bacterial overgrowth is confirmed by the presence of at least $10^{5}$ colony forming units per $\mathrm{ml}^{265}$. Although culture of gastric and intestinal aspirates have been widely applied, to our knowledge, Dolby et al. ${ }^{186}$ and Stockbrügger et al. ${ }^{185}$ are the only ones, who cultured gastric and duodenal mucosal biopsies to assess the presence of the non- $H$.pylori bacterial growth. In both studies biopsy specimens were washed three times and were ground before inoculation.

\section{Breath tests}

A non-invasive method for the detection of bacterial overgrowth is the application of breath tests. Both ${ }^{14} \mathrm{C}$ - and $\mathrm{H}_{2}$-breath tests are used for the detection of intestinal bacterial overgrowth, as bacteria can deconjugate bile-salts and ferment carbohydrates.

Administration of radio-labelled ${ }^{14} \mathrm{C}$-glycocholate results in increased levels of ${ }^{14} \mathrm{CO}_{2}$ in the expired breath ${ }^{266.267}$. However, this method takes six hours and cannot be used in patients with ileal diseases ${ }^{265,268}$. Better results in the detection of smallintestinal bacterial overgrowth are obtained by using the 1. gram ${ }^{14} \mathrm{C}$ xylose breath test ${ }^{269}$.

Bacteria can also ferment carbohydrates with the production of hydrogen, which is absorbed, and can partly be exhaled. After overnight fasting, either a glucose, lactose or lactulose solution is given and $\mathrm{H}_{2}$ production can be measured. False negative results may occur when using glucose because this is rapidly absorbed. Better results can be obtained with lactulose which is poorly absorbed and can distinguish between small-bowel bacterial overgrowth and ileal diseases ${ }^{265,268}$. However, acceleration of small-intestinal transit results in false positive results by colonic fermentation of substrate and false negative breath tests can occur in patients receiving antibiotics and in non- $\mathrm{H}_{2}$ - producers $^{270}$. 
The hydrogen-breath test can also be used for the detection of intragastric bacterial overgrowt $\mathrm{h}^{187}$. However, an unchanged $\mathrm{H}_{2}$-breath test is found after treatment with cimetidine while an increase of the bacterial concentration was found in gastric juice ${ }^{27 !}$. 


\section{References}

1 Bizzozero G. Ueber die schlauchformigen drusen des magendarmkanals und die beziehungen ihres epithels zu dem oberflachen-epithel der schleimhaut. Arch Micr Anat $1893 ; 42: 82$.

2 Doenges JL. Spirochaetes in the gastric glands of macacus rhesus and of man without related disease. Arch Pathol 1939; 27; 469-477.

3 Warren JB, Marshall B. Unidentified curved bacilli on gastric epithelium in active chronic gastritis. Lancet $1983 ; 1: 1273-1274$.

Validation of the publication of new names and new combinations previously effectively published outside the IJSB. Intern J Syst Bacteriol 1985; 35: 223-225.

Dooley $\mathrm{CP}$, Cohen $\mathrm{H}$. The clinical significance of Campylobacter pylori. Review. Ann Intern Med 1988; 108: 70-79.

6 Goodwin CS, Worsley BW. Microbiology of Helicobacter pylori. Gastroenterol Clin N Am 1993; 22: 5-19.

7 Fennerty MB. Helicobacter pylori. Review article. Arch Intern Med 1994; 154" $721 \% 727$.

8 Mégraud $\mathbb{F}$, Bonnet $\mathrm{E}$, Garnier $\mathrm{M}$, Lamouliatte $\mathrm{H}$. Characterization of Campylobacter pyloridis by culture, enzymatic profile and protein content. J Clin Microbiol 1985; 22: 1007-1010.

9 Dick JD. Helicobacter (Campylobacter) pylori: A new twist to an old disease. Annu Rev Microbiol 1990; 44: 249-269.

10 Marshall B. Unidentified curved bacilli on gastric epithelium in active chronic gastritis. Lancet 1983; i: 1273-275.

11 Hachem CY, Clarridge JE, Evans DG, Graham DY. Comparison of agar based media for primary isolation of Helicobacter pylori. J Clin Pathol 1995; 48: 714-716.

12 Hazell SL, Markesich DG, Evans DG, Graham DY. Influence of media supplements on growth and survival of Campylobacter pylori. Eur J Clin Microbiol Inf Dis 1989; 8: 597-602.

13 Blaser MJ. Helicobacter pylori and the pathogenesis of gastroduodenal inflammation. J Inf Dis 1990; 161: 626-633.

14 Bode $G$, Malfertheiner $P$, Nilus $M$, Lehnhardt $G$, Ditschuneit $H$. Ultrastructural localisation of urease in outer membrane and periplasm of Campylobacter pylori (letter). J Clin Pathol 1989; 42: 778-779.

15 Bode G, Maltertheiner P, Ditschuneit $H$. Pathogenetic implications of ultrastructural findings in Campylobacter pylori related gastroduodenal disease. Scand I Gastroenterol 1988; 23 (suppl 142): 25-39.

16 Pounder RE, NG D. The prevalence of Helicobacter pylori infection in different countries. Aliment Pharmacol Ther 1995; 9 (supp1 2): 33-39.

17 Goodman KJ, Correa PA. The transmission of Helicobacter pylori. A critical review of the evidence. Internat J Epidemiol 1995; 24: 875-887. 
18 Parsonnet J. The incidence of Helicobacter pylori infection. Aliment Pharmacol Ther 1995: 9 (suppl 2): 45-51.

19 Graham DY, Malaty HM, Evans DG, Evans DJ, Klein PD, Adam E. Epidemiology of Helicobacter pylori in an asymptomatic population in the United States. Effect of age, race, and socioeconomic status. Gastroenterol 1991; 100: 1495-1501.

20 Replogle ML, Glaser SL, Hiatt RA, Parsonnet J. Biologic sex as risk factor for Helicobacter pylori infection in healthy young adults. Am J Epidemiol 1995; 142: 856-863.

21 Dooley CP, Cohen $\mathrm{H}_{3}$ Fitzgibbons PL et al. Prevalence of Helicobacter pylori infection and histological gastritis in asymptomatic persons. $N$ Engl J Med 1989; 321: $1562-1566$.

22 Gasbarrini G, Pretolani $S$, Bonvicini $F$ et al. A population based study of Helicobacter pylori infection in a European country: the San Marino Study. Relations with gastrointestinal diseases. Gut 1995; 36: 838-844.

23. Ramirez-Ramos A, Gilman RH, Recavarren S et al. Campylobacter pyloridis in a developing country. Gastroenterol 1987; $92: 1588$.

24 Hopkins RJ, Vial PA, Ferreccio C et al. Seroprevalence of Helicobacter pylori in Chile: vegetables may serve as one route of transmission. J Infect Dis 1993; 168: 222-226.

25 Malaty HM, Kim JG, Kim SF, Graham DY. Prevalence of Helicobacter pylori infection in Korean children: inverse relation to socioeconomic status despite a uniformly high prevalence in adults. Am J Epidemiol 1996; 143: 257-262.

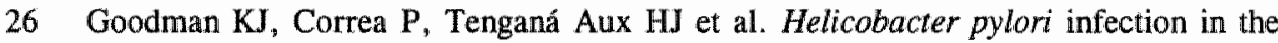
Colombian Andes: A population-based study of transmission pathways. Am J Epidemiol 1996; 144: 290-299.

27 Kuipers EJ, Pena AS, van Kamp G et al. Seroconversion for Helicobacter pylori. Lancet $1993 ; 342: 328-331$.

28 Malaty HM, Graham DY. Importance of childhood socioeconomic status on the current prevalence of Helicobacter pylori. Gut 1994; 35: 742-745.

29 Berkowicz J, Lee A. Person-to-person transmission of Campylobacter pylori. Lancet 1987; 2: 680-681.

30 Vincent $\mathrm{P}$, Gottrand $\mathrm{F}$, Pernes $\mathrm{P}$ et al. High prevalence of Helicobacter pylori infection in cohabiting children. Epidemiology of a cluster, with special emphasis on molecular typing. Gut 1994; 35: 313-316.

31 Drumm B, Perez-Perez GI, Blaser MJ, Sherman PM. Intrafamilial clustering of Helicobacter pylori infection. N Engl J Med 1990; 322: 359-363.

32 Bamford KB, Bickley J, Collins ISA et al. Helicobacter pylori: comparison of DNA fingerprints provides evidence for intrafamilial infection. Gut 1993; 34: 1348-1350.

33 Mendall MA, Northfield TC. Transmission of Helicobacter pylori infection. Gut 1995; 37: 1-3.

34 Mapstone NP, Lynch DAF, Lewis FA et al. PCR identification of Helicobacter pylori in faeces from gastritis patients. Lancet 1993; $341: 447$. 
35. Enroth H, Engstrand L. Immunomagnetic separation and PCR for dettection of Helicobacter pylori in water and stool specimens. I Clin Microbiol 1995; 33: 2162-2165.

36 Banatvala $\mathrm{N}$, Lopez $\mathrm{CR}$, Owen $\mathrm{R}$ et al. Helicobacter pylori in dental plaque. Lancet $1993 ; 341: 380$.

37 Ferguson DA, Li C, Patel NR, Mayberry WR, Chi DS, Thomas E. Isolation of Helicobacter pylori from saliva. J Clin Microbiol 1993; 31: 2802-2804.

38 Nguyen AH, Engstrand L, Genta RM, Graham DY, El-Azaatari FAK. Detection of Helicabacter pylori in dental plaque by reverse transcription-polymerase chain reaction. $J$ Clin Microbiol 1993; 31: 783-787.

39 Rawles IW, Harris ML, Paull G et al. Antibody to Campylobacter pyloridis in endoscopy personnel, patients, and controls. Gastroenterol 1987; $92: 1589$.

40 Lin SK, Lambert JR, Katz B et al. High prevalence of Helicobacter pylori infection in practising gastroenterologists. Gastroenterol 1991; 100: A111.

41 Tytgat GNI. Endoscopic transmission of Helicobacter pylori. Aliment Pharmacol Ther 1995: 9 (suppl 2): 105-110.

42 Marshall BJ, Warren JR. Unidentified curved bacilli in the stomach of patients with gastritis and peptic ulceration. Lancet 1984; i: 1311-1315.

43 Price $\mathrm{AB}$, Levi J, Dolby et al. Campylabacter pyloridis in peptic ulcer disease: microbiology, pathology, and scanning electron microscopy. Gut 1985; 26: 1183-1188.

44 Rathbone BJ, Wyatt J,, Worsley BW, Trejdosiewicz LK, Heatley RV, Losowsky MS. Immune response to Campylobacter pyloridis. Lancet 1985; i: 1217.

45 Buck GE. Relation of Campylobacter pyloridis to gastritis and peptic ulcer. J Infect Dis 1986; 153: 664-669.

46 Drumm B, Sherman P, Cutz E, Karmali M. Association of Campylobacter pylori on the gastric mucosa with antral gastritis in children. $N$ Engl J Med 1987; 316: $1557-1561$.

47 Hazell SL, Hennessy WB, Borody TJ et al. Campylobacter pyloridis gastritis II: Distribution of bacteria and associated inflammation in the gastroduodenal environment. Am J Gastroenterol 1987; 82: 297-301.

48 Dixon MF. Helicobacter pylori and peptic ulceration: histopathological aspects. I Gastroenterol Hepatol 1991; 6: 125-130.

49 Morris A, Nicholson G. Ingestion of Campylobacter pyloridis causes gastritis and raised fasting gastric pH. Am J Gastroenterol 1987; 82: 192-199.

50 Marshall BJ, Armstrong JA, McGechie DB, Glancy RJ. Attempts to fulfil Koch"s postulates for pyloric Campylobacter. Med J Aust $1985 ; 142: 436439$.

51 Glupszynski $\mathbf{Y}$, Burette A. Labbe M, Deprez C, De Reunck M, Deltenre M. Campylobacter pylori-associated gastritis: a double blind placebo-controlled trial with amoxycillin. Am J Gastroenterol 1988; 83; 365-372. 
52 Rauws EA, Langenberg W, Houthoff HI, Zanen HC, Tytgat GNI. Campylobacter pyloridis-associated chronic active antral gastritis: a prospective study of its prevalence and the effects of antibacterial and antiulcer treatment. Gastroenterol $1988 ; 94: 33-40$.

53 Valle J, Seppälä $K$, Sipponen $\mathbb{P}$, Kosunen $T$. Disappearance of gastritis after eradication of Helicobacter pylori. Scand J Gastroenterol 1991; 26: 1057-1065.

$540^{\prime}$ Connor $H^{\prime}$, Axon ATR, Dixon MF. Campylobacter-like organisms is unusual in type A (pemicious anaemia) gastritis. Lancet 1984; ii: 1091.

55 Flejou JF, Baham P, Smith AC, Stockbrüger RW, Rode J, Price AB. Pernicious anaemia and Campylobacter like organisms: is the gastric antrum resistant to colonization. Gut 1989; 30: 60-64.

56 Ormand JE, Talley NJ, Shorter RG et al. Prevalence of Helicobacter pylori in specific forms of gastritis. Further evidence supporting a pathogenic role for H.pylori in chronic nonspecific gastritis. Dig Dis Sc 1991; 36: 142-145.

57 Siurala M, Sipponen, Kekki M. Chronic gastritis: dynamic and clinical aspects. Scand J Gastroenterol Suppl 1985; 100: 69-76.

58 Kuipers EJ, Uyterlinde AM, Pena AS et al. Long-term sequelae of Helicobacter pylori and peptic ulceration. Lancet $1995 ; 445: 1525-1528$.

59 Siurala M, Sipponen P, Kekkil M. Campylobacter pylori in a sample of Finnish population: relations to morphology and functions of the gastric mucosa. Gut 1988; 29: 909-915.

60 Sobala GM, Axon ATR, Dixon MF. Morphology of chronic antral gastritis: relationship to age, Helicobacter pylori status and peptic ulceration. Eur J Gastroenterol Hepatol 1992; 4: 825-829.

61 McNulty CAM, Watson DM. Spiral bacteria of the gastric antrum. Lancet 1984; i: 1068-1069.

62 Marshall BJ, McGechie DB, Rogers PA, Glancy RJ. Pyloric Campylobacter infection and gastroduodenal disease. Med J Aust 1985; 142: 439-444.

63 Booth L, Holdstock G, MacBride $\mathrm{H}$ et al, Campylobacter pyloridis and associated serum $\mathrm{IgG}$ and $\operatorname{IgA}$ antibody responses in patients undergoing upper gastrointestinal endoscopy. J Clin Pathol 1986; 39: 215-219.

64 Von Wulffen H, Heeseman J, Bützow GH et al. Detection of Campylobacter pyloridis in patients with antrum gastritis and peptic ulcers by culture, complement fixation tests, and immunoblot. J Clin Microbiol 1986; 24: 716-720.

65 Tytgat GNJ, Noach LA, Rauws ENJ. Helicobacter pylori infection and duodenal ulcer relapse. Gastroenterol Clin North Am 1993; 22: 127-139.

66 Vorobjova T, Maaroos HI, Uibo R et al. Helicobacter pylori: histological and serological study on gastric and duodenal ulcer patients in Estonia. Scand J Gastroenterol 1991; 26 (suppl 186): 84-89. 
Louw JA, Falck V, van Rensberg C, Zak J, Adams G, Marks IN. Distribution of Helicobacter pylori colonization and associated gastric inflammatory changes: difference between patients with duodenal and gastric ulcers. J Clin Pathol 1993; 46: 754-756.

68 Nonura A, Stemmermann GN, Chyou PH, Perez-Perez GI, Blaser MJ. Helicobacter pylori infection and the risk for duodenal and gastric ulceration. Ann Intern Med 1994; 120: $977-981$.

69 Sipponen P, Varis K, Fräki O, Korri UM, Seppälä K, Siurala M. Cumulative 10 year risk of symptomatic duodenal and gastric ulcer in patients with or without chronic gastritis. Scand J Gastroenterol 1990; 25: 966-973.

70 Vaira D, Miglioli M, Mule $\mathrm{P}$ et al. Prevalence of peptic ulcer in Helicobacter positive blood donors. Gut 1994; 35: 309-312.

71 Kuipers EJ, Thijs JE, Festen HPM. The prevalence of Helicobacter pylori in peptic ulcer disease. Aliment Pharmacol Ther 1995; 9 (suppl 2); 59-69.

72 Graham DY, Campylobacter pylori and peptic ulcer disease. Gastroenterol 1989; 96: 615-625.

73 Sipponen P. Natural history of gastritis and its relationship to peptic ulcer disease. Digestion 1992; 51 (suppl 1): 70-75.

74 Marshall BJ, Goodwin CS, Warren JR et al. Prospective double-blind trial of duodenal ulcer relapse after eradication of Campylobacter pylori. Lancet 1988; ii: 1437-1442.

75 Graham DY, Lew GM, Klein PD et al. Effect of treatment of Helicobacter pylori on the long-term recurrence of gastric and duodenal ulcer. A randomnized controlled study. Ann Intern Med 1992; 16: 705-708.

76 Hentschel $E_{3}$ Brandstatter G, Dragosics B et al. Effect of ranitidine and amoxycillin plus metronidazole on the eradication of Helicobacter pylori and the recurrence of duodenal ulcer. N Engl J Med 1993; 326: 308-312.

77 Seppälä K, Pikkarainen P, Sipponen P, Kivilaakso E, Gormsen MH and the Fimnish gastric ulcer study group. Cure of peptic gastric ulcer associated with eradication of Helicobacter pylori. Gut 1995; 36: 834-837.

78 Bayerdörffer $\mathrm{E}$, Miehlke $\mathrm{S}$, Lehn $\mathrm{N}$ et al. Cure of gastric ulcer disease after cure of Helicobacter pylori infection. German gastric ulcer study. Eur J Gastroenterol Hepatol 1996; 8: 343-349.

79 Blaser MJ, Chyou PH, Nomura A. Age at establishment of Helicobacter pylori infection and gastric carcinoma, gastric ulcer, and duodenal ulcer risk. Cancer Res $1995 ; 55 ; 562-265$.

80 Hansson L-E, Nyrén O, Hsing AW et al. The risk of stomach cancer in patients with gastric or duodenal ulcer disease. N Engl J Med 1996; 335: 242-249.

81 Majewski SIH, Goodwin CS. Restriction endonuclease analysis of the genome of Campylobacter pylori with a rapid extraction method; evidence for considerable genomic variation. J Infect Dis 1988; 157: 465-471. 


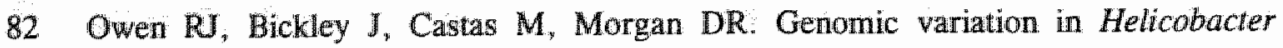
pylort: applicated to identification of strains. Scand J Gastroenterol 1991; 26: 43-50.

83 Desal $M$, Linton D, Aven RJ, Cameron $H$, Stanley J. Genetic diversity of Helicobacter pylori indexed with respect to clinical symptomatology, using a $16 \mathrm{~s}$ rRNA and a species-specific DNA probe. J Appl Bact 1993; 75:574-582.

84 Tummuru MKR; Cover TL, Blaser MJ. Cloning and expression of a highmolecular-mass major antigen of Helicobacter pylori: evidence of linkage to cytotoxin production. Inf Imm 1993; 61: 1799-1809.

85 Figura N, Gugkelmetti P. Rossolini A et al. Cytotoxic production by Campylobacter pylori strains isolated from patients with peptic ulcers and from patients with chronic gastritis only. J Clin Microbiol 1989; 27:225m226.

86 Crabtree JE, Taylor JB, Wyatt JI et al. Mucosal IgA recognition of Helicobacter pylori $120 \mathrm{kDa}$ protein, peptic ulceration and gastric pathology. Lancet 1991; 338: 332-335.

87 Laurén $P$. The two histological main types of gastric carcinoma. Diffuse and socalled intestinall type. Acta Pathol Microbiol Scand 1965; 64: 31-49.

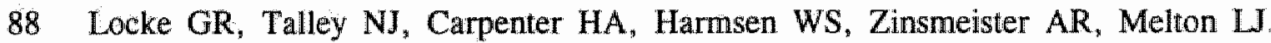
Changes in the site- and histology-specific incidence of gastric cancer during a 50 year period. Gastroenterol 1995; 109: 1750-1756.

89 Wingo $\mathrm{P}$, Tong $\mathrm{T}$, Bolden $\mathrm{S}$. Cancer statistics 1995. CA 1995; 45: 8-30.

90 Neugut AI, Hayek M, Howe G. Epidemiology of gastric cancer. Sem Oncol 1996; 23: $281-291$.

91 Thomas RM, Sobin LH. Gastrointestinal cancer. Cancer 1994; 75: 154-170.

92 Fuchs CS, Mayer RJ. Review article: Gastric carcinoma. N Engl J Med 1995; 333: 32-41.

93 Nomura A, Stemmermann GN. Review article: Helicobacter pylori and gastric cancer. J Gastroenterol Hepatol. 1993; 8: 294-303.

94 Loffeld RJLF, Willems I, Flendrig JA, Arends JW. Helicobacter pylori and gastric carcinoma. Histopathol 1990; 17: 537-541.

95 Parsonnet J, Vandersteen D, Goates J, Sibley RK, Pritikin J, Chang Y. Helicobacter pylori infection in Intestinal- and Diffuse-type gastric adenocarcinomas. I Natl Cancer Inst 1991; 83: 640-643.

96 Buruk F, Berberoglu U, Pak I, Aksaz $\mathrm{E}_{\text {, }}$ Celen O. Gastric cancer and Helicobacter pylori infection. Br I Surg 1993; 80: 378-379.

97 Nogueira AMMF, Ribeiro GM, Rodriguez MAG et al. Prevalence of Helicobacter pylori in Brazilian patients with gastric carcinoma. Am J Clin Pathol 1993; 100: 236-239.

98 Forman D, Newell DG, Fullerton F et all. Association between infection with Helicobacter pylori and risk of gastric cancer: evidence from a prospective investigation. Br Med J 1991; 302: 1302-1305. 
99 Nomura A, Stemmermann GN, Chyou P-H, Kato I, Perez-Perez GI, Blatsert MI. Helicobacter pylori infection and gastric carcinoma among Japanese Americans in Hawaii. N Engl J Med 1991; 325: 1132-1136.

100 Parsonnet J, Friedman GD, Vandersteen DP et al. Helicobacter pylori infection and the risk of gastric carcinoma. N Engl J Med 1991; 325: 1127-1131.

101 Eurogast Study Group. An international association between Hellicobacter pylori and gastric cancer. Lancet 1993; 341: 1359-1362.

102 Lee WJ, Lin JT, Shun CT et al. Comparison between resectable gastric adenocarcinomas seropositive and seronegative for Helicobacter pylori. Br J Surg $1995 ; 82: 802-805$.

103 Blaser MJ, Kobayashi $K$, Cover TL, Cao $P$, Feurer ID, Perez-Perez GI. Helicobacter pylori infection in Japanese patients with adenocarcinoma of the stomach. Int J Cancer 1993; 55: 799-802.

104 Kikuchi S, Wada O, Nakajima T et al. Serum anti-Helicabacter pylori antibody and gastric carcinoma among young adults. Cancer 1995; 75: 2789-2793.

105 Sipponen $P$, Kekki M, Siurala M. Atrophic chronic gastritis and intestinal metaplasia in gastric carcinoma. Cancer 1983; 52: 1062-1068.

106 Correa R. The epidemiology of gastric cancer. World J Surg 1991; 15: 228-234.

107 Karnes WE, Samloff IM, Siurala M, Sipponen P, Kim SWR, Walsch JH. Positive serum antibody and negative tissue staining for Helicobacter pylori in subjects with atrophic gastritis. Gastroenterol 1991; 101: 167-174.

108 Sipponen P, Kosunen TU, Valle J, Riihelä, Seppälä K. Helicabacter pylori infection and chronic gastritis in gastric cancer. J Clin Pathol 1992; 45: 319-323.

109 Wee A, Kang JY, Teh M. Helicobacter pylori and gastric cancer: correlation with gastrïtis, intestinal metaplasia, and tumour histology. Gut 1992; 33: 1029-1032.

110 Hansson L-E, Engstrand L, Nyrén O, Lindgren A. Prevalence of Helicobacter pylori infection in subtypes of gastric cancer. Gastroenterol 1995; 109: 885-888.

111 Sierra R, Parkin DM, Munoz G. Cancer in Costa Rica. Cancer Res 1989; 49: 717-724.

112 Forman D, Sitas F, Newell DG et al. Geographic association of Helicobacter pylort antibody prevalence and gastric cancer mortality in rural China. Int J Cancer 1990; 66: $2569-2574$.

113 Kuipers EJ, Gracia-Casanova J, Pena AS et al. Helicobacter pylon serology in patients with gastric carcinoma. Scand J Gastroenterol 1993; 28: 433-437.

114 Webb PM, Yu MC, Forman D et al. An apparent lack of association between Helicobacter pylori infection and risk of gastric cancer in China. Int J Cancer 1996; 67: 603-607.

115 Caygill CPJ, Hill MJ, Kirkham JS, Northfield TC. Mortality from gastric cancer following gastric surgery for peptic ulcer. Lancet 1986; i: 929-931.

116 Tersmette AC, Giardiello FM, Tytgat GNJ, Offerhaus GJA. Carcinogenesis after remote peptic ulcer surgery: the long-term prognosis of partial gastrectomy. Scand J Gastroenterol 1995; 30 (Suppl 212): 96-99. 
117 Kuster GGR, Remine WH, Dockerty MB. Gastric cancer in pernicious anaemia and in patients with and without achlorhydria. Am Surg 1972; 175:783 789 .

118 Stockbrigger RW, Menon GG, Beilby JOW, Mason RR, Cotton PB. Gastroscopic screening in 80 patients with pernicious anaemia. Gut 1983; 24: 1141-1147.

119 Schafer LW, Larson PE, Melton LJ, Higgins JA, Zinsmeister AR. Risk of development of gastric carcinoma in patients with pernicious anaemia: A populationbased study in Rochester, Minnesota. Mayo Clin Proc 1985; 60: 444-448.

120 Sjöblom SM, Sipponen $P$, Järvinen $H$. Gastroscopic follow up of pernicious anaemia patients. Gut $1993 ; 34: 28-32$.

121 Sipponen $P$, Kekki $M$, Haapakoski J, Ihamäki $T$, Siurala $M$. Gastric cancer risk in chronic atrophic gastritis: statistical calculations of cross-sectional data. Int J Cancer 1985; 35: $173-177$.

122 Colin Jones DG. Postmarketing surveillance of the safety of cimetidine: 12 month mortality report. Br Med J Clin Res Ed 1983; 286: 1713-1716.

123 Muller AF, Maloney A, Jenkens D, Dowling $F_{*}$ Smith $P$, Bessell EM, Toghill PJ. Primary gastric lymphoma in clinical practice 1973-1992. Gut 1995; 36: 679-683.

124 Wotherspoon AC, Ortiz-Hidalgo C, Falzon M, Isaacson G. Helicobacter pyloriassociated gastritis and primary B-cell gastric lymphoma. Lancet 1991; 338: 1175-1176.

125 Eidt S, Stolte M. Prevalences of lymphoid follicles and aggregates in Helicobacter pylori gastritis in antral and body mucosa. J Clin Pathol 1993; 46: 832-835.

126 Carlson SJ, Yokoo H, Vanagunas A. Progression of gastritis to monoclonal B-cell lymphoma with resolution and recurrence following eradication of Helicobacter pylori. JAMA 1996; 275 : 937-939.

127 Parsonnet $J$, Hansen $S$, Rodriguez $L$ et al. Helicobacter pylori infection and gastric lymphoma. N Engl J Med 1994; 330: 1267-1271.

128 Doglioni $\mathrm{C}$, Wotherspoon $\mathrm{AC}$, Moschini $\mathrm{A}$, de Boni $\mathrm{M}$, Isaacson $\mathrm{PG}$. High incidence of primary gastric lymphoma in northeastern Italy. Lancet 1992; 339: 834-835.

129 Wotherspoon DC, Doglioni C, Diss TC et al. Regression of primary low-grade B-cell gastric lymphoma of mucosa-associated lymphoid tissue type after eradication of Helicobacter pylori. Lancet 1993; 342: 575-577.

130 Weber DM, Dimopoulos MA, Anandu DP, Pugh WC, Steinback G. Regression of gastric lymphoma of mucosa-associated lymphoid tissue with antibiotic therapy for Helicobacter pylori. Gastroenterol 1994; 107: 1835-1838.

131 Roggero E, Zucca E, Pinotti G et al. Eradication of Helicobacter pylon in primary gastric low-grade lymphoma of mucosa-associated lymphoid tissue. Ann Intern Med $1995 ; 122: 767-769$.

132 Fischbach W, Kolve ME, Dragosics B and the German-Austrian Gastrointestinal Study Group. Prevalence of Helicobacter pylori infection in primary gastric lymphoma of the MALT. There is a difference between low-grade and high-grade lymphoma. Gut 1995; 37 (suppl 2): A75. 
133 Karat D, O'Hanlon DM, Hayers N, Scott D, Raimes SA, Griffin SM. Prospective study of Helicobacter pylori infection in primary gastric lymphoma. Br J Surg 1995; 82: $1369-1370$.

134 Chen $X G$, Correa $P$, Offerhaus J. Ultrastructure of the gastric nucosa harbouring Campylabacter-like organisms. Am J Clin Pathol 1986; 86: 575-582.

135 Newell DG. Virulence factors of Helicobacter pylori. Scand J Gastroenterol 1991; 26 (suppl 187): 31-38.

136 Sarosiek J, Peura DA, Guerrans RL et al. Mucolytic effects of Helicobacter pylori. Scand J Gastroenterol 1991; 26 (suppl 187): 47-55.

137 Dunn BE. Pathogenic mechanisms of Helicobacter pylori. Gastroenterol Clin N Am $1993 ; 22: 43-47$.

138 Eaton KA, Krakowka S. Effect of gastric $\mathrm{pH}$ on urease dependent colonization of gnotobiotic piglets by Helicobacter pylori. Inf Imm 1994; 62: 3604-3607.

139 Mobley HLT, Hu LT, Foxall PA. Helicobacter pylori urease: properties and role in pathogenesis. Scand J Gastroenterol 1991; 187 (suppl): 39-46.

140 Noach LA, Rolf TM, Tytgat GNJ. Electron microscopic study of association between Helicobacter pylori and gastric and duodenal mucosa. J Clin Pathol 1994; 47: $699-670$.

141. Crabtree JE. Immune and inflammatory responses to Helicobacter pylori infection. Scand J Gastroenterol 1996; 31 (suppl 215): 3-10.

142 Levi S, Beardshall K, Haddad G, Playford R, Ghosh P, Calam J. Campylobacter pylori and duodenal ulcers: the gastrin link. Lancet 1989; i: 1167-1168.

143 Mossi S, Meyer-Weiss B, Renner EL, Merki HS, Gamboni G, Beglinger C. Influence of Helicobacter pylori, sex, and age on serum gastrin and pepsinogen concentration in subjects without and patients with duodenal ulcer. Gut 1993; 34: $752-756$.

144 El-Omar EM, Penman ID, Ardill JES, Chittajallu RS, Howie C, McColl KEL. Helicobacter pylori infection and abnormalities of acid secretion in patients with. duodenall ulcer disease. Gastroenterol 1995; 109: 681-691.

145 Wyatt JI, Rathbone BJ. Immune response of the gastric mucosa to Campylobacter pylori. Scand J Gastroenterol 1988; 23 (suppl 142): 44-49.

146 Heatley JE, Wyatt JI, Sobala GM et al. Systemic and mucosal humoral responses to Helicobacter pylori in gastric cancer. Gut 1993; 34: 1339-1343.

147 Crabtree $\mathrm{JE}$, Wyatt $\mathrm{JI}_{*}$ Sobala GM et al. Systemic and mucosal humorall responses to Helicobacter pylori in gastric cancer. Gut $1993 ; 34: 1339-1343$.

148 Hazell SL, Evans DJ, Graham DY. Helicobacter pylori catalase. J Gen Microbiol 1991; 137: 57-61.

149 Moran AP. Pathogenic properties of Helicobacter pylori. Scand J Gastroenterol 1996; 31 (suppl 215): 22-31.

150 Piotrowski J, Yamaki K, Slomiany BL. Inhibition of gastric mucosal laminin receptor by Helicobacter pylori lipopolysaccharide: effect of sucralfate. Am I Gastroenterol $1991 ; 86: 1756-1760$. 
151 Leunk RD, Johnson PT, David BC, Kraft WG, Morgan DR. Cytotoxic activity in broth-culture filtrates of Campylobacter pylori. J Med Microbiol 1988; 26: 93-99.

152 Cower TL, Dooley CP, Blaser MJ. Characterization of and humoral serologic response to proteins in Helicobacter pylori broth culture supernatants with vacuolizing cytotoxin activity. Inf Imm 1990; 58: 603-610.

153 Tee W, Lambert $\mathrm{JR}_{\text {; }}$ Dwyer B. Cytotoxin production by Helicobacter pylori from patients with upper gastrointestinal tract disease. I Clin Microbiol 1995; 33: 1203-1205.

154 Kuipers EJ, Pérez Pérez GI, Meuwissen SGM, Blaser MJ. Helicobacter pylori and atrophic gastritis: importance of the cagA status. J Natl Cancer Inst 1996; 88: 465-466.

155 Hirai $M$, Azuma $T$, Ito $S$, Kato $T$, Kohli $Y$, Fujiki $N$. High prevalence of neutralizing activity to Helicobacter pylori cytotoxin in serum of gastric-carcinoma patients. Int J Cancer 1994; 56: 56-60.

156 Baik S-C, Youn H-S, Chung M-H et al. Increased oxidative DNA damage in Helicobacter pylori-infected human gastric mucosa. Cancer Res 1996; 56: 1279-1282.

157 Fan XG, Kelleher D, Fan XI, Xia HX, Keeling PWN. Helicobacter pylori increases proliferation of gastric epithelial cells. Gut 1996; 38: 19-22.

158 Tytgat GNJ. Current indications for Helicobacter pylori eradication therapy. Scand J Gastroenterol 1996: 31 (suppl 215): 70-73.

159 Tytgat GNJ. Review article: treatments that impact favourably upon the eradication of Helicobacter pylori and ulcer recurrence. Aliment Pharmacol Ther 1994; 8: 359-368.

160 Sung JJY, Chung SCS, Ling TKW et al. Dual therapy versus triple therapy for Helicobacter pylori-associated duodenal ulcers. Dïg Dis Sc 1996; 41: 453-457.

161 Unge P. Review of Helicobacter pylori eradication regimens. Scand J Gastroenterol 1996; 31 (suppl 215): 74-81.

162 Goddard A, Logan R. One-week low-dose triple therapy: New standards for Helicobacter pylori treatment. Eur $J$ Gastroenterol Hepatol 1995; $7: 1$-3.

163 Hudson $N$, Brydon WB, Eastwood MA, Ferguson A. Palmer KR. Successful Helicobacter pylori eradication incorporating one-week antibiotic regimen. Aliment Pharmacol Ther 1995; $9: 47-50$.

164 De Boer WA, Driessen WMM, Potters VPJ, Tytgat GNJ. Randomnized study comparing 1 with 2 weeks of quadruple therapy for eradicating Helicobacter pylori. Am J Gastroenterol 1994; 89: 1993-1997.

165 Rauws EAJ, van der Hulst RWM. Current guidelines for the eradication of Helicobacter pylori in peptic ulcer disease. Drugs 1995; 50: 984m990.

166 Borody "TJ. Andrews P, Fracchia G, Brandl S, Shortis NP, Bal H. Omeprazole enhances efficacy of triple therapy in eradicating Helicobacter pylori. Gut 1995; 37: 477-481. 
167 Xia HX, Buckley M, Hyde D, Keane CT, OMorain CA. Effects of antibiotic resistance on clarithromycin-combined triple therapy for Heticobacter pylori. Gut 1995; 37 (suppl 1): A55.

168 Vasquez A, Valdez Y, Gilman RH et al. Metronidazole and clarithromycin resistance in Helicobacter pylori determined by measuring MICs of antimicrobial agents in collour indicator Egg Yolk Agar in a miniwell format. J Clin Microbiol 1996; 34: 1232-1234.

169 Sharma S, Prasad KN, Chamoli D, Ayyagari A. Antimicrobial susceptibility pattern and biotyping of Helicobacter pylori isolates from patients with peptic ulcer disease. Indian J Med Res 1995; 102: 261-266.

170 Midolo $\mathrm{PD}$, Korman MG, Turnidge JD, Lambert JK. Helicobácter pylori resistance to tetracycline. Lancet $1996 ; 347 ; 1194-\$ 195$.

171 Guyton AC. Textbook of Medical Physiology. Seventh Edition. W.B. Saunders Company, Philadelphia 1986.

172 Junqueira LC, Carneiro J, Long JA. Functionele histologie, vierde geheel herziene druk, Wetenschappelijke uitgeverij Bunge, Utrecht 1987.

173 Sherwood. WC, Goldstein F, Haurain FI, Wirts W. Studies of the small-intestinal bacterial flora and intestinal absorption in pernicious anemia. Am J Dig Dis 1964; $9: 416-425$.

174 Gray JD, Shiner M. Influence of gastric pH on gastric and jejunal flora. Gut 1967; 8: $574-581$.

175 Drasar BS, Shiner M, McLeod GM. Studies on the intestinal flora. I. The bacterial flora of the gastrointestinal tract in healthy and achlorhydric persons. Gastroenterol $1969 ; 56: 71-79$.

176 Muscroft TJ, Deane SA, Younds D, Burdon DW, Keighley MRB. The microflora of the postoperative stomach. Br J Surg 1981; 68: 560-564.

177 Gianella RA, Broitman SA, Zamcheck N. Gastric acid barrier to ingested microorganisms in man: studies in vivo and in vitro. Gut 1972; 13: 251-256.

178 Hill M. Normal and pathological microbial flora of the upper gastrointestinal tract. Scand J Gastroenterol 1984; 20 (Suppl 111): 1-5.

179 Gatehouse D, Dimock F, Burdon DW, Alexander-Wiliams J, Keighley MRB. Prediction of wound sepsis following gastric operations. $\mathrm{Br} J$ Surg 1978; 65: $551-554$

180 Forsythe SJ, Dolby JM, Webster ADB, Cole JA. Nitrate- and nitrite-reducing bacteria in the achlorthydric stomach. J Med Microbiol 1988; 25:253-259.

181 Vanzant FR, Alvarez WC, Eusterman GB, Dunn HL, Berkson J. The normal range of gastric acidity from youth to old age. Arch Intern Med 1932; 49:345-359.

182 Bins $M$, Burgers $P$, Selbach $S$, w Wettum $T$, Lamers $C$, wan Tongeren $J$. The relation between basal gastric $\mathrm{pH}$ and serum gastrin. Digestion 1983; 23: 271-273.

183 Watt PCH, Sloan IM, Donaldson ID, Patterson CC, Kennedy TL. Relationship between histology and gastric juice $\mathrm{pH}$ and nitrite in the stomach after operation for duodenal ulcer. Gut 1984; $25: 246-252$. 
184 Stockbringger $\mathbb{R W}$, Cotton $\mathrm{PB}$, Menon $\mathrm{GG}$ et al. Pernicious anaemia, intragastric bacterial overgrowth and possible consequences. Scand J Gastroenterol 1984; 19: $355-364$.

185 Stockbrügger RW, Armbrecht U, Rode JW, Teall AJ, Oberholzer VG, Croker JR, Cotton PB. The bacterial overgrowth syndrome is uncommon in pernicious anaemia: results of a follow-up study. Microbial Ecol Health Dis 1990; 3: 209-215.

186 Dolby MM, Webster ADB, Borriello SP, Barclay FE, Bartholomew BA, Hill MJ. Bacterial colonization and nitrite concentration in the achlorhydric stomachs of patients with primary hypogammaglobulinaemia or classical pernicious anaemia. Scand J Gastroenteroll 1984; 19: 105-110.

187 Armbrecht $\mathbb{U}$, Bosaeus I, Gilbers $\mathrm{R}$, Seeberg S, Stockbrügger R. Hydrogen $\left(\mathrm{H}_{2}\right)$ breath test and gastric bacteria in acid-secreting subjects and in achlorhydria and post-gastrectomy patients before and after antimicrobial treatment. Scand I Gastroenterol $1985 ; 20: 805-813$.

188 Meyrick Thomas $J$, Misiewicz JJ, Cook AR et al. Effects of one year's treatment with ranitidine and of truncal vagotomy on gastric contents. Gut 1987; 28: 726-738.

189 Keighley MRB, Youngs $\mathrm{D}$, Poxon $\mathrm{V}$ et al. Intragastric $\mathrm{N}$-nitrosation is unlikely to be responsible for gastric carcinoma developing after operations for duodenal ulcer. Gut 1984; 25: 238-245.

190 Carboni M, Guadagni S, Pistoia MA et al. The microflora of the gastric juice after Billroth I and Billroth II partial gastrectomy. Scand J Gastroenterol 1986; 21; 461-470.

191 Husebye E. Gastrointestinal motillty disorders and bacterial overgrowth. J Intern Med 1995; $237: 419-427$.

192 Stockbrigger RW, Seeberg S, Hellner L, Jaup BH, Dotevall G. Intragastric bacteria and nitrite after short-term treatment with different doses of antimuscarinic drugs. Scand J Gastroenterol 1984; 19: 14-23.

193 Ruddell WSJ, Axon ATR, Findlay JM, Bartholomew BA, Hill MJ. Effect of cimetidine on the gastric bacterial flora. Lancet 1980; i: 672-674.

194 Snepar R. Poprad GA, Romano JM, Kobasa WD, Kaye D. Effect of cimetidine and antacid on gastric microbial flora. Infect Imm 1982; 36:518-524.

195 Stockbrïgger RW, Cotton PB, Eugenides N, Bartholomew BA, Hill MJ, Walters CL. Intragastric nitrites, nitrosamines, and bacterial overgrowth during cimetidine treatment. Gut 1982; 23: 1048-1054.

196 Sharma BK, Santana IA, Wood EC et al. Intragastric bacterial activity and nitrosation during, and after treatment with omeprazole. $\mathrm{Br}$ Med J 1984; 289; 717-719.

197 Verdu $E_{n}$ Viani $F$, Armstrong $D$ et al. Effects of omeprazole on intragastric bacterial counts, nitrates, nitrites, and $\mathrm{N}$-nitroso compounds. Gut 1994; 35: 455-460.

198 Karmeli Y, Stalnikowitz R, Eliakim R, Rahav G. Conventional dose of omeprazole alters gastric flora. Dig Dis Sc 1995; 40: 2070-2073. 
199 Fried M, Siegrist H, Frei R et al. Duodenal bacterial overgrowth during treatment in outpatients with omeprazole: Gut 1994; $35: 23-26$.

200 Houben GMP, Hooi J, Brummer RJM, Stobberingh EE, Stockbrügger RW. Are intragastric $\mathrm{N}$-nitroso compounds elevated after short-term acid suppression? Eur $\mathrm{J}$ Cancer Prev 1996; 5 (suppll 1): 83-87.

201 Cook GC. Hypochlorhydria and vulnerability to intestinal infection. Eur J Gastroenterol Hepatol 1994; 6: 693-695.

202 Nordbring F. Contraction of Salmonella Gastroenteritis following previous operation of the stomach. Acta Med Scand 1962; 171: 783-790.

203 Neal KR, Brij SO, Slack RCB, Hawkey CJ, Logan RFA. Recent treatment with $\mathrm{H}_{2}$ antagonists and antibiotics and gastric surgery as risk factors for salmonella infection. Br Med J 1994; 308: 176.

204 Nwokolo CU, Loft DE, Holder R, Langman MJS. Increased incidence of bacterial diarrhoea in patients taking gastric acid secretory drugs. Eur $\mathbf{J}$ Gastroenterol Hepatol 1994; 6: 697-699.

205 Cook GC. Infective gastroenteritis and its relationship to reduced gastric acidity. Scand J Gastroenterol 1985; 20 (suppl 111): 17-21.

206 Kochhar R, Talwar P, Singhs S, Mehta SK. Invasive Candidiasis following cimetidine therapy. Am J Gastroenterol 1988; 83: 102-103.

207 Larner AJ. Risk factors for Salmonella infection. Loss of gastric acid lined to Candidiasis. Br Med J 1994; 308: 596-597.

208 Roberts SH, James O, Jarvis EH. Bacterial overgrowth syndrome without "blind loops": a cause for malnutrition in the elderly. Lancet 1977; ii: 1193-1195.

209 Tabaqchali S, Booth CC. Jejunal bacteriology and bile-salt metabolism in patients with intestinal malabsorption. Lancet 1966; ii: 12-15.

210 Domellöf L, Reddy BS, Weisburger JH. Microflora and deconjugation of bile acids in alkaline reflux after partial gastrectomy. Am J Surg 1980; 140: 291-295.

211 Walan A, Ström M. Metabolic consequences of reduced gastric acidity. Scand J Gastroenterol 1995; 20 (suppl 111): 24-29.

212 Magee PN. Nitrosamines and human cancer: introduction and overvilew. Eur J Cancer Prev 1996; 5 (suppl 1): 7-10.

213 Bartsch H, Spiegelhalder B. Environmental exposure to N-nitroso compounds (NNOC) and precursors: an overview. Eur J Cancer Prev 1996; 5 (suppl 1): 11-18.

214 Matanen van JMS, Dallinga JW, Kleinjans JCS. Environmental exposure to $\mathbb{N}$. nitroso compounds and their precursors. Eur J Cancer Prev 1996; 5 (suppl 1): 29-31.

215 Hill MJ. Endogenous N-nitrosation. Overview. Eur J Cancer Prew 1996; 5 (suppl. 1): 47-50.

216 Hill MJ. Factors controlling endogenous N-nitrosation. Eur J Cancer Prev 1996; 5 (suppl 1); 71-74. 
217 Xa GP, Reed PI. N-mitroso compounds in fresh gastric juice and their relation to intragastric $\mathrm{pH}$ and nitrite employing an improved analytical method. Carcinogenesis 1993; 14: 2547-2551.

218 Reed PI Smith PLR, Haines $\mathrm{K}$, House FR. Effect of cimetidine on gastric juice $\mathbb{N}$ nitrosamine concentration. Lancet 1981; ii: 553-555.

219 Pignatelli B, Walters CL. Analytical techniques for total $\mathrm{N}$-nitroso compounds. Eur I Cancer Prev 1996; 5 (suppl 1): 51-58.

220 Walters CL. Analytical techniques for the determination of total N-nitroso compounds. Eur J Cancer Prev 1996; 5 (suppl 1): 59-61.

221 Preussmann R. Carcinogenetics of nitroso ureas in humans. In "Carcinogenicity of alkylating cytostatic drugs", (eds Schmahl D, Kaldor JM). IARC Scientific publications no. 78. International agency for Research on Cancer, Lyon, 1986, pp. 223-229.

222 Reed PI, N-nitroso compounds, their relevance to human cancer and further prospects for prevention. Eur J Cancer Prev 1996; 5 (suppl 1): 137-147.

223 Caygill CPJ. Epidemiology relating $\mathrm{N}$-nitroso compounds to human cancer. Eur J Cancer Prev 1996; 5 (suppl 1): 125-130.

$224 \mathrm{Li} \mathrm{SH}$, Oshima $\mathrm{H}, \mathrm{Fu} \mathrm{HM}$ et al. Urinary excretion of $\mathrm{N}$-nitroso-amino acids and nitrate by inhabitants of high- and low-risk areas for oesophageal cancer in Northern China: endogenous formation of nitrosoproline and its inhibition by vitamin $C$. Cancer Res 1986; 46: 1485-1491.

225 Ruddell WSJ, Bone ES, Hill MJ, Walters CL. Pathogenesis of gastric cancer in pernicious anaemia. Lancet 1978; i: 521-523.

226 Borch K. Epidemiologic, clinicopathologic, and economic aspects of gastroscopic screening of patients with pernicious anaemia. Scand J Gastroenterol 1986; 21: 21-30.

227 Ruddell WSJ, Bone ES, Hill MJ, Blendis LM, Walters CI. Gastric-juice nitrite: A risk factor for cancer in the hypochlorhydric stomach. Lancet 1976; ii: 1037-1039.

228 Brown KE, Peura DA. Diagnosis of Helicobacter pylori infection. Gastroenterol Clin N Ain 1993; 22: 105-115.

229 Peura DA. Helicobacter pylori: a diagnostic dilemma and a dilemma of diagnosis. Gastroenterol 1995: 109: 313-315.

230 Mégraud F. Advantages and disadvantages of current diagnostic tests for the detection of Helicobacter pylori. Scand J Gastroenterol 1996; 31 (suppl 215): 57-62.

231 Gray SF, Wyatt JL, Rathbone BJ. Simplified techniques for identifying Campylobacter pyloridis. J Clin Pathol 1986; 39: 1279.

232 Warthin AS, Starry AC. A more rapid and improved method of demonstrating spirochaetes in tissues. Am J Syph 1920; 4: 97-103.

233 Barthel IS, Everett ED. Diagnosis of Campylobacter pylori infections: The "Gold Standard" and the alternatives. Rev Infect Dis 1990; 12: s107-s114.

234 The Gastrointestinal Physiology Working Group: Rapid identification of pyloric Campylobacter in Peruvians with gastritis. Dig Dis Sc 1986; 31 : 1089-1094. 
235 Madan E, Kemp J, Westblom TU, Subile M, Secton S, Cook I. Evaluation of staining methods for identifying Campylobacter pylori: Am J Clin Pathol 1988; 90: 450-453.

236 Alpert LC, Graham DY, Evans DJ et al. Diagnostic possibilities for Campylobacter pylori infection. Eur J Gastroenterol Hepatol 1989; 1: 17-26.

237 Potters HVPJ, Loffeld RILF, Stobberingh E, van Spreeuwel JP, Arends JW. Rapid staining of Campylobacter pyloridis. Histopathol 1987; 11: 1223.

238 Aymard B, Labouyrie E, de Korwin JD, Ferr R, Duprez D. Histological staining methods for detection of gastric Campylobacter-like organisms (GLOs): a comparative study. Gastroenterol 1988; 94 (suppl): A16.

239 Walters LL, Budin RE, Paull G. Acridine-orange to identify Campylobacter pyloridis in formalin fixed, paraffin-embedded gastric biopsies. Lancet 1986; i: 42 .

240 Chodos JE, Dworking BM, Smith $\mathrm{F}$ et al. Campylobacter pylori and gastroduodenal disease: A prospective endoscopic study and comparison of diagnostic tests. Am J Gastroenterol 1988; 83: 1226-1230.

241 Deltenre $M$, Glupczynski $Y$, DePrez $C$ et al. The reliability of urease tests, histology and culture in the diagnosis of Campylobacter pylori infection. Scand $J$ Gastroenterol 1989: 24: 19-24.

242 Coudron PE; Kirby D. Comparison of rapid urease tests, staining techniques, and growth on different solid media for detection of Helicobacter pylori. J Clin Microbiol 1989; 27: 1527-1530.

243 Krajden SJ, Bohnen J, Anderson J et al. Comparison of selective and nonselective media for recovering of Campylobacter pylori from antral biopsies. I Clin Microbiol $1987 ; 25: 1117-1118$.

244 Lambert T, Mégraud F, Gergand G, Courvalin P. Susceptibility of Campylobacter pyloridis to 20 antimicrobial agents. J Antimicrobial Chem Ther 1986; 30: 510-511.

245 McNulty CA, Dent JC. Susceptibility of clinical isolates of Campylobacter pyloridis to twenty-one antimicrobial agents. Eur J Clin Microbiol Infect Dis 1988; 7: 566-569.

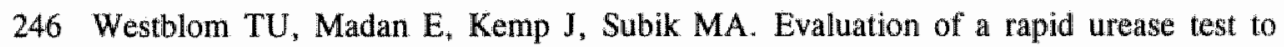
detect Campylobacter pylori infection. J Clin Microbiol 1988; 26: 1393-1394.

247 Marshall BJ, Warren RJ, Francis GJ, Langton SR. Rapid urease test in the management of Campylobacter pyloridis associated gastritis. Am J Gastroenterol 1987; 82: 200-210.

248 Clayton $\mathrm{CL}$, Kleanthous $\mathrm{H}$, Coates PJ, Morgan DD, Tabaqchali S. Sensitive detection of Helicobacter pylori by using polymerase chain reaction. I Clin Microbiol 1992; 30: 192-200.

249 Westblom TU, Phadris S, Ynag P, Czinn SJ. Diagnosis of Helicobacter pylori infection by means of a polymerase chain reaction for gastric juice aspirates. Clin Inf Dis 1993; 16:367-371. 
250 Hoshina $S$, Kahn $S$, Jiang $W$ et al. Direct detection and amplification of Helicobacter pylori ribosomal $16 \mathrm{~s}$ Gene segments from gastric endoscopic biopsies. Diagn Microbiol Inf Dis 1990; 13: 473-479.

251 Weiss J, Mecca J, Silva E, Gassner D. Comparison of PCR and other diagnostic techniques for detection of Helicobacter pylori infection in dyspeptic patients. J Clin Microbiol 1994; 32: 1663-1668:

252 Valentine $\mathrm{JL}$, Athru RR, Mobley HLT, Dick JD. Detection of Helicobacter pylori by using the polymerase chain reaction. J Clin Microbiol 1991; 29: 689-695.

253 A1-Zaatari FAK, Nguyen AH, Genta RM, Klein PD, Graham DY. Determination of Helicobacter pylori status by reverse transcription-polymerase chain reaction. Dig Dis Sc 1995; 40: 109-113.

254 Fanty GT, Zheng Q-X, James SP. Conventional cleaning and disinfection techniques eliminate the risk of endoscopic transmission of Helicobacter pylori. Am J Gastroenterol 1995; 90: 227-232.

255 Catherton J, Spiller RC. The urea breath test for Helicobacter pylori. Leading article. Gut 1994; $35: 723-725$.

256 Graham DY, Klein PD, Evans ID, Evans DG, Boutton TW. Campylobacter pylori detected noninvasively by the ${ }^{13} \mathrm{C}$-urea breath test. Lancet 1987 ; i: $1174-1177$.

257 Pena AS, Endtz HP, Offerhaus GJA et al. Value of serology (Elisa and immunoblotting) for the diagnosis of Campylobacter pylori infection. Digestion 1989; 44: 131-141.

258 Feldman RA, Deeks JJ, Evans SJW and the Helicobacter pylori study group. Multilaboratory comparison of eight commercially available Helicobacter pylori serology kits. Eur J Clin Microbiol Infect Dis 1995; 14: 428-433.

259 Loffeld RJ, Stobberingh E, Arends JW. A review of diagnostic technique for Helicobacter pylori. Dig Dis 1993; 11: 173-180.

260 Liston R, Pitt MA. Banerjee AK. IgG Elisa antibodies and detection of Helicobacter pylori in elderly patients. Lancet 1996; 347: 269.

261 Raymond $J$, Kalach $N$, Bergeret $M$ et al. Evaluation of four serological tests for diagnosis of Helicabacter pylori infection in children. Eur J Clin Microbiol Infect Dis $1996 ; 15: 415-417$.

262 Taha AS, Reed J, Boothmann P et al. Serological diagnosis of Helicabacter pylori: Evaluation of four tests in the presence or absence of non-steroidal inflammatory drugs. Gut 1993; 34: 461-465.

263 Goodwin CS, Blincow E, Peterson G et al. Enzyme-linked immunosorbent assay for Campylobacter pyloridis: Correlation with presence of $C$. pyloridis in the gastric mucosa. J Inf Dis 1987; 155: 488-494.

264 Hirschil AM, Brandstätter G, Dragosics B et al. Kinetics of specific IgG antibodies for monitoring the effect of anti-Helicobacter pylori chemotherapy. J Infect Dis 1993; 168: 763-766.

265 Yamada T, Alpert DH, Owyang C, Powell DW, Silversten FE. Textbook of Gastroenterology, volume 2. J.B. Lippincott Company, Philadelphia, 1991. 
266 Farivar S, Fromm H, Schindler D, Schmidt FW. Sensitivity of bile acid breath test in the diagnosis of bacterial overgrowth in the small intestine with and without the stagnant (blind) loop syndrome. Dig Dis Sc 1979; 24: 33-40.

267 Peled Y, Levy-Gigi C, Ayalon D, Gilat T. The cholate glycine-1 ${ }^{14} \mathrm{C}$ breath test in various gastrointestinal disorders. Digestion $1979 ; 19: 267-279$.

268 Rhodes JM, Middleton P, Jewell DP. The lactulose hydrogen breath test as a diagnostic test for small-bowel bacterial overgrowth. Scand I Gastroenterol 1979; 14: $333-336$.

269 King CE, Toskes PP, Guilarte TR, Lorenz E, Welkos SL. Comparison of the onegram $\mathrm{d}^{14} \mathrm{C}$ Xylose breath test to the ${ }^{14} \mathrm{C}$ bile acid breath test in patients with smallintestine bacterial overgrowth. Dig Dis Sc 1980; 25; 53-58.

270 Kerlin P, Wong L. Breath hydrogen testing in bacterial overgrowth of the small intestine. Gastroenterol 1988; 95: 982-988.

271 Armbrecht U, Seeberg $\mathrm{S}$, Stockbrügger RW. Hydrogen $\left(\mathrm{H}_{2}\right)$ breath excretion in peptic disease before and during treatment with ranitidine. Scand J Gastroenterol $1987 ; 22: 1211-1216$. 


\section{Aims of the study}

A Helicobacter pylori (H.pylori) infection is associated with duodenal and gastric ulcers, gastric cancer and primary gastric lymphoma. In clinicial conditions or lesions associated with a decreased gastric acidity, a non- $H . p y l o r i$ bacterial flora can colonize the stomach. In the histological sequence of H.pylori-associated gastritis towards atrophic gastritis, intestinal metaplasia and gastric cancer, the intragastric $\mathrm{pH}$ increases. In this sequence, both H.pylori and/or non-H.pylori bacteria may be present. Until now, most attention has been paid to the presence and role of H.pylori in the pathogenesis of these conditions. To detect H.pylori, usually non-specific histological staining methods or bacteriological culture are used with a relatively low sensitivity. The role of the non- $H$.pylori flora in the abovementioned conditions is insufficiently documented. To assess the contribution of either type of bacterial flora in the pathogenesis of the clinical conditions mentioned above, it is important to use sensitive and specific detection methods to distinguish H.pylori and non-H.pylori flora.

The studies in this thesis describe the following subjects:

* Optimalisation of culture procudures for the detection of H.pylori (Chapter II).

* Evaluation of a specific immunohistochemical stain in comparison with nonspecific staining methods for the histological detection of H.pylori in clinical situations where both H.pylori and/or non-H.pylori can be present (Chapter III and IV).

* Use of the immunohistochemical stain and the modified Giemsa stain to assess the total intragastric bacterial flora in clinical situations associated with H.pylori: peptic ulcer disease (Chapter V), primary gastric lymphoma (Chapter VI) and gastric cancer (Chapter VII).

In all situations, the presence, gastroduodenal distribution and density of both H.pylori and non-H.pylori intragastric bacterial flora were related to clinical findings. 


\title{
Chapter II
}

\section{Influence of oropharyngeal flora and specimen pretreatment on the recovery of Helicobacter pylori}

\author{
D Jonkers, E Stobberingh, R Stockbrügger
}




\section{Summary}

The recovery of Helicobacter pylori was studied in vitro in the presence of different concentrations of oropharyngeal flora. The effect on the bacterial yield of Helicobacter pylori and oropharyngeal flora by washing biopsies once, twice, or thrice before culture was then studied in biopsies taken from 35 patients. A low rate of recovery of low Helicobacter pylori concentrations $\left(\leq 10^{3} \mathrm{cfu} / \mathrm{ml}\right)$ was related to the presence of relatively high amounts of oropharyngeal flora $\left(\geq 10^{4} \mathrm{cfu} / \mathrm{ml}\right)$. After three washings a decrease in oropharyngeal flora between 10-fold and 100-fold cfu/biopsy was observed in seven patient samples. In another three specimens a more than 100 -fold reduction in cfu/biopsy was observed. For Helicobacter pylori, a 60-fold decrease in log cfu/biopsy was observed in only one patient. Pretreatment of the specimens by washing of the biopsies improved the recovery of small amounts of Helicobacter pylori in 10 of 28 patients. For optimal detection of Helicobacter pylori in gastric mucosal biopsies, washing of the specimens in addition to the use of selective media is recommended. 


\section{Introduction}

Helicobacter pylori (H.pylori), a Gram negative microorganism, has been identified in cases of duodenal and gastric ulcer disease, gastric cancer and MALTlymphoma ${ }^{1-3}$. Isolation of H.pylori from gastric mucosal biopsies is important to confirm the role of this microorganism in the pathogenesis of these diseases and it offers the additional advantage of having an isolate available for antibiotic susceptibility testing.

Although, it could be expected that only H.pylori is present in the gastric biopsy specimen, use of inhibitors of gastric acid secretion, as in many patients with duodenall and gastric ulcer disease, or progression of gastritis towards atrophic gastritis results in an increase in the gastric $\mathrm{pH}^{4}$, and consequently in an increase in contaminating flora from the respiratory and/or gastrointestinal tract ${ }^{5,6}$. The presence of other flora may influence the detection of the fastidiously growing H.pylori ${ }^{7,8}$. To optimalize the recovery of H.pylori from specimens containing contaminating oropharyngeal or faecal flora, use of selective media seems most useful ${ }^{9}$. Another approach is washing of the specimens to remove the contaminating flora ${ }^{10,11}$.

In the present study we evaluated the effect of the use of both selective media and washing of specimens on the yield of H.pylori from gastric biopsy specimens.

\section{Material and methods}

\section{Influence of selective media on growth of oropharyngeal flora and Helicobacter pylori}

Samples of $0.01 \mathrm{ml}$ of suspensions $\left(10^{7} \mathrm{cfu} / \mathrm{ml}\right)$ of 14 clinical samples of oropharyngeal flora identified as viridans streptococci, Neisseria spp. and Corynebacterium spp. (in about equal concentrations) and 10 clinical strains of H.pylori were used to inoculate three selective plates with the five segments method $^{12}$. The Skirrow medium ${ }^{13}$ contained Columbia agar (Oxoid CM331, Oxoid, UK) with 5\% sheep blood and a selective supplement (Oxoid SR069) comprising vancomycin, trimethoprim and polymyxin B. CPS plates ${ }^{7}$ contained blood agar base no. 2 (Oxoid CM271) with 7\% laked horse blood (Oxoid SR048) and Dent selective supplement (Oxoid SR147). Nal medium ${ }^{14}$ contained Columbia agar with $5 \%$ sheep blood, vancomycin $10 \mathrm{mg} / \mathrm{l}$ (Eli Lily, The Netherlands), trimethoprim $5 \mathrm{mg} / \mathrm{l}$ (La Roche, The Netherlands), and nalidixic acid $20 \mathrm{mg} / 1$ (Sterling-Winthrop, UK). All plates were incubated under micro-aerophilic conditions $\left(10 \% \mathrm{CO}_{2}, 5 \% \mathrm{O}_{2}\right)$ at $37^{\circ} \mathrm{C}$ for 5 to 7 days. 


\section{Influence of oropharyngeal flora on recovery of Helicobacter pylori}

Oropharyngeal flora from clinical specimens as described above was used to study in vitro the influence of this flora on the rate of recovery of different concentrations of clinical isolates of H.pylori as follows: $1 \mathrm{ml}$ of different concentrations of H.pylori from $10^{2}$ to $10^{5} \mathrm{cfu} / \mathrm{ml}$ in physiological saline was thoroughly mixed with $1 \mathrm{~m}$ l of ten-fold dilutions of oropharyngeal flora from $10^{1}$ to $10^{7} \mathrm{cfu} / \mathrm{ml}$. Aliquots of $0.01 \mathrm{ml}$ of the mixture and of both bacterial suspensions separately were used to inoculate blood agar plates (Oxoid CM271, with 5\% sheep blood) and Skirrow plates selective for H.pylori with the five-segments method. Blood agar plates for growth of oropharyngeal flora were incubated at $37^{\circ} \mathrm{C}$ for two days; the H.pylori plates were kept under micro-aerophilic conditions (10\% $\mathrm{CO}_{2}, 5 \% \mathrm{O}_{2}$ ) at $37^{\circ} \mathrm{C}$ for 5 to 7 days. Each experiment was performed in triplicate.

\section{Washing the biopsy specimens}

In the endoscopy department, biopsy specimens were obtained from patients $(\mathrm{n}=35)$ who were likely to have either bacterial overgrowth due to reduced gastric acid secretion as a consequence of atrophic gastritis or gastric surgery, or H.pylori due to the presence of peptic ulcer disease. From each patient four biopsies of neighbouring tissue (mean weight $\pm \mathrm{SD}: 12 \pm 5 \mathrm{mg}$ per biopsy) were taken from antrum $(n=34)$ or corpus $(n=1)$, using an Olympus GIFQ gastroscope (Zoeterwoude, The Netherlands). The endoscope and the biopsy forceps were disinfected with $2 \%$ glutaraldehyde before each examination. In each patient the same biopsy forceps was used to take the four specimens. Each specimen was collected separately in a tube with $2 \mathrm{ml}$ sterile saline. The washing procedure was as follows. Each tube was shaken 20 seconds with a vortex. Using sterile forceps the specimen was then transferred either to the agar plates or to a second tube with $2 \mathrm{ml}$ sterile saline, and the whole procedure was repeated once or twice (corresponding to two or three washings). The five segments method was used to inoculate blood agar plates for (facultative) aerobic bacterial growth and H.pylori plates as described above.

Bacterial growth was assessed quantitatively by determining the number of colony-forming units (cfu). A not fully grown first segment, corresponded to $10^{\mathrm{i}}$ to $10^{2} \mathrm{cfu} / \mathrm{ml}$, a fully overgrown first segment to $10^{3} \mathrm{cfu} / \mathrm{ml}$, a fully overgrown second segment to $10^{4} \mathrm{cfu} / \mathrm{ml}$ and so on, overgrowth in all five segments corresponded to $10^{7} \mathrm{cfu} / \mathrm{ml}$. 


\section{Identification of bacteria}

For the identification of the microorganisms standard microbiological methods were used $^{15}$. Oropharyngeal flora included Streptococci spp., Neisseria spp., and Corynebacterium spp.; faecal flora included Enterobacteriaceae and Enterococcus faecalis. H.pylori was identified initially as small translucent colonies, $1 \mathrm{~mm}$ in diameter, and was further identified by Gram stain and positive urease, catalase, and oxidase reactions.

\section{Results}

Influence of selective media on growth of oropharyngeal flora and Helicobacter pylori

In a preliminary study we studied the growth of 14 clinical samples of oropharyngeal flora and 10 clinical strains of H.pylori on the three types of media. Contaminating flora was almost completely inhibited on the Nal medium except in two samples. On the CPS and the Skirrow media contaminating flora was observed in 12 and 8 samples respectively, counts being higher on the CPS medium. Growth of H.pylori was similar on both the CPS and Skirrow media, but on the Nal medium growth of $H$.pylori was inhibited and the colonies were often smaller.

The higher number of samples with contaminant growth on the CPS medium is in accordance with the antibacterial activity of the antibiotics used. Polymyxin B has good antibacterial activity against both Pseudomonas spp. and Enterobacteriaceae, and cefsulodin has especially good activity against Pseudomonas spp. but lower activity against Enterobacteriaceae. As the aim of our study was an optimal isolation of H.pylori with minimal contaminant flora we decided to test the effects of washing using only the Skirrow medium.

\section{Recovery of Helicobacter pylori in the presence of oropharyngeal flora}

When H.pylori concentrations were $\geq 10^{4} \mathrm{cfu} / \mathrm{ml}$, the recovery of this organism was not influenced by the presence of oropharyngeal flora in concentrations ranging from $10^{1}$ to $10^{7} \mathrm{cfu} / \mathrm{ml}$. However, when H.pylori concentrations were $\leq 10^{3}$ $\mathrm{cfu} / \mathrm{ml}$, the recovery was markedly reduced in the presence oropharyngeal flora in concentrations of $10^{3} \mathrm{cfu} / \mathrm{ml}$ or higher (Figure II.1). 

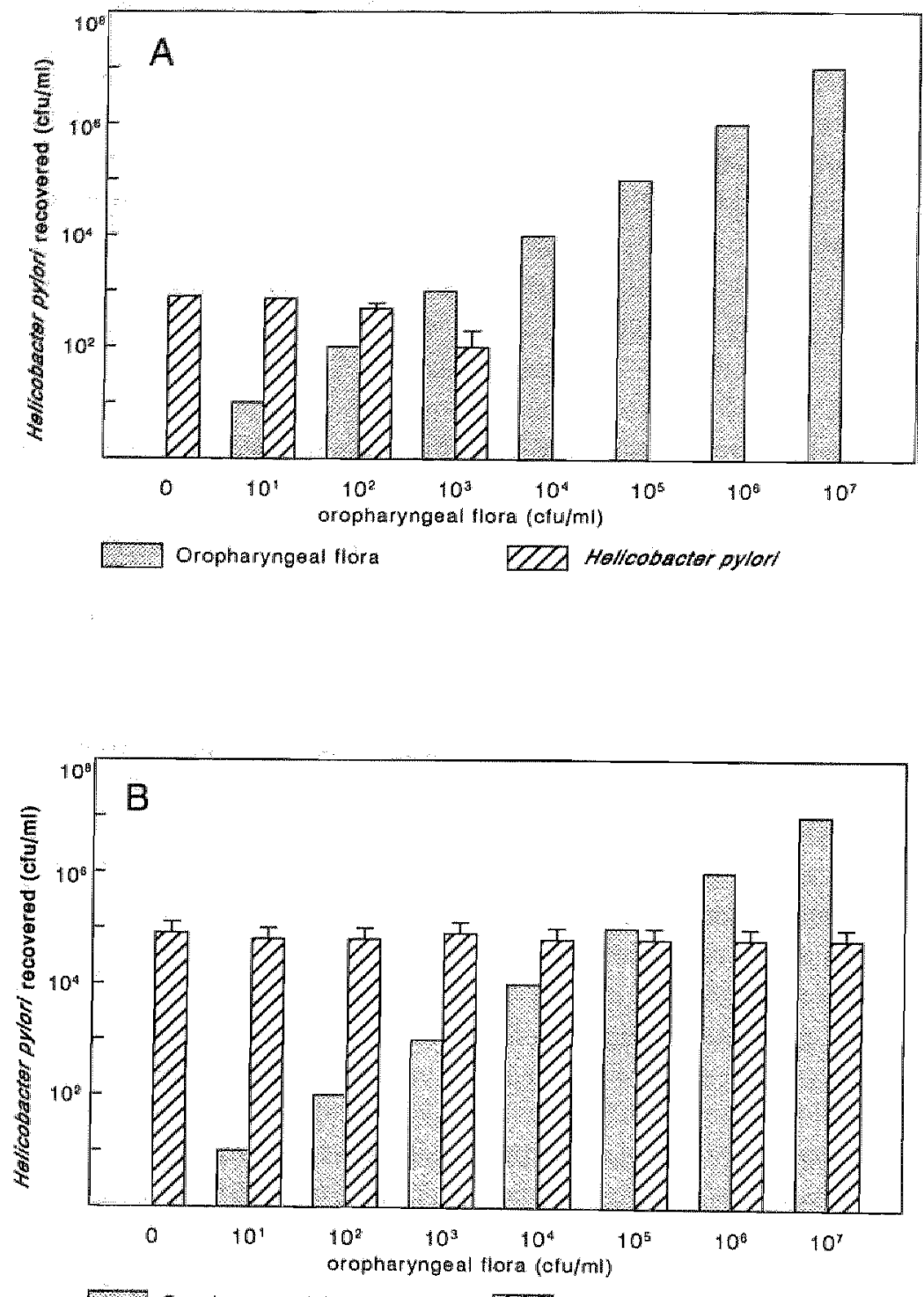

Oropharyngeal flora

DZ2 Holicobactor pylori

Figure II.1: Recovery of Helicobacter pylori (A, original concentration $10^{3} \mathrm{efu} / \mathrm{ml}$; $B$, origina] concentration $10^{\mathrm{s}} \mathrm{cfu} / \mathrm{ml}$ ) added to different concentrations of oropharyngeal flora 


\section{Pretreatment of the specimens by washing}

The bacteria isolated from the 35 biopsies comprised oropharyngeal flora in 28 , H.pylori in 17, and faecal flora in 7 biopsies. Both oropharyngeal flora and H.pylori were present in 15 biopsies (Table II.1). In the H.pylori positive patients, H.pylori counts were low ( $\leq 10^{3}$ cfu/biopsy) in 8 of 17 patients.

Table I.1: Bacterial flora in gastric biopsies from 35 patients before: washing

\begin{tabular}{lccc}
\hline No. of & \multicolumn{2}{c}{ Counts (cfu/biopsy) } \\
biopsies & median & concentration \\
\hline Flora or H.pylori & 28 & & $\left(2-3.0 \times 10^{6}\right)$ \\
Oropharyngeal flora & 17 & $8.2 \times 10^{2}$ & $\left(8-1.0 \times 10^{7}\right)$ \\
Helicobacter pylori & 7 & $5.0 \times 10^{9}$ & $\left(2-2.5 \times 10^{9}\right)$ \\
Faecal flora & 15 & $1.9 \times 10^{1}$ & \\
Flora + H.pylori & & $1.3 \times 10^{3}$ & $\left(2-3.0 \times 10^{6}\right)$ \\
Oropharyngeal flora & & $5.0 \times 10^{3}$ & $\left(8-1.0 \times 10^{6}\right)$ \\
\hline Helicobacter pylori & & &
\end{tabular}

Table II.2: Number of patients with a 10-fold or 100 -fold decrease in cfu/biopsy after one, two or three washings compared to no washing for oropharyngeal flora (OF) $(\mathrm{n}=28)$ and H.pylori $(\mathrm{n}=17)$

\begin{tabular}{lcccccc}
\hline Decrease & \multicolumn{2}{c}{ One washing } & \multicolumn{2}{c}{ Two washings } & \multicolumn{2}{c}{ Three washings } \\
& OF & H.pylori & OF & H.pylori & OF & H.pylori \\
\hline No decrease & 14 & 14 & 11 & 11 & 8 & 11 \\
$\leq 10$-fold & 10 & 3 & 9 & 6 & 10 & 5 \\
$>10$ to $\leq 100$ fold & 4 & - & 5 & - & 7 & 1 \\
$>100$-fold & - & - & 3 & - & 3 & - \\
\hline
\end{tabular}


The effect of washing the biopsies before inoculation on the yield of oropharyngeal flora and H.pylori is shown in Table II.2. After three washings an at least 10-fold decrease in the counts of oropharyngeal flora was observed in the biopsies of 7 of 28 patients. In another three patients an at least 100 -fold decrease was found. Oropharyngeal flora was still present in relatively low counts after three washings in 26 of 28 patients. In the case of H.pylori, a 60 -fold reduction was observed in the specimen of only one patient after three washings. Pretreatment of the specimens by washing of the biopsies improved the recovery of small amounts of H.pylori in at least 10 of 28 patients.

\section{Discussion}

The main feature of the present study was to evaluate the use of both selective media and washing of specimens before inoculation on the rate of recovery of H.pylori in biopsy specimens. In 10 of 28 patients the recovery of small numbers of H.pylori was improved by washing the specimens prior to inoculation.

In the past decade several different selective media have been reported to optimalize the yield of H.pylori and to reduce the influence of other contaminating flora. The Skirrow medium used in this study contains vancomycin, trimethoprim and polymyxin B, and is suitable for isolation of the majority of H.pylori strains ${ }^{7.13}$. The antibiotics in this medium are considered to be inhibitory for oropharyngeal and faecal flora as vancomycin inhibits all Gram-positive microorganisms, and trimethoprim and polymyxin B inhibits Gram-negative rods i.e. Haemophilus spp., Enterobacteriaceae and Pseudomonas aeruginosa. As some polymyxin B susceptible H.pylori strains have been described ${ }^{16}$, the Skirrow selective medium might be inhibitory for these microorganisms. An alternative supplement described. by Goodwin et al. ${ }^{14}$ contains nalidixic acid and amphotericin $B$ instead of polymyxin B. Nalidixic acid reduces the growth of Enterobacteriaceae and Pseudomonas spp. Amphotericin B was added to inhibit growth of Candida spp. which are often present in the oropharyngeal flora. As nalidixic acid susceptible H.pylori strains have been reported ${ }^{17}$, this supplement might also be inhibitory for these strains. Goodwin et al. ${ }^{14}$ reported good results in terms of isolation of H.pylori and inhibition of contaminants using this medium in combination with $1 \%$ Isovitalex and $7 \%$ horse blood. Dent and $\mathrm{McNulty}^{17}$ evaluated a CPS medium which contains cefsulodin and amphotericin B. Comparing the CPS and the Skirrow media, they concluded that the CPS medium did not inhibit H.pylori and that the colonies were often larger and more easily recognized on it. They reported growth of contaminating flora on CPS medium in 11 biopsies compared to growth 
on Skirrow medium in 5 biopsies. We observed optimal isolation of H.pylori with the lowest rate of contaminating flora using the Skirrow selective medium compared to CPS and Nal media. Therefore, we used the Skirrow medium to study the effect of washing.

The endoscopic procedures applied in our endoscopy unit to obtain biopsies are optimal and not expected to influence culture results ${ }^{18}$. All biopsies were kept in sterile saline at $4^{\circ} \mathrm{C}$ and cultured within four hours. These conditions were in accordance with those described by others ${ }^{19,20}$.

This study shows that the detection of H.pylori by culture can be disturbed by the presence of high amounts of oropharyngeal flora $\left(\geq 10^{4} \mathrm{cfu} / \mathrm{ml}\right)$. Although this findings was obtained by in vitro experiments, clinical observations support this finding. Stolte and Bethke ${ }^{8}$ found a reduction of H.pylori in the antrum after profound acid inhibition and suggested that bacterial competition might be responsible for this.

On the basis of these findings we recommend that specimens are washed before inoculation in addition to the use of Skirrow medium for optimal isolation of H.pylori from gastric biopsy specimens. Further studies with large number of patient samples will be needed to demonstrate significantly the positive effect of washing the specimens on the recovery of H.pylori. 


\section{References}

1 Warren JR, Marshall B. Lnidentified curved bacilli on gastric epithelium in active chronic gastritis. Lancet 1983; i: 1272-1273.

2 Calam J. Helicobacter pylori, review. Eur J Clin Inwest 1994; 24: 501-510.

3 Marshall BJ. Helicobacter pylori. Am J Gastroenteroll 1994; 89 (suppl): 116-128.

4 Katelaris PH, Seow F, Lin BPC, Napoli J, Ngu MC, Jones DB. Effect of age, Helicobacter pylori infection, and gastritis with atrophy on serum gastrin and gastric acid secretion in healthy men. Gut $1993 ; 34: 1032-1037$.

5 Stockbrigger RW, Cotton PB, Eugenides N, Bartholomew BA, Hill MJ, Walters $\mathrm{CL}$. Intragastric nitrites, nitrosamines and bacterial overgrowth during cimetidine treatment. Gut 1982; $23: 1048-1054$.

6 Verdu $E$, Viani $F$, Armstrong $D$ et al. Effect of omeprazole on intragastric bacterial counts, nitrates, nitrites and $\mathrm{N}$-nitroso compounds (NOC). Gut 1994; 35: 455-460.

7 Dent JC, McNulty CAM. Evaluation of a new selective medium for Campylobacter pylori. Eur J Clin Microbiol Inf Dis 1988; 7: 555 558.

8 Stolte M, Bethke B. Elimination of Helicabacter pylori under treatment with omeprazole. Z Gastroenterol 1990; 28: 271-274.

9 Alpert LC, Graham DY, Evans DJ et al. Diagnostic possibilities for Campylobacter pylori infection. Eur J Gastroenterol Hepatol 1989; 1: 17-26.

10 Dolby JM, Webster ADB, Boriello SP, Barclay FE, Bartholomew BA, Hill MJ. Bacterial colonization and nitrite concentration in the achlorhydric stomachs of patients with primary hypogammaglobulinaemia or classical pernicious anaemia. Scand J Gastroenterol 1984; 19: 105-110.

11 Stockbrügger $\mathrm{RW}$, Armbrecht $U_{3}$ Rode $J W$ et al. The bacterial overgrowth syndrome is uncommon in pernicious anaemia: results of a follow-up study. Microbial Ecol Health Dis 1990; 3: 209-215.

12 Cruickshank R, Duguid JP, Marmion BP, Swain RHA. Medical Microbiology. Volume Two: The practice of Medical Microbiology (12h ed). Churchill Livingstone, Edinburgh, 1975.

13 Krajden S, Bohnen J, Anderson J et all. Comparison of selective and nonselective media for recovery of Campylobacter pylori from antral biopsies. J Clin Microbiol 1987: $25: 1117-1118$.

14 Goodwin CS, Blincow ED, Warren JR, Waters TE, Sanderson CR, Easton L. Evaluation of cultural techniques for isolating Campylobacter pyloridis from endoscopic biopsies of gastric nucosa. J Clin Pathol 1985; 38: 1127-1131.

15 Balows A, Hausler WJ, Herrmann KL. Manual of Clinical Microbiology (5th ed). American Society for Microbiology, Washington, DC, 1991.

16 McNulty CA, Dent JC. Susceptibility of clinical isolates of Campylobacter pylori to twenty-one antimicrobial agents. Eur J Clin Microbiol Inf Dis 1988; 7: 566-569. 
17 Lambert $T$, Mégraud F, Gerbaud $G$, Courvalin P. Susceptibility of Campylobacter pyloridis to 20 antimicrobial agents. J Antimicrob Chemother $1986 ; 30 * 510-511$

18 Engelshoven van I, Vriese W, Brummer $R$, Stobberingh $E$, Stockbrïgger $R$. The risk of endoscopically transferred infection is mainly determined by patients with hypochlorhydric gastric juice containing pathogenic bacteria. Eur J Gastroenterol Hepatol 1991; 3 (suppl 1): 7.

19 Roosendaal R, Kuipers EJ, Pena AS, de Graaff J. Recovery of Helicobacter pylori from gastric biopsy specimens is not dependent on the transport medium used. I Clin Microbiol 1995; 33: 2798-2800.

20 Han SW, Flamm R, Hachem CY et al. Transport and storage of Helicobacter pylori from gastric mucosal biopsies and clinical isolates. Eur J Clin Microbiol Inf Dis $1995 ; 14: 349-352$. 


\section{Chapter III}

\section{Evaluation of immunohistochemistry for the detection of Helicobacter pylori in gastric mucosal biopsies}

D Jonkers, E Stobberingh, A de Bruine, JW Arends, R Stockbrügger 


\section{Summary}

A reliable diagnosis of Helicobacter pylori (H.pylori) is important in clinical practice and research. To evaluate sensitivity, specificity and inter-observer variation of three histological staining methods for the diagnosis of intragastric $H$.pylon bacterial flora, four observers assessed the presence of H.pylori in a test set of pairs of gastric biopsies taken from 40 patients during Glendoscopy. Histological slides of one biopsy of each patient (formalin fixed and paraffin embedded) were stained with a modified Giemsa (MG), the Warthin-Starry (WS), and an immmunohistochemical method (IMM) using purified polyclonal H.pylori antisenum (DAKO B471). As a standard bacterial culture was performed on the adjacent biopsy "using the four quadrants method. Special attention was paid to the presence of non-H.pylori bacterial flora.

Twenty out of 40 specimens were H.pylori positive by culture. Using culture as a standard sensitivity for $H$.pylori was $90.0 \pm 1.0 .0 \%$ with $\mathrm{MG}, 70.0 \pm 14.1 \%$ with WS. and $83.8 \pm 11.1 \%$ with IMM stain. Specificity was $53.8 \pm 19.3,82.5 \pm 9.6$ and 90.0 \pm 0.0 , respectively. Of 37,14 and 8 false positive scores by all observers for MG, WS and IMM, respectively, non-H.pylori flora was cultured from 17,6 , and 4 of the corresponding adjacent biopsies. Non-H.pylori flora may account for overdiagnosis of H.pylori in gastric biopsies. Kappa values for the variance between the four observers were 0.28 for MG, 0.57 for WS, and 0.83 for IMM.

Immunohistochemical staining for H.pylori is highly specific and has a low interobserver variation. We advise that in situations where gastric histology is the main diagnostic tool IMM should be used for the detection of H.pylori. 


\section{Introduction}

In the recent decade Helicobacter pylori ( $H$. pylori) has been associated with chronic atrophic gastritis of type B, duodenal and gastric ulcers, and also with the pathogenesis of gastric cancer and MALT lymphoma ${ }^{\mathrm{l}-5}$. Extensive research in this field is ongoing.

However, it is known that also other bacteria (Gram-negative and Grampositive) can be found in the gastric lumen, more permanently in states of reduced gastric acid secretion such as achlorhydric atrophic gastritis type $A^{6,7}$, after gastric surgery $^{8-10}$, and (recently of growing importance) after profound medical acid inhibition ${ }^{11-13}$. However, also in normal subjects transient presence of bacteria in the stomach can be expected after every meal before the gastric acid has effected its bactericidal action ${ }^{14}$.

Although it is known that non-Helicobacter pylori (non-H.pylori) bacterial flora can exist concurrently with H.pylori, little attention has been paid to the confounding effect of such flora in the histological detection of H.pylori.

It was the aim of this study, to compare sensitivity, specificity and interobserver variation of the modified Giemsa, Warthin-Starry silver stain, and immunohistochemistry in single biopsies for the detection of H.pylori, in the presence or absence of non-H.pylori flora irrespective of the clinical context. For the purpose of this study culture of gastric mucosal biopsies was used as a standard.

\section{Material and methods}

\section{Specimens}

Gastric biopsies were obtained from patients $(n=40)$ attending the Department of Gastroenterology for open access endoscopy. Using an Olympus GIFQ gastroscope (Zoeterwoude, The Netherlands), two neighbouring biopsies were obtained, at most $1 \mathrm{~cm}$ apart, from antrum $(n=37)$ or body $(n=3)$. The first biopsy was used for bacteriological culture and the second for histological staining, i.e. modified Giemsa stain (MG), Warthin Starry silver stain (WS), and immunohistochemical stain (IMM).

\section{Culture}

The biopsies for culture were transported in sterile saline $(0.9 \%)$, kept at $4^{\circ} \mathrm{C}$, and cultured within 4 hours as described previously ${ }^{15}$. In short, after washing each 
specimen twice, a blood agar plate (Oxoid CM271 with $5 \%$ sheep blood) for total (facultative) aerobic flora and a selective Campylobacter plate (Columbia agar base (Oxoid CM331) supplemented with 5\% sheep blood and Skirrow selective supplement (Oxoid SR069E) for the detection of H.pylori were inoculated by four quadrants method ${ }^{16}$ : Blood agar plates were incubated aerobically for 2 days and CAM plates micro-aerophilically for 4-7 days. Standard microbiological methods were used for the quantification and identification of the bacteria ${ }^{17}$. H.pylori was identified by the appearance of small translucent colonies on the agar-plate and confirmed by Gram stain as well as positive test results for urease, catalase and oxidase activity.

\section{Histological staining}

Biopsies for histological examination were formalin fixed and paraffin embedded. Serial sections $(4 \mu \mathrm{m})$ were cut onto three glass slides for MG, WS, and IMM, respectively. The MG and WS staining techniques were performed as described by Gray et al. ${ }^{18}$ and Warthin and Starry ${ }^{19}$, respectively. For the IMM a purified polyclonal H.pylori antiserum was used (DAKO B471; ITK diagnostics BV, Uithoorn, The Netherlands) in a 1:500 dillution. Staining was performed without pepsin treatment and with biotin-conjugated swine-anti-rabbit-antibodies (1:1000) (DAKO E431) as second layer, followed by streptABC-HRP (1: 1000) (DAKO K377). Sections were stained with diamino-benzidine (DAB) with $10 \%$ imidazole to intensify the reaction and they were counterstained with haematoxylin. To test cross reactivity of the polyclonal H.pylori antiserum with other microorganisms, suspensions of H.pylori, Campylobacter jejuni, Campylobacter coli, Escherichia coli, Klebsiella pneumoniae, Pseudomonas aeruginosa, Streptococcus viridans and Staphylococcus aureus as well as tissue sections of the descendending colon, the sigmoid colon and the duodenum were stained immunohistochemically. Positive and negative control slides were always included. The negative controls included both a H.pylori negative specimen and a H.pylori positive specimen treated as described above without the primary antiserum.

\section{Scoring and (statistical) analysis}

All histological slides were scored blindly for the presence of H.pylori by four observers, i.e. two microbiologists (observers 1 and 2) and two pathologists (observer 3 and 4). All observers had a training in the assessment of H.pylori on histological slides. H.pylori was characterised by the appearance of a $S$-shaped rod and the localisation in the gastric mucus layer on the surface epithelium as well as within the mucus layer. Two sections of each biopsy were examined completely at $400 \mathrm{x}$ magnification. In case of doubt a $1000 \mathrm{x}$ (oil immersion) magnification was 
used.

With culture as standard method sensitivity, specificity, positive (PPV) and negative predictive value (NPV) of each staining method, presented as a mean of the four observers, were analyzed statistically with an ANOVA-test and Student t-test.

Concordance between observers in scoring $H$.pylori positive or negative for each staining method is presented according to the presence of H.pylori and nonH.pylori flora by culture. Inter-observer variation for the total score of each stain is given by kappa values calculated for four observers as described by Schouten et al. ${ }^{20}$.

\section{Results}

Of 40 patients biopsy specimens were obtained. Endoscopic diagnosis, histology of the biopsy, treatment before endoscopy, $\mathrm{pH}$ of gastric juice, and cullure results are presented in Table III.1.

\section{Crossreactivity}

Suspensions of 40 different H.pylori strains stained positive by IMM (brown) within one minute of incubation with $\mathrm{DAB}$. In contrast, only a very light brown staining was visible after two to four minutes with Campylobacter jejuni and Campylobacter coli. No cross reactivity was seen with the other bacterial species tested. Sections of descending colon, sigmoid, and duodenum (obtained from three, two and three patients, respectively) did not show a positive staining with the IMM.

\section{Culture results}

By culture, 20 out of 40 biopsy specimens were found to be H.pylori positive and 20 were $H . p y l o r i$ negative. Non- $H$.pylori flora was present by culture in a total of 22 specimens (11 $\mathrm{H}$.pylori positive and $11 \mathrm{H}$.pylori negative specimens) always including oropharyngeal flora such as Streptococci viridans, Neisseria spp. and Corynebacterium spp., and twice Escherichia coli in addition.

The median gastric $\mathrm{pH}$ in patients with specimens positive for non-H.pylori alone was 7.0 compared to 2.5 when no bacterial flora was cultured. When $H$.pylori was cultured, alone or in combination with non-H.pylori, the median $\mathrm{pH}$ values were 1.8 and 5.8 , respectively. 
Table Hr.1: Clinical data and culure results (log efu/biopsy) of patients included ( $\mathrm{n}=40$ )

\begin{tabular}{|c|c|c|c|c|c|c|}
\hline $\begin{array}{l}\text { pat } \\
\text { pir }\end{array}$ & $\begin{array}{l}\text { endoscopic: } \\
\text { diagnosils }\end{array}$ & $\begin{array}{l}\text { histollogy } \\
\text { antrum/corpous }\end{array}$ & treatiment & $\begin{array}{c}\text { pH } \\
\text { g.juice }\end{array}$ & $\begin{array}{c}\text { culture } \\
\mathrm{Hp}\end{array}$ & $\begin{array}{l}\text { culture } \\
\text { nonHp }\end{array}$ \\
\hline $\mathbb{1}$ & \multirow{10}{*}{ normal } & cai & omeprazole & 7.0 & 0.30 & 5.48 \\
\hline 4 & & $\mathrm{ci}, \mathrm{im}$ & ranitidine & 6.0 & 2.00 & 1.65 \\
\hline 12 & & nor & cimetidine & 1.0 & - & - \\
\hline 14 & & nor & - & 1.5 & - & 0.70 \\
\hline 1.5 & & nor & . & 2.0 & - & 1.00 \\
\hline 17 & & cai : & ranitidine & 7.0 & 5.00 & 3.49 \\
\hline 18 & & nor & - & 7.0 & - & 1.00 \\
\hline 19 & & nor & omeprazole & 5.0 & - & - \\
\hline 27 & & cai, atr & - & 7.0 & - & $\therefore$ \\
\hline 40 & & cail & - & - & - & 4.00 \\
\hline 2 & \multirow[t]{15}{*}{ gastritiss } & cai,aty & ranitidine & 1.5 & 3.00 & $3.04^{*}$ \\
\hline 3 & & nor & - & 1.5 & - & 1.88 \\
\hline 5 & & $\mathrm{cil}$ & ASA & 7.0 & - & 2.23 \\
\hline 7 & & cal & omeprazole & 5.0 & - & 0.85 \\
\hline 8 & & cai,, $\mathrm{m}$ & omeprazole & - & - & 2.20 \\
\hline 11 & & cail $\mathrm{reg}_{\mathrm{g}}$ & ranitidine & 5.5 & 3.00 & 0.78 \\
\hline 16 & & cal, atr & ASA & 5.5 & 5.00 & 1.62 \\
\hline 22 & & cail, reg & omeprazole & 4.5 & 4.00 & 1.48 \\
\hline 26 & & nor & - & 2.0 & 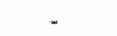 & - \\
\hline 33 & & cai & - & 2.0 & 4.00 & - \\
\hline 35 & & $\mathrm{cai}$ & - & 2.0 & - & - \\
\hline 36 & & ci & - & - & 5.00 & - \\
\hline 37 & & cai & - & - & 2.00 & 2.00 \\
\hline 44 & & ci,im & omeprazole & 7.0 & - & 3.18 \\
\hline 45 & & cai & omeprazole/bismuth & 3.0 & 6.00 & 1.32 \\
\hline 1.3 & \multirow[t]{3}{*}{ duodenal ulcer } & $\mathrm{cai}$ & ranitidine & 1.5 & 7.00 & - \\
\hline 28 & & cail & - & - & 3.00 & - \\
\hline 31 & & cai,reg & $\therefore$ & 1.5 & $-\cdots$ & - \\
\hline 9 & \multirow[t]{6}{*}{ gastric ulcer } & cai, reg & omeprazole & 7.0 & - & $1.30^{\circ *}$ \\
\hline 20 & & & ranitidine & 6.0 & 3.70 & 2.08 \\
\hline 30 & & $\mathrm{cai}, \mathrm{im}$ & cimetidine & - & 4.00 & - \\
\hline 38 & & cai & calciumacety Isalicylate & 1.0 & 5.00 & . \\
\hline 39 & & & NSAID & 1.5 & 3.00 & - \\
\hline 43 & & cai im & - & 5.5 & 4.00 & - \\
\hline 23 & bulbitis & $\mathrm{ai}$ & omeprazole & 7.0 & - & 3.32 \\
\hline 10 & \multirow{2}{*}{ oesophagitis } & nor & . & 3.0 & - & - \\
\hline 21 & & $\mathrm{ci}$ & farnotidine & 6.5 & 5.00 & 2.34 \\
\hline 29 & \multirow[t]{3}{*}{ carcinoma } & cai, im & $=$ & - & - & . \\
\hline 32 & & cai,im & antacid & 5.5 & - & - \\
\hline 34 & & cai & antacid & 5.5 & 2.06 & . \\
\hline
\end{tabular}

* Ecoli 0.48*** Ecoli 1.00; *** Gram statin was positive.

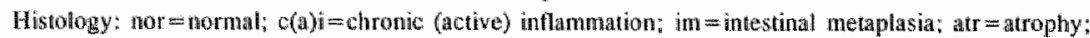
$\mathrm{reg}=$ regenerative changes; aly = arypia.

ASA $\approx$ acetyl salicilic acid 


\section{Histological staining}

True and false positive findings for the detection of H.pylori by MG, WS, and IMM for each of the four observers, based on culture results, are presented in Table III.2. The highest number of false positive scores for all observers, either pathologists or microbiologists, was obtained with the MG. Distinctly less true and false positive results were found with the WS whereas the IMM showed a high score of true positives combined with a low proportion of false negatives. Table III. 3 shows mean percentages of sensitivity, specificity, PPV, and NPV of each staining method averaged from all four observers. A significantly lower specificity was found with MG (53.8\%) compared to WS $(82.5 \%)$ and IMM (90.0\%). The sensitivity was lowest for WS (70.0\%) compared to MG $(90.0 \%)$ and IMM $(83.8 \%)$.

Table III.2: True and (false) H.pylori positive slides of modified Giemsa (MG), Warthin-Starry (WS) and immunohistochemistry (IMM) for each observer ${ }^{*}$

\begin{tabular}{cccc}
\hline Observer & MG & WS & IMM \\
\hline 1 & $19(5)$ & $16(2)$ & $19(2)$ \\
2 & $19(13)$ & $16(6)$ & $16(2)$ \\
3 & $19(12)$ & $14(4)$ & $18(2)$ \\
4 & $15(7)$ & $10(2)$ & $14(2)$ \\
\hline
\end{tabular}

* Based on culture results: H.pylori positive $(\mathrm{n}=20), H . p y l o r i$ negative $(\mathrm{n}=20)$

Table III.3: Sensitivity, specificity, positive and negative predictive walue (o) of each staining nethod for the detection of H.pylori (mean \pm SD of foum observers) in 40 single gastric biopsios with culture as standard

\begin{tabular}{lccc}
\hline & MG & WS & IMM \\
\hline sens & $90.0 \pm 1.0 .0$ & $70.0 \pm 14.1$ & $83.8 \pm 11.1$ \\
spect.2 $^{1.2}$ & $53.8 \pm 1.9 .3$ & $82.5 \pm 9.6$ & $90.0 \pm 0.0$ \\
ppvi.2 $^{1.0}$ & $67.0 \pm 8.9$ & $80.7 \pm 7.0$ & $89.2 \pm 1.3$ \\
npv & $85.6 \pm 9.3$ & $74.2 \pm 7.6$ & $85.4 \pm 8.7$ \\
\hline
\end{tabular}

1) Anova: $p<0.01$, 2) Student i-test: spec MG-WS $p=0.05$; spec MG-IMM $p=0.03$; pp MG-IMM $p=0.02$ 
Of the 37 false positive scores in the MG by the four observers, oropharyngeal flora was cultured in 17 occasions including once Escherichia coli. The remaining 20 occasions were culture negative both for H.pylori and non-H.pylori bacterial flora. Of the total 14 and 8 false positive slides in the WS and IMM, respectively, non-H.pylori flora was cultured in 6 and 4 occasions.

The concordance between the four observers for MG, WS and IMM in the presence or absence of H.pylori and non-H.pylori by culture are shown in Table III.4. In total, concordance between the four observers in scoring H.pylori positive or negative was $50.0 \%, 62.5 \%$ and $85.0 \%$ for MG, WS and IMM, respectively. Especially in the absence of H.pylori by culture, concordance between observers was much lower in MG compared to WS and IMM. When H.pylori was present by culture, concordance between observers was lowest for WS compared to MG and IMM.

Presented by the kappa values, the overall agreement for MG, WS and IMM in all 40 biopsies by the four observers was $0.28,0.57$ and 0.83 , respectively. Thus, the variation between observers was highest for MG and lowest for IMM.

Table III.4: Concardance between four observers in scoring H.pylori positive or negative per staining method in the presence or absence of H.pylori and non-H.pylori flora by culture

\begin{tabular}{lllllll}
\hline Culture results & \multicolumn{2}{l}{ modiffed Giemsa } & \multicolumn{2}{l}{ Warthin Starry } & \multicolumn{2}{l}{ Immunostaining } \\
\hline Hp+/nonHp- & $7 / 9$ & $(77.8 \%)$ & $4 / 9$ & $(44.4 \%)$ & $6 / 9$ & $(66.7 \%)$ \\
Hp- $/$ nonHp- & $5 / 11$ & $(45.5 \%)$ & $9 / 11$ & $(81.8 \%)$ & $11 / 11$ & $(100 \%)$ \\
$\mathrm{Hp}+/$ nonHp+ & $7 / 11$ & $(63.6 \%)$ & $6 / 11$ & $(54.5 \%)$ & $8 / 11$ & $(72.7 \%)$ \\
$\mathrm{Hp}-/$ nonHp+ & $1 / 9$ & $(11.1 \%)$ & $6 / 9$ & $(66.7 \%)$ & $9 / 9$ & $(100 \%)$ \\
& & & & & & \\
Total & $20 / 40$ & $(50.0 \%)$ & $25 / 40$ & $(62.5 \%)$ & $34 / 40$ & $(85.0 \%)$ \\
\hline
\end{tabular}

\section{Discussion}

The present study showed that in single gastric biopsies, the IMM is the most sensitive and specific staining method for the histological detection of H.pylori compared to the MG and WS stains. In addition, using IMM, the lowest interobserver variation was found concerning the presence of H.pylori.

To investigate the reliability of the histological diagnosis of H.pylori we chose a random test set of pairs of adjacent biopsies from 40 patients with different 
endoscopic diagnoses, amongst them disorders in which H.pylori and/or nonH.pylori flora could be expected. They included cases with high gastric $\mathrm{pH}$ with or without medical gastric acid inhibition. Culture of the biopsies confirmed in many cases that H.pylori and non-H.pylori flora were present simultaneously. Tissue concentrations of non-H.pylori flora were on average somewhat lower than those of H.pylori, but could exceed the latter in single cases. In view of the similar preparation of the biopsies before culture, such as washing twice, one may conclude that the non-H.pylori flora identified not only is due to transient contamination, but can supposed to be resident in the gastric mucosa.

A gold standard for the detection of H.pylori is not available, neither with direct nor with indirect test methods ${ }^{21}$. Bacteriological culture of H.pylori is usually considered to be very specific but not highly sensitive ${ }^{22-24}$. In view of this, we have paid special attention to pretreatment of the specimens and culture media ${ }^{15}$. However, using culture as a standard we were aware of the possibility of some false negative results. These could be due to low numbers of H.pylori present in the specimen or to non-viable organisms ${ }^{25}$. Furthermore, sampling error can occur when biopsies are taken with some distance from each other. Two patients (nr 31 and 40) were scored positive for H.pylori with all staining methods, but were negative on culture. These culture results may be falsely negative, especially in patient $\mathrm{nr} 31$ were H.pylori was also seen on Gram stain. However, exclusion of these cases ( $5 \%$ of all) from the calculations would not essentially have changed the conclusions.

Comparing our culture techniques with those reported by Loffeld et al. ${ }^{26}$ from the same laboratory, we have to comment that in the latter studly neither the culture methods for H.pylori were optimal, nor a special effort was made to detect nonH.pylori bacterial flora. However, also in that study IMM was highly specific and more sensitive than MG. Furthermore, using positivity of any two of the four detection methods (culture, IMM, MG, or WS) as a standard to overcome possible sensitivity problems by culture, will not essentially change the conclusions concerning sensitivity and specificity of IMM, MG and WS.

The main objective of the present study was to compare three histological detection methods for H.pylori in one specimen and not to assess the H.pylori status of the patients. Therefore, no pathophysiological parameters, extra biopsies, or additional (non-invasive) tests such as the urea-breath test, were used as they were suggested by Cutler et al. ${ }^{21}$.

The MG stain is most frequently used for the histological detection of H.pylori as it is easy to perform ${ }^{27-29}$. In the present study the MG falsely suggested the presence of $H$.pylori not only in biopsies exclusively containing non-H.pylori flora, but also in some others being culture-negative for both H.pylori and non- 
H.pylori. This might indicate that with the MG stain also non-bacterial staining artefacts, such as dye precipitation ${ }^{27,28}$, can confound the H.pylori diagnosis.

The WS silver stain is a cumbersome and expensive technique, and background precipitation of silver may be difficult to differentiate from bacteria ${ }^{28,29}$. Conipared with the MG a better ${ }^{27.28}$, similar ${ }^{30}$, or worse ${ }^{18.24 .29}$ identification of H.pylori has been reported in the literature. In the present study the WS obtained a middle position between MG and IMM with respect to the specificity. The sensitivity of WS was low compared to MG and IMM. That may lead to underdiagnosis of $H . p y l o r i$.

The IMM method applied in this study was based on a commercially available antibody, the specificity of which had been documented by others, who had not found any cross reactivities ${ }^{25}$. We found a slight crossreactivity with Campylobacter spp., a bacterium which is however unlikely to occur in the gastric lumen ${ }^{31}$. With the IMM both a high sensitivity and a high specificity were obtained, resulting in a negative predictive value for the presence of $H$.pylori comparable to that of the MG and the highest positive predictive value.

What are the clinical and scientific consequences of our findings? Most clinicians will be able to make a diagnosis of current H.pylori gastric infection with the help of multiple biopsies, culture, CLO test, serology and application of breath tests. Hence, histology is the method most frequently used. Optimal sensitivity and specificity should be granted. In this study two confounding factors of histological H.pylori diagnosis were investigated: the presence of non-H.pylori flora and the inter-observer variation. Both factors seem to be connected. Presence of nonH.pylori flora occurs in multiple occasions and false interpretations can be overcome by IMM. Non- H.pylori flora may particularly contribute to the interobserver variation known for $\mathbf{M G}^{32}$. We could show that IMM had the lowest interobserver variation. This thas recently been confirmed by Few et al..$^{33}$.

In conclusion, we advise that in situations, where histology is the main diagnostic tool for the detection of H.pylori, IMM should be routinely used. 


\section{References}

1 Calam J. Helicobacter pylori, review. Eur J Clin Inwest 1994; 24: 501-510.

2 Cover TL, Blaser MJ. Helicobacter pylori: a bacterial cause of gastritis, peptic ulcer disease, and gastric cancer. ASM News 1995; 61: 21-26.

3 Fennerty MB. Helicobacter pylori, review article. Arch Intern Med 1994; 154: 721-727.

4 Marshall BJ, Warren JR. Unidentified curved bacilli in the stomach of patients with gastritis and peptic ulceration. Lancet 1984; i: 1311-1314.

5 Nomura $A_{*}$ Stemmermann GN, Chyou P, Perez-Perez GI, Blaser MJ. Helicobacter pylori infection and the risk for duodenal and gastric ulceration. Ann Intern Med 1994; 120: $977-981$.

6 Dolby JM, Webster ADB, Borriello SP, Barclay FE, Bartholomew BA, Hill MJ. Bacterial colonization and nitrite concentration in the achlorhydric stomachs of patients with primary hypoglammaglobinaemia or classical pernicious anaemia. Scand J Gastroenterol 1984; 19: 105-110.

7 Stockbrügger $\mathrm{RW}$, Cotton $\mathrm{PB}$, Menon GG et al. Pernicious anaemia, intragastric bacterial overgrowth and possible consequences. Scand J Gastroenterol 1984; 19 : 355-364.

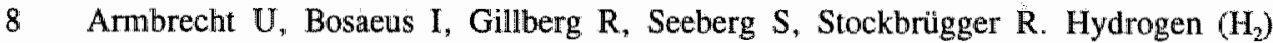
breath test and gastric bacteria in acid-secreting subjects and in achlorhydric and post-gastrectomy patients before and after antimiciobial therapy. Scand J Gastroenterol 1985; 20: 805-813.

9 Carboni M, Guadagni S, Pistoia MA et al. The microflora of the gastric juice after Billroth I and Billroth II partial gastrectomy. Scand J Gastroenterol 1986; 21 : $461-470$.

10 Muscroft TJ, Deane SA, Youngs D, Burdion DW, Keighley, MRB. The microflora of the postoperative stomach. Br J Surg 1981; 68: 560-564.

IL Ruddell WSJ, Axon ATR, Findlay JM, Bartholomew BA, Hill MJ. Effect of cimetidine on the gastric bacterial flora. Lancet 1980; i: 672-674.

12 Sharma BK, Santana JA, Wood EC et a]. Intragastric bacterial activity and nitrosation before, during, and after treatment with omeprazole. Br Med J 1984; 289: 717-719.

13 Verdu $\mathrm{E}$, Viani $\mathrm{F}$, Armstrong $\mathrm{D}$ et al. Effect of omeprazole on intragastric bacterial counts, nitrates, nitrites and N-nitroso compounds (NOC). Gut 1994; 35: 455-460.

14 Drasar BS, Shiner M, McLeod GM. Studies on the intestinal flora. Gastroenterol 1969; 56: 71-79.

15 Jonkers D, Stobberingh E, Stockbrügger R. The influence of oropharyngeall flora and specimen pretreatment on the recovery of Helicobacter pylori. Eur $\mathrm{J}$ Clin Microbiol Infect Dis $1996 ; 15: 378-382$. 
16 Cruickshank R, Duguid JP, Marmion BP, Swain RHA. Medical Microbiology. Volume Two: The practice of Medical Microbiology (12th ed). Churchill Livingstone, Edinburgh, 1975.

17 Balows A, Hausler WJ, Herman KL et al. Manual of Clinical Microbiology, $5^{\text {th }}$ edition, 1991. American Society for Microbiology, Washington D.C.

18 Gray SF, Wyatt JL, Rathbone BJ. Simplified techniques for identifying Campylobacter pyloridis. J Clin Pathol 1986; 39: 1279.

19 Warthin AS, Starry AC. A more rapid and improved method of demonstrating spirochaetes in tissues. Am J Syph 1920; 4: 97-99.

20 Schouten $H$. Klinische Statistiek, een praktische inleiding. $2^{\text {th }}$ edition. Medical Informatica and Statistics, University of Limburg, Maastricht, 1990.

21 Cutler AF, Havstad S, Ma CK, Blaser MJ, Perez-Perez GI, Schubert TT. Accuracy of invasive and non-invasive tests to diagnose Helicobacter pylori infection. Gastroenterol 1995; 109: 136-141.

22 Brown KE, Peura DA. Diagnosis of Helicabacter pylori infection. Gastroenterol Clin N Am 1993; 22: 105-115.

23 Dick JD. Helicabacter (Campylobacter) pylori: a new twist to an old disease. Ann Rev Microbiol 1990; 44: 249-269.

24 Deltenre $M$, Glupczynski $Y$, De Prez $C$ et al. The reliability of urease test, histology and culture in the diagnosis of Campylobacter pylori infection. Scand J Gastroenterol 1989; 24 (suppl 160): 19-24.

25 Anderssen LP, Holck S, Povlsen CO. Campylobacter pylori detected by indirect immunohistochernical technique. APMIS 1988; 96: 559-564.

26 Loffeld RJLF, Stobberingh E, Flendrig JA, Arends JW. Helicobacter pylori in gastric biopsy specimens. Comparison of culture, modified Giemsa stain and immunohistochemistry. A retrospective study. J Pathol 1991; 165: 69-73.

27 Alpert LC, Graham DY, Evans DJ et al. Diagnostic possibilities for Campylobacter pylori infection. Eur $\mathbf{J}$ Gastroenterol Hepatol 1989; 1: 17-26.

28 Barthel JS, Everett ED. Diagnosis of Campylobacter pylori infections: The "Gold Standard" and the alternatives. Rev Inf Dis 1990; 12: s107-s114.

29 Madan E, Kemp J, Westblom TU, Subik M, Secton S, Cook J. Evaluation of staining methods for identifying Campylobacter pylori. Am J Clin Pathol 1988: 90: 450-453.

30 Aymard B, Labouyrie E, de Korwin JD, Ferr R, Duprez D. Histological staining methods for detection of gastric Campylobacter like organisms (GCLOs): a comparative study. Gastroenterol 1988; 94 (suppl): A16.

31 Skirrow MB. Foodborne illness. Lancet 1990; 336: 921-923.

32 Santucci R, Amorosi A, Pilleri S et al. Observer variation in histological assessment of Helicobacter pylori on gastric biopsies. Gastroenterol 1994; 106 (suppl): A172.

33 Few MJ, Codd J, Marker AJ. Grading Helicobacter pylori infection in gastric biopsies. J Pathol 1996; 178 (suppl): 16A. 


\section{Chapter IV}

Ongoing gastric acid inhibition is a confounding factor in Helicobacter pylori diagnosis

D Jonkers, G Houben, E Stobberingh, R Stockbrügger

Eur J Gastroenterol Hepatol 1997; 9: 49-53 


\section{Summary}

Eradication of Helicobacter pylori (H.pylori) by antibiotics in combination with gastric acid inhibition can result in overgrowh of non-H.pylori bacterial flora. This may confound the histological detection of H.pylori at eradication control if non-specific staining methods are used.

In 18 patients treated with amoxycillin ( 2 weeks) and omeprazole (6 weeks), endoscopically obtained gastric juice was cultured and two biopsies of corpus, antrum and duodenum were taken before and after eradication therapy (with gastric acid inhibition still going on) for culture and for histology to assess the intragastric bacterial flora. By histology, modified Giemsa (MG) and a H.pylori specific immunohistochemical stain (IMM) were evaluated.

Median pH of gastric juice was $1.5(n=18)$ before and $7(n=17)$ after eradication therapy, when patients were still on omeprazole. After therapy, culture showed a significant decrease $(\mathrm{p}<0.05$ ) in mean amount of H.pylori in corpus, antral and duodenal biopsies and a significant increase of non-H.pylori flora $(\mathrm{p}<0.05)$ in gastric juice, corpus, antral and duodenal mucosia. With culture as a standard, 16 and 4 biopsy specimens were scored falsely positive for H.pylori by $\mathrm{MG}$ and IMM, respectively, and H.pylori was not detected in 23 and 13 biopsy specimens when culture was H.pylori positive.

Because of the possible presence of non- $H$,pylori flora after eradication therapy the use of IMM is recommended in this situation for the histological detection of H.pylori, especially in those patients with ongoing gastric acid inhibitory therapy. 


\section{Introduction}

H.pylori has been associated with duodenal ulcers, gastric ulcers, gastritis, and also gastric cancer and mucosa-associated lymphoid tissue (MALT) lymphoma- ${ }^{1-3}$. Eradication therapy for H.pylori often consists of profound gastric acid inhibition in combination with antibiotics ${ }^{46}$. Use of gastric acid inhibitors like $\mathrm{H}_{2}$-receptor antagonists and proton pump inhibitors can result in an increased intragastric $\mathrm{pH}$ with the possible consequence of bacterial overgrowth in the stomach ${ }^{7.9}$.

As the presence of other bacteria than H.pylori may confound the accurate histological detection of H.pylori, we assessed the presence of H.pylori and other bacterial flora before and after eradication therapy, when patients were still treated with strong gastric acid inhibition. In this situation, we compared the modified Giemsa stain (MG) with a specific immunohistochemical stain (IMM) for the detection of H.pylori.

\section{Material and methods}

\section{Patients and treatment}

Patients with a duodenal ulcer, gastric ulcer or erosive bulbitis diagnosed during endoscopy (between March 1994 and March 1995), who were planned to receive eradication therapy for H.pylori, were included $(\mathrm{n}=18)$. Eradication therapy consisted of amoxycillin $1 \mathrm{gr}$ b.i.d. for 2 weeks and omeprazole $20 \mathrm{mg}$ b.i.d for 6 weeks. Patients were excluded if they used gastric acid inhibitors before the first endoscopy, were not able to return for a second endoscopy at six weeks or received other treatment regimens.

\section{Specimens}

Before and at the end of therapy (after 6 weeks when patients were still on omeprazole $20 \mathrm{mg}$ twice daily), gastric juice and two biopsies each of corpus, antrum and duodenum were obtained during endoscopy. One biopsy was collected in sterile saline and kept at $4^{\circ} \mathrm{C}$ until bacteriological culturing within 4 hours. The second biopsy was fixed in formalin, embedded in paraffin, and slides were cut for modified Giemsa stain (MG) and Immunohistochemistry (IMM). Gastric juice was used for bacteriological culture. The $\mathrm{pH}$ of the juice was measured using $\mathrm{pH}$ paper strips with grading steps of 0.5 from pH 0 to $\mathrm{pH} 14$ (Schleicher \& Schüll GmbH; Dassel, Germany). 


\section{Culture}

Gastric juice was cultured quantitatively using the five segments method ${ }^{10}$ inoculating 1,10 and $100 \mu \mathrm{l}$ on each of the following agar plates: blood, CLED (Cysteine lactose electrolytes deficient agar), Campylobacter and chocolate agar plates. Blood agar plates (Oxoid CM271, Basingstoke, UK, with 5\% sheep blood) for total (facultative) aerobic bacterial growth and CLED (Oxoid CM423) for enhanced detection of Enterobacteriaceae were incubated at $37^{\circ} \mathrm{C}$ during two days. Campylobacter agar plates (Columbia agar base (Oxoid CM331) supplemented with $5 \%$ sheep blood and Skirrow selective supplement (Oxoid SR069E)) and chocolate agar plates (brain heart infusion, Difco 0037-05-2, Detroit, USA; with 5\% sheep blood and $2 \%$ yeast extract) both for the detection of H.pylori, were kept under microaerophilic conditions $\left(\mathrm{CO}_{2} 10 \%, \mathrm{O}_{2} 5 \%\right)$ at $37^{\circ} \mathrm{C}$ for 7 days.

All biopsy specimens were washed twice in sterile saline to reduce contaminating flora, weighed carefully, and ground in $0.4 \mathrm{ml}$ sterile saline with a tissue grinder (no. 43950, ICN Flow Biomedicals NVSA; Asse-Relegem, Belgium $)^{11}$. After homogenization $0.1 \mathrm{ml}$ was inoculated on agar plates using the five segments method.

Bacterial growth was assessed quantitatively as log colony forming units (cfu) per millilitre gastric juice or per gram tissue. In a not full-grown first segment numbers of colonies were counted $(1 \log$ to $2 \log$ ). A full grown first segment corresponded to $3 \log$ cfu, growth in the second segment to $4 \log$ cfu, up to growth in all five segments which corresponded to $7 \mathrm{log}$ cfu. For the identification of the microorganisms standard microbiological methods were used ${ }^{12}$.

\section{Histology}

The modified Giemsa stain was performed as described by Gray et al. ${ }^{13}$. For immunohistochemistry a purified polyclonal antiserum against H.pylori was obtained from ITK diagnostics BV (DAKO B471, ITK diagnostics BV, Uithoorn, The Netherlands). The antiserum was raised in rabbits after immunization with heat-treated cells of one H.pylori strain ${ }^{14}$.

Staining was performed using the polyclonal antiserum in a 1:500 dilution and biotin-conjugated swine-anti-rabbit-antibodies (1:1000) (DAKO E431) as second layer, followed by streptABC-HRP (1:1000) (DAKO K377). Sections were stained with diaminobenzidine $(\mathrm{DAB})$ with $10 \%$ imidazol to intensify the reaction and were counterstained with haematoxylin. Slides were assessed blindly for the presence of H.pylori by the S-shaped appearance and the localisation in the gastric mucus layer at 400 magnification. If necessary a $1000 \mathrm{x}$ oil immersion magnification was used. 


\section{Analysis of results}

Amounts of H.pylori and non-H.pylori bacterial flora detected by culture were compared statistically by the non-parametric paired Wilcoxon test. For the purpose of this study bacterial culture was used as standard to compare results by MG and IMM for the detection of H.pylori.

\section{Results}

\section{Patients}

Eighteen patients (12 men and 6 women; mean age $51.8 \pm 11.6$ SD) with a duodenal ulcer $(n=13)$, a gastric ulcer $(n=3)$, or erosive bulbitis $(n=2)$ were allotted to eradication therapy for H.pylori. Before treatment all patients were H.pylori positive by either MG or by culture in antrum or corpus. Median $\mathrm{pH}$ of gastric juice was 1.5 (range 1.0-2.5) $(n=18)$. After eradication therapy, when patients were still on omeprazole $20 \mathrm{mg}$ twice daily, with the last dose taken about 12 hours before control endoscopy, the median $\mathrm{pH}$ was 7.0 (range 1.0-7.0) $(\mathrm{n}=17)$.

\section{Culture results}

Mean $\log \mathrm{cfu} / \mathrm{ml}$ gastric juice and mean $\log \mathrm{cfu} / \mathrm{gr}$ biopsy of all 18 patients before and after therapy for H.pylori and for non-H.pylori bacterial flora are given in Figure IV.1. H.pylori and non-H.pylori flora were detected by culture in 15 and 7 patients before therapy, and in 9 and 15 patients after therapy, respectively.

Before therapy, H.pylori was found in the gastric juice of only one patient; in the biopsy specimens, relatively high mean amounts of H.pylori were found in body $(4.8 \mathrm{log})$, antrum $(5.3 \mathrm{log})$ and duodenum $(3.5 \mathrm{log})$. After therapy, a significant decrease in mean amounts of H.pylori was found in corpus $(2.7 \mathrm{log})$ $(p=0.02)$, antral $(1.8 \log )(p=0.003)$ and duodenal biopsies $(0.3 \log )(p=0.001)$. Before therapy, the highest amounts of H.pylori were found in the antrum, whereas after therapy, the highest amounts were present in the corpus biopsies.

Before therapy only small amounts of non-H.pylori flora were present in corpus $(0.5 \log )$, antrum $(1.2 \mathrm{log})$ and duodenum $(0.3 \mathrm{log})$. No growth was found in the gastric juice. After therapy, mean amounts of non-H.pylori flora increased significantly in gastric juice $(4.5 \mathrm{log})(\mathrm{p}=0.003)$ as well as in corpus $(3.0 \mathrm{log})$ $(\mathrm{p}=0.004)$, antral $(3.1 \mathrm{log})(\mathrm{p}=0.01)$ and duodenal biopsies $(3.4 \mathrm{log})(\mathrm{p}=0.001)$.

Bacterial flora other than H.pylori consisted of oropharyngeal flora such as Streptococci viridans, Neisseria spp. and Corynebacterium spp.; in addition, in 
three patients faecal like flora, i.e. Enterobacteriaceae, was found after therapy.
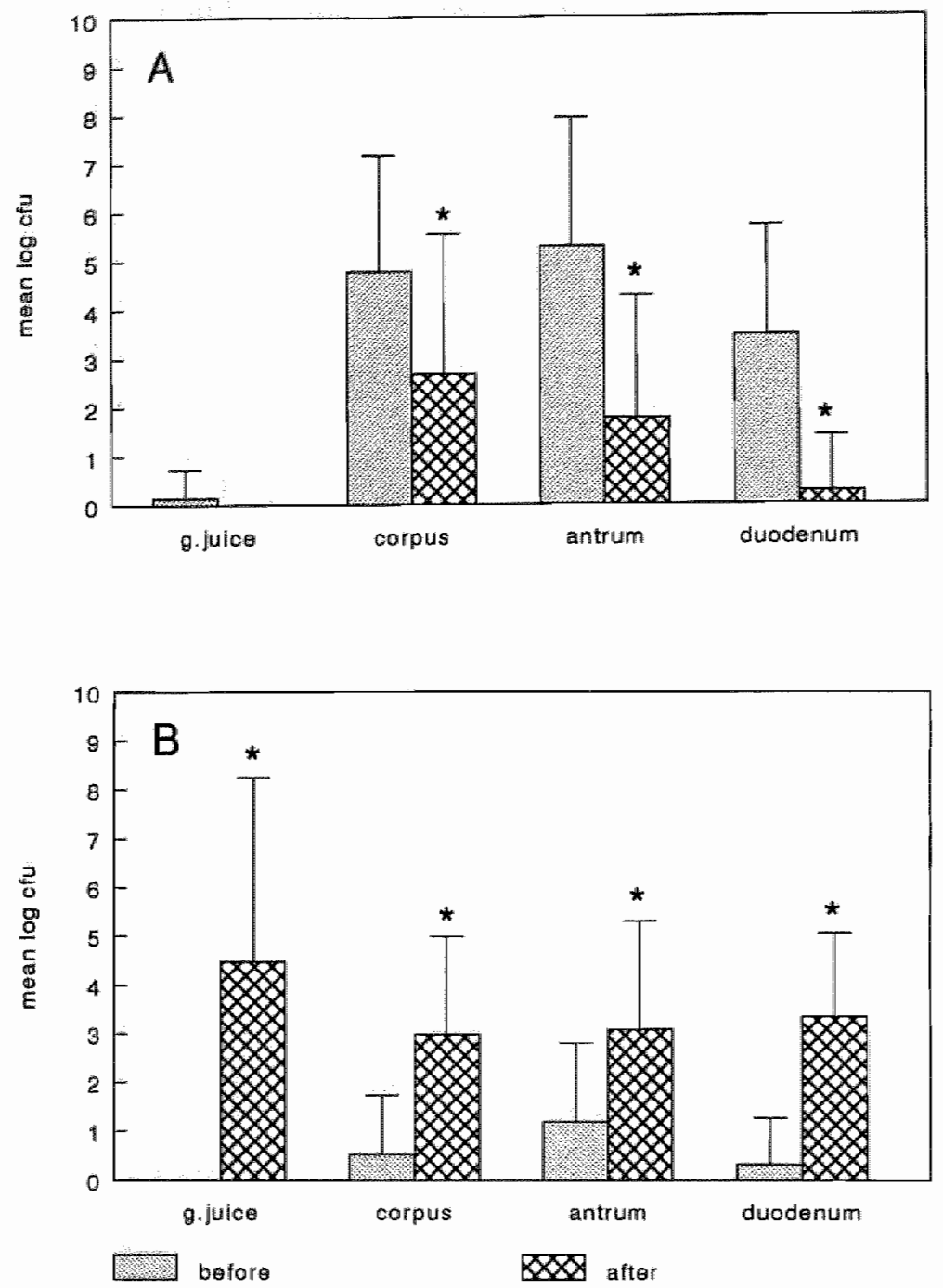

Figure IV.1: Presence of Helicobacter pylori (A) and non-Helicobacter pylori bacterial flora (B) by culture (mean \pm SD log cfu per ml gastric juice or per gr biopsy) before and after eradication therapy $(\mathrm{n}=18)$. "Wilcoxon: $\mathrm{p}<0.05$ 


\section{Assessment of Helicobacter pylori by culture, MG and IMM}

For each patient the presence of H.pylori by culture, MG, IMM and Gram stain before and after therapy are given in Tables IV.1 and IV.2. Before treatment, 15 patients were H.pylori positive by culture and three by $\mathrm{MG}$ in any of the specimens. After treatment, the corpus specimens of nine patients were still positive by culture. When H.pylori was detected by Gram stain, it was also positive by culture. In one corpus, one antral and four duodenal biopsies, H.pylori was not detected by Gram stain whereas culture was found to be positive.

Table IV. 1: Presence $(+)$ or absence $(-)$ of H.pylori by culture, MG, IMM and Gram stain in compus, antrum and duodenum before therapy

\begin{tabular}{|c|c|c|c|c|c|c|c|c|c|c|c|c|}
\hline \multirow[t]{2}{*}{ Patient } & \multicolumn{4}{|c|}{ corpus } & \multicolumn{4}{|c|}{ antrum } & \multicolumn{4}{|c|}{ duodenum } \\
\hline & Cul & MG & IMM & $\mathbf{G r r}^{1}$ & Cull & MG & IMM & Gr & Cull & MG & IMM & Gr \\
\hline 1 & + & - & - & + & + & + & + & + & + & - & + & + \\
\hline 2 & + & + & + & + & + & + & + & + & + & + & + & - \\
\hline 3 & - & + & - & - & - & + & - & - & - & - & - & - \\
\hline 4 & - & + & + & - & - & + & + & - & - & - & - & - \\
\hline 5 & + & + & + & + & + & + & + & + & + & - & + & + \\
\hline 6 & + & + & + & + & + & + & + & + & - & - & + & - \\
\hline 7 & + & - & + & + & + & + & + & + & + & - & - & + \\
\hline 8 & + & - & + & + & + & + & + & + & + & - & - & + \\
\hline 9 & + & - & + & + & + & + & + & + & + & + & + & + \\
\hline 10 & 4 & - & - & + & + & + & + & + & + & - & - & - \\
\hline 11 & + & + & + & + & + & + & + & + & + & 4 & + & - \\
\hline 12 & + & - & - & + & + & + & + & + & 4 & + & - & + \\
\hline 13 & + & + & + & + & + & + & + & + & + & $\#$ & + & 4 \\
\hline 14 & - & - & - & - & - & + & - & - & - & - & - & - \\
\hline 15 & + & + & + & + & of & + & + & + & H & - & + & $\#$ \\
\hline 16 & + & + & + & - & + & + & + & + & $\#$ & + & + & + \\
\hline 17 & + & + & + & + & + & + & + & + & + & - & - & - \\
\hline 18 & + & + & + & + & + & + & + & + & + & - & - & + \\
\hline
\end{tabular}

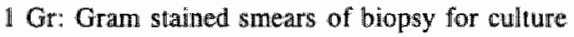


As shown in Table IV.1, before therapy, culture positive antral biopsies were also found to be positive by MG and IMM, but H.pylori was not detected in six corpus and eight duodenal biopsies by $\mathrm{MG}$ and in three corpus and six duodenal biopsies by IMM. Non-H.pylori was cultured from three and two of the corpus biopsies and in one duodenal biopsy when H.pylori was not detected by MG and IMM, respectively.

Table IV.2 Presence ( + ) or absience (-) of H.pylori by culture, MG, IMM and Gram in corpus, antrun and duodenum after therapy

\begin{tabular}{|c|c|c|c|c|c|c|c|c|c|c|c|c|}
\hline \multirow[t]{2}{*}{ Patient } & \multicolumn{4}{|c|}{ corpus } & \multicolumn{4}{|c|}{ antrum } & \multicolumn{4}{|c|}{ duodenum } \\
\hline & Cul & $\mathrm{MG}$ & IMM & Gr & Cull & MG & $\mathbf{M M}$ & $\mathrm{Gr}$ & Cul & MG & IMM & Gr \\
\hline 1 & + & + & + & + & + & - & - & + & - & - & - & - \\
\hline 2 & + & - & - & + & + & + & + & + & + & - & - & + \\
\hline 3 & + & - & - & + & + & + & + & + & - & + & - & - \\
\hline 4 & - & + & - & - & - & + & - & - & - & + & - & - \\
\hline 5 & - & - & - & - & - & + & - & - & - & - & - & - \\
\hline 6 & + & + & + & + & - & - & - & - & - & - & - & - \\
\hline 7 & - & - & - & - & - & - & - & - & - & + & - & - \\
\hline 8 & + & - & + & + & - & - & - & - & - & - & - & - \\
\hline 9 & - & - & + & - & - & + & - & - & - & - & - & - \\
\hline 10 & + & + & + & + & + & + & + & + & - & - & - & - \\
\hline $\mathbb{\|}$ & - & - & - & - & - & - & - & - & - & - & - & - \\
\hline 12 & - & - & - & - & - & - & - & - & - & - & - & - \\
\hline 13 & + & - & + & + & + & - & + & - & - & - & - & - \\
\hline 14 & - & - & - & - & - & - & - & - & - & - & - & - \\
\hline 15 & - & - & - & - & - & + & - & - & - & + & - & - \\
\hline 16 & + & + & + & + & + & + & + & + & - & + & - & - \\
\hline 17 & $t$ & - & + & + & + & - & + & + & - & - & - & - \\
\hline 18 & - & - & - & - & - & - & - & - & - & + & - & - \\
\hline
\end{tabular}

After treatment (Table IV.2) using microscopy, H.pylori was not detected by MG and IMM in five and two corpus, three and one antral, and one and one duodenal biopsies, respectively, whereas culture of these specimens yielded H.pylori. Moreover, non-H.pylori flora was cultured from all but one corpus biopsy. 
In contrast biopsies H.pylori negative by culture after therapy, scored positively by microscopy, i.e. one corpus biopsy was IMM positive and one corpus, four antral and six duodenal biopsies were MG positive. Non-H.pylori flora was cultured in all of them except for two antral biopsies.

Before therapy active inflammation was found in antral and/or corpus biopsies from 17 patients. One patient (no. 3) showed chronic inflammation only. After therapy, active inflammation was still found in antrall or corpus biopsies from seven of nine patients positive for H.pylori by culture. Two patients (no. 1 and 13) showed chronic inflammation. Of the nine patients with biopsies culture negative for H.pylori, one patient showed active inflammation in corpus (no, 14), in one patient no inflammation was found (no. 7), and seven showed chronic inflammation in antrum and/or corpus. Of these seven patients, the numbers $4,5,9,15$, and 18 were scored positive by histology but H.pylori-negative by culture. Only slight chronic inflammation was found in the antrum and corpus of no. 18 and in antrum only of the others while no inflammation was found in the corpus, supporting that these were true culture-negatives.

\section{Discussion}

Although the number of patients in this study was relatively low the results showed that ongoing gastric acid inhibition is a confounding factor for the accurate histological diagnosis of H.pylori in gastric biopsies when a non-specific staining method is used. Because of the low eradication rate $(55 \%)$ not more than 18 patients were included in this study.

At low gastric $\mathrm{pH}$, before therapy, non-H.pylori flora is cultured in only minor amounts and use of MG does not result in many false positive H.pylori scores. However, after eradication therapy for H.pylori, many clinicians continue to treat their patients with gastric acid inhibitors for a prolonged period of time until symptoms have disappeared and/or until successful. H.pylori eradication has been verified by control biopsies ${ }^{6.15}$. In the patient population studied, ongoing gastric acid inhibition resulted in a median fasting gastric $\mathrm{pH}$ of 7.0 (range 1.0 7.0), only in four of the 17 patients was the gastric pH less than 3.5. As expected culture of the gastric specimens revealed other bacteria (mainly oropharyngeal flora) in addition to H.pylori. Similar situations may occur when H.pylori positive subjects have been treated with gastric acid inhibition before H.pylori diagnosis and in patients with atrophic gastritis. As decreased gastric acidity increased the presence of other bacterial flora in the gastric lumen and in the mucosa of corpus, antrum and duodenum, the accurate histological detection of remaining H.pylori 
was rendered more difficult. After therapy, $H$. pylori was not detected by MG (i.e. false negative) in about half of the 17 culture positive specimens. However, with a specific immunohistochemical staining method only three of the positive specimens were missed. Also false positive results were much more frequently observed by MG (11 times) than by IMM (once), especially when non-H.pylori flora was present by culture. It is very likely that this flora may lead to both false positive and false negative results when using only a non-specific staining method for the histological detection of H.pylori. Better results are obtained by IMM compared to MG.

Recently, our culture procedures for H.pylori have been optimalized ${ }^{11}$. Washing and grinding of the specimens was carried out to detect low amounts of H.pylori and to reduce contaminating oropharyngeal flora. In addition, Skirrow selective medium was used for optimal isolation of $H$.pylori in combination with the lowest rate of non-H.pylori flora. Therefore, in the present study culture was used as a standard to compare the usefulness of IMM and MG for the detection of H.pylori. Furthermore, H.pylori culture results were always positive when Gram stained smears of the biopsies were positive. Only in one patient before therapy (no. 4) were biopsy specimens of antrum and corpus were positive both by IMM and $\mathrm{MG}$ but not by culture. This single exception does not influence the conclusions concerning the usefulness of $\mathrm{MG}$ and IMM for the detection of H.pylori.

Surprisingly, the histological detection of H.pylori often failed (both by IMM and $\mathrm{MG}$ ) in the duodenal biopsies in comparison with culture results. A possible explanation might be the use of a homogeneous sample of a whole ground biopsy for culture, whereas only sections of a biopsy are used for histology. This may particularly influence detection in duodenal biopsies containing low amounts of H.pylori.

The specificity of the polyclonal antiserum used was tested and no cross reactivity was found with Campylobacter jejuni, Campylobacter coli, Klebsiella pneumoniae, Psevdomonas aeruginosa, Streptococcus viridans and Staphylococcus aureus. In addition forty different H.pylori strains isolated from different patients were found to be positive. Comparing the same H.pylori antiserum in an immunohistochemical stain with a cresyl-violet stain (comparable to the modified Giemsa stain), Navratil et al ${ }^{16}$ found a high sensitivity and specificity for both stains after eradication therapy for H.pylori with a slightly higher sensitivity of the IMM stain. However, patients in that study had been off gastric acid inhibition (lansoprazole) more than four weeks before re-testing and it is to be expected that gastric $\mathrm{pH}$ had returned to normal.

The histological diagnosis of H.pylori in patients with ongoing gastric acid 
inhibition therapy will remain unreliable if only non-specific staining methods (such as the modified Giemsa) are used. In this common clinical situation, false positive and false negative histological detection of H.pylori may occur. The use of a highly specific immunohistochemical stain is strongly recommended for the histological diagnosis of $H$.pylori to prevent unnecessary repetition of eradication therapy. 


\section{References}

1. Nomura A, Stemmermann GN. Helicobacter pylori and gastric cancer. J Gastroenterol Hepatol 1993; 8: 294-303.

2 Calam J. Hellcobacter pylori. Rev Eur J Clin Invest 1994; 24 : 501-510.

3 Fennerty MB. Helicobacter pylori. Review Article. Arch Intern Med 1994; 154 : $721-727$.

4. Hentschel E, Brandstätter $G$, Dragosics B et al. Effect of ranitidine and amoxycillin plus metronidazole on the eradication of Helicobacter pylori and the recurrence of duodenal ulcer. New Engl J Med 1993; 5: 308-312.

5 Logan RPH, Gummer PA, Schaufelberger HD et al. Eradication of Helicobacter pylori with clarithromycin and omeprazole. Gut 1994; 35: 323-326.

6 Bayerdörffer E, Miehlke S, Mannes GA et al. Double blind trial of omeprazole and amoxycillin to cure Helicobacter pylori infection in patients with duodenal ulcers. Gastroenterol $1995 ; 108: 1412-1417$.

7 Stockbrügger RW, Cotton $\mathrm{PB}$, Eugenides $\mathrm{N}$, Bartholonew $\mathrm{BA}$, Hill $\mathrm{MJ}$, Walters CL. Intragastric nitrites, nitrosamines, and bacterial overgrowth during cimetidine treatment. Gut $1982 ; 23: 1048-1054$.

8 Sharma BK, Santana IA, Wood EC et al. Intragastric bacterial activity and nitrosation before, during, and after treatment with omeprazole. Br Med $\mathfrak{I} 1984$; 289: 717-719.

9 Verdu $\mathbb{E}$, Viani $F$, Armstrong D, Fraser $R$ et al. Effect of omeprazole on intragastric bacterial counts, nitrates, nitrites, and $N$-nitroso compounds. Gut 1994; 35: $455-460$.

10 Cruickshank R, Duguid JP, Marmion BP, Swain RHA. Cultivation of bacteria and fungi. In Medical Microbiology. Twelfth edition, volume II. Edinburgh, Churchill Livingstone; $1975: 153-154$.

11 Jonkers D, Stobberingh E, Stockbrügger $\mathbb{R}$. The influence of oropharyngeal flora and specimens pretreatment on the recovery of Helicobacter pylori. Eur $\mathrm{J}$ Clin Microbiol Infect Dis $1996 ; 15: 378-382$.

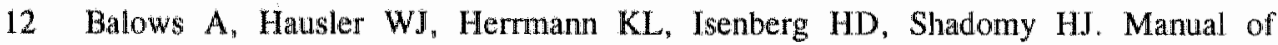
Clinical Microbiology, $5^{\text {th }}$ edition. Washington D.C.: American Society for Microbiology; 1991.

13 Gray SF, Wyatt JL, Rathbone BJ. Simplified techniques for identifying Campylobacter pyloridis. J Clin Pathol 1986; 39: 1279.

14 Anderssen LP, Holck $\mathrm{S}$, Povlsen $\mathrm{CO}$. Campylobacter pylori detected by indirect immunohistochemical technique. APMIS 1988; 96: 559-564.

15 Graham DY. A reliable cure for Helicobacter pylori infection. Gut 1995; 37 : 154-156.

16 Navratil E, Soule JC, Rousseau M et al. Comparison of immunohistochemistry and histology for the diagnosis of Helicobacter pylori infection after treatment. Gut 1995; 37 (suppl 2): A54. 


\section{Chapter V}

The gastroduodenal distribution of Helicobacter pylori in patients with duodenal and gastric ulcer: relation to inflammatory changes, mucosal atrophy and intestinal metaplasia in the stomach and gastric metaplasia in the duodenum

D Jonkers, G Houben, A de Bruine, JW Arends,
E Stobberingh, R Stockbrügger 


\section{Summary}

The relation between H.pylori infection, inflammation, mucosal atrophy, intestinal and gastric metaplasia was studied in 49 patients with a duodenal ulcer (DU) (median age 56 years, $33 \mathrm{M} / 16 \mathrm{~F}$ ) and 47 patients with a gastric ulcer (GU) (median age 67 years, $22 \mathrm{M} / 25 \mathrm{~F}$ ). At least two biopsy specimens of duodenal bulb, antrum and corpus mucosa were abtained for histology. Serial sections were stained by modified Giemsa (MG) and Immunohistochemistry (IMM) (DAKO B471) for the detection of H.pylori. Bacterial density was graded semi-quantitatively. Haematoxylin-Eosin (HE) stained sections were used for the histological classification of chronic and active inflammation, mucosal atrophy and intestinal metaplasia. An additional section of duodenal bulb was stained with the PAS/Alcian blue to assess the presence of gastric metaplasia.

H.pylori was found in $81.6 \%$ cases of DU and in $83.0 \%$ cases of GU. In DU and GU patients, H.pylori was found in $79.6 \%$ and $79.5 \%$ of corpus, $77.6 \%$ and $72.3 \%$ of antral, and $16.7 \%$ and $20.0 \%$ of duodenal bulb mucosal biopsies, respectivelly. In DU patients, the density of $H_{\text {p }}$ pylori was significantly lower in corpus compared to antrum biopsies $(p<0.001)$. No such difference was observed in GU patients. Furthermore, the $H$,pylori density was higher in corpus of GU than of DU patients. Inflammatory scores followed the density of $H$.pylori infection. Significantly higher prevalences of mucosal atrophy and intestinal metaplasia were found in GU than DU patients $(P<0.05)$. The occurrence and extent of gastric metaplasia were comparable in the duodenal bulb of both DU and GU patients.

In conclusion, some differences were found in the gastroduodenal distribution of H.pylori in $\mathrm{DU}$ and $\mathrm{GU}$ patients which may contribute to differences in presentation of the both conditions. The higher prevalence of precancerous lesions (atrophy and intestinal metaplasia) in GU patients will be associated with the higher risk for gastric cancer. No evidence was found for a role of gastric metaplasia in the differential pathogenesis of DU and GU. It is probable that also other bacterial factors (such as differences in H.pylori isolates), host factors, and environmental factors play a role in the differentiation between the two forms of peptic ulcer disease. 


\section{Introduction}

Helicobacter pylori (H.pylori) can be found in $90 \%-100 \%$ of patients with duodenal ulcer (DU) ${ }^{1-6}$ and in $60 \%-100 \%$ of patients with gastric ulcer (GU) $)^{1,3,4,6.7}$. Eradication of H.pylori results in a significant reduction of both $\mathrm{DU}^{\mathrm{Q} .9}$ and GU recurrence ${ }^{10.12}$ suggesting an important - possibly causative - role of $H$.pylori in the pathogenesis of DU and GU.

H.pylori has several properties which can induce tissue damage: production of ammonia resulting from its extreme urease activity, production of cytotoxins, and induction of local and humoral inflammatory responses ${ }^{6,13,14}$. In addition, there are other possible pathogenetic mechanisms: DU patients and healthy volunteers with H.pylori infection have higher basal and stimulated plasma gastrin concentrations and higher basal and stimulated acid output compared to those who are negative for H.pylori ${ }^{15-17}$. Also pepsinogen I and II concentrations are higher in H.pylori positive subjects ${ }^{16}$.

Kozol et al. ${ }^{2}$ describes four mechanisms by which H.pylori may contribute to the pathogenesis of duodenal ulceration: First, H.pylori may colonize areas of gastric metaplasia in the duodenum and cause a duodenal ulcer by local mucosal damage. A second mechanism results from an increased acid secretion and hypergastrinaemia associated with H.pylori. Gastrin release could be stimulated by local $\mathrm{pH}$ increase in the gastric mucosa by the production of ammonia through the urease activity, or by a direct effect of inflammatory mediators on gastrin producing cells. Increased intragastric acidity has been associated with the development of gastric metaplasia ${ }^{18}$. Thirdly, the duodenal mucosa could be damaged by passage of inflammatory mediators from the gastric lumen into the duodenum. Finally, the duodenal mucosa may be directly damaged by an immune response to H.pylori. These mechanisms are not necessarily mutually exclusive. The aetio-pathogenetic role of H.pylori in GU patients has hardly been discussed.

Before the H.pylori era, many other factors were found to contribute to the development of DU and GU, such as genetic predisposition, diet, smoking and psychosocial factors. However, the precise pathophysiological mechanisms and differences of such mechanisms in DU and GU are not clear yet.

In this study, DU and GU patients were compared in terms of gastroduodenal distribution and density of H.pylori, prevalence of precancerous lesions of the gastric mucosa (atrophy and intestinal metaplasia) and the prevalence of gastric metaplasia in the duodenal bulb, in order to look for differences between both patients groups that may contribute to the differences in the presentation of peptic ulcer disease. 


\section{Material and methods}

\section{Patients and specimens}

Specimens were obtained from patients with newly diagnosed duodenal or gastric ulcers during open access endoscopy. Prior to gastroscopy, four DU and two GU patients used $\mathrm{H}_{2}$-antagonists and one $\mathrm{DU}$ and one $\mathrm{GU}$ patient were using omeprazole. NSAIDs were used by five DU and six GU patients. At the endoscopy, the $\mathrm{pH}$ of gastric juice was measured using $\mathrm{pH}$ paper strips with grading steps of 0.5 from $\mathrm{pH} 0$ to 14 (Schleicher \& Schüll GmbH; Dassel, Germany).

At least two adjacent biopsies were taken from corpus, antral and duodenal bulb mucosa for histology using an Olympus GIFQ gastroscope. Biopsies were fixed in formalin and embedded in paraffin; serial sections of $4 \mu \mathrm{m}$ were cut and stained by Haematoxylin-Eosin (HE), modified Giemsa (MG) ${ }^{19}$ and an immunohistochemical stain (IMM) against H.pylori using a purified polyclonal antiserum (DAKO B471, ITK Diagnostics BV, Uithoorn, The Netherlands) ${ }^{20}$. Duodenal biopsies were also stained with the periodic acid Schiff (PAS)/Alcian blue stain.

\section{Detection of Helicobacter pylori}

The MG and IMM slides were scored without knowledge of the clinical diagnosis for the presence of H.pylori at 400 magnification and graded 0-3: no H.pylori found (grade 0); occasionally H.pylori found after searching (grade 1); scattered H.pylori bacteria in many fields (grade 2); numerous H.pylori bacteria in most fields (grade 3 ) $^{1,21}$. The presence of H.pylori by MG and IMM was characterised by the S-shaped appearance of the bacteria in MG or by immunoreactivity in IMM and by their localisation in the gastric mucus layer as well as in the gastric pits. At least two cross-sections of all biopsies were examined completely. Special attention was paid to the presence of non-H.pylori bacteria through assessment of morphology and localisation of microorganisms in the $\mathrm{MG}$ stain in combination with absent immunoreactivity in the identical area of a consecutive slide.

\section{Histological findings in corpus and antrum}

HE stained corpus and antrum sections were scored for the presence of chronic inflammation, neutrophil activity, intestinal metaplasia and mucosal atrophy according to the Sydney classification ${ }^{22}$. Duodenal bulb biopsies were scored for the presence of chronic and active inflammation on HE stained sections. The extent of gastric antral metaplasia was assessed with the PAS/Alcian blue stain using a 
scale of $0 \%-100 \%$ involvement of the epithelial layer present in the biopsies: The score was based on mutually agreed values of two observers (who were not aware of the diagnosis of DU or GU) and divided into four grades: no gastric metaplasia present (grade 0 ) $; 10 \%$ or less (grade 1 ); between $10 \%$ and $50 \%$ (grade 2 ); $50 \%$ of more gastric type epithelium present (grade 3 ).

\section{Statistical analysis}

Age and intragastric $\mathrm{pH}$ of $\mathrm{DU}$ and GU patients were compared with a MannWhitney $\mathrm{U}$ test. Prevalences of H.pylori positive duodenal, antral and corpus mucosal biopsies and prevalence of chronic and active inflammation, mucosal atrophy, and intestinal metaplasia were analyzed between and within DU and GU patients using a Chi-Square test and a McNemar test, respectively. Differences in density of H.pylori were analyzed with a Mann-Whitney U test between DU and GU patients and with a Wilcoxon test within DU and GU patients. The prevalence and grading of gastric metaplasia in the duodenal bulb of DU and GU patients were analyzed using a Chi-Square test and a Mann Whitney $U$ test, respectively. A p-value $<0.05$ was considered to be significant.

\section{Results}

\section{Patients}

Biopsy specimens were obtained from 49 DU (33 male and 16 female) and $47 \mathrm{GU}$ (22 male and 25 female) patients. Biopsies from corpus, antrum and duodenum were available of $48 \mathrm{DU}$ and $42 \mathrm{GU}$ patients. Duodenal biopsies were missing from $1 \mathrm{DU}$ and $2 \mathrm{GU}$ patients and corpus biopsies were missing from $3 \mathrm{GU}$ patients. In most cases two or more biopsies from each site were available, except for 6 times antral, 4 times corpus and 2 times duodenal sampling (from $7 \mathrm{DU}$ and 3 GU patients). Median age for DU was 56 (21-85) years and for GU 67 (34-93) years $(\mathrm{p}<0.01)$. The median $\mathrm{pH}$ of gastric juice was $1.5(1.0-7.0)$ for DU and 1.5 (1.0-7.5) for GU patients with a pH above 3.5 in 5 of $43(11.6 \%)$ DU and in 14 of $39(35.9 \%)$ GU patients $(p<0.01)$. After exclusion of the few patients treated with gastric acid inhibitors, still a significantly higher intragastric $\mathrm{pH}$ was found in GU as compared to DU patients $(\mathrm{p}<0.05)$.

\section{Prevalence and density of Helicobacter pylori}

H.pylori was detected by IMM in $40 / 49(81.6 \%)$ DU and $39 / 47(83.0 \%)$ GU patients. Comparing the presence of H.pylori according to IMM and $\mathrm{MG}$ stains, 
respectively, minor but not significant differences in detection were found. Concordance between both stains was $98.0 \%$ for DU and $89.4 \%$ for GU patients. Non-H.pylori bacteria were detected in 5 DU $(10.2 \%)$ patients and in $8 \mathrm{GU}$ patients $(17.0 \%)$. Because of the higher sensitivity and specificity of IMM compared to MG for the detection of H.pylori ${ }^{20}$, the results of IMM were used for further analyses.

The prevalence of H.pylori in corpus, antrum or duodenum of DU patients was not statistically different from GU patients (Table V.1 and V.2). Neither were any differences observed in H.pylori infestation observed between antrum and corpus biopsies within the group of DU and GU patients (Table V.2). H.pylori prevalences were found with a similar frequency in duodenum of both DU and GU patients and were encountered significantly less frequently than in the antrum or corpus of these patient groups $(p<0.001)$.

Table V.1: Presence (\%) of H.pylori, chronic and active inflammation, intestinal metaplasia and mucosal atrophy scores in corpus, antrum and duodemum of DU and GU patients.

\begin{tabular}{|c|c|c|c|c|c|c|}
\hline Histollogy & \multirow{2}{*}{\multicolumn{2}{|c|}{$\begin{array}{l}\text { corpus } \\
n=49\end{array}$}} & \multirow{2}{*}{\multicolumn{2}{|c|}{$\begin{array}{c}\text { antrum } \\
n=49\end{array}$}} & \multirow{2}{*}{\multicolumn{2}{|c|}{$\begin{array}{c}\text { duodenuma } \\
\mathrm{n}=48\end{array}$}} \\
\hline DU patients & & & & & & \\
\hline H.pylori (IMM) & 39 & $(79.6 \%)$ & 38 & $(77.6 \%)$ & 8 & $(16.7 \%)$ \\
\hline chron inflamm & 30 & $(61.2 \%)$ & 42 & $(85.7 \%)$ & 27 & $(56.3 \%)$ \\
\hline act inflarmm & 9 & $(18.4 \%)$ & 31 & $(63.3 \%)$ & 9 & $(18.8 \%)$ \\
\hline intest metapl & 1 & $(2.0 \%)$ & 16 & $(32.7 \%)$ & - & $(0.0 \%)$ \\
\hline mucosal atrophy & 1 & $(2.0 \%)$ & 9 & $(18.4 \%)$ & - & $(0.0 \%)$ \\
\hline GU patients & \multicolumn{2}{|c|}{$n=44$} & \multicolumn{2}{|c|}{$n=47$} & \multicolumn{2}{|c|}{$n=45$} \\
\hline H.pylori (IMM) & 35 & $(79.5 \%)$ & 34 & $(72.3 \%)$ & 9 & $(20.0 \%)$ \\
\hline ehroni inflamm & 34 & $(77.39$ 湐) & 44 & $(93.6 \%)$ & 19 & $(42.2 \%)$ \\
\hline act inflamm & 20 & $(45.5 \%)$ & 35 & $(74.5 \%)$ & 5 & $(11.1 \%)$ \\
\hline intest metapl & 9 & $(20.5 \%)$ & 25 & $(53.2 \%)$ & - & $(0.0 \%)$ \\
\hline mucosal atrophy & 8 & $(18.2 \%)$ & 13 & $(27.7 \%)$ & - & $(0.0 \%)$ \\
\hline
\end{tabular}

For DU patients the density of H.pylori was significantly higher in antral than in corpus biopsies $(p<0.001)$ (Figure V.1a). Similar densities were found in antrum and corpus of GU patients (Figure V.1b). Comparing DU with GU 
patients, no significant differences in the H.pylori density were found in antrum but a significantly higher H.pylori density was found in corpus of GU than of DU patients $(\mathrm{p}<0.01$ ) (Table V.2). The H.pylori density in duodenal bulb biopsies was significantly higher in DU than GL patients $(\mathrm{p}<0.05)$. However, these results are based on small numbers.
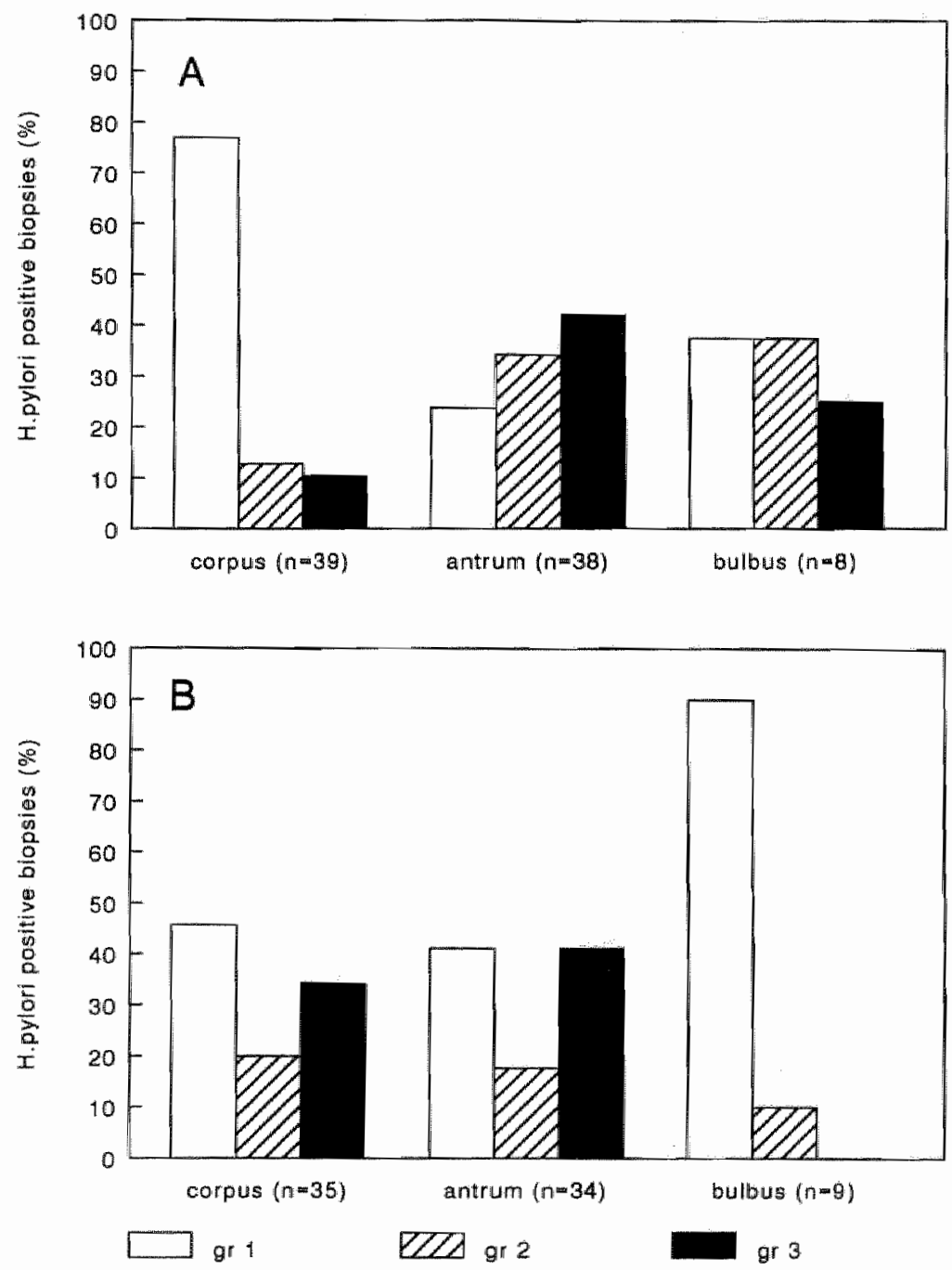

Figure V.1: Density of H.pylori positive corpus, antral and duodenal biopsies of DU patients (A) and GU patients (B) 


\section{Histological findings in the stomach and their relation to Helicobacter pylori}

In both $\mathrm{DU}$ and $\mathrm{GU}$ patients, chronic and active gastritis were significantly more frequent in antrum than corpus. This difference was more pronounced for DU than GU patients (Table V.1 and V.2). Although antrum gastritis occurred to a similar degree in DU and GU patients, GU patients more frequently showed chronic $(p<0.05)$ and active inflammation $(p<0.01)$ in the corpus (Table V.1 and V.2).

Table $V_{n} 2$ Statistical differences in prevalence and density of H.pylori and the presence of inflammation (chronic and artive), intestinal metaplasia and mucosal atrophy between and within DU and GU patients

\begin{tabular}{|c|c|c|c|}
\hline & DU patients & & GU patients: \\
\hline \multirow[t]{3}{*}{ H.pylori prevalence } & antrum & $=$ & antrum \\
\hline & & & \\
\hline & corpus & $=$ & corpus \\
\hline \multirow[t]{3}{*}{ H.pylori density } & antrum & $=$ & antrum \\
\hline & $>\cdots$ & & $=$ \\
\hline & corpus & $<^{* *}$ & corpus \\
\hline \multirow[t]{3}{*}{ Chronic inflammation } & antrum & $=$ & antrum \\
\hline & $>*$ & & $>^{*}$ \\
\hline & corpus & $<$ & corpus \\
\hline \multirow[t]{3}{*}{ Active inflammation } & antrum & $=$ & antrum \\
\hline & $>^{\cdots}$ & & $>^{* *}$ \\
\hline & corpus & $<$ & corpus \\
\hline \multirow[t]{3}{*}{ Intestinai metaplasin } & antrum & $<$ & antrum \\
\hline & $>^{* * n+1}$ & & $>^{* \cdots}$ \\
\hline & corpus & $<*$ & corpus \\
\hline \multirow[t]{3}{*}{ Mucosal atrophy } & antrum & $=$ & antrum \\
\hline & $>\cdots$ & & $=$ \\
\hline & corpus & $<$ & corpus \\
\hline
\end{tabular}

${ }^{*} p<0.05 ; " \bar{*} p<0.01 ; \cdots p<<0.001$ 
Intestinal metaplasia and mucosal atrophy were found in both DU and GU patients. Intestinal metaplasia was more frequently in antrum than corpus of both groups $(\mathrm{p}<0.001)$, and significantly more often in GU than in DU patients $(p<0.05)$ (Table V.1 and V.2). DU patients with intestinal metaplasia in the antrum (median age 68 (range 37-79) years) were significantly older than those without intestinal metaplasia (median age 45 (range 21-85) years) $(p<0.01$ ). Mucosal atrophy occurred more often in antrum and corpus of GU patients than of DU patients, although the difference was significant for the corpus only $(\mathrm{p}<0.05)$. In both patient groups mucosal atrophy was found more frequently in antrum than corpus, being significant only for DU patients $(p<0.01)$. In GU patients, the presence of intestinal metaplasia and mucosal atrophy in the corpus was associated with a significantly higher intragastric $\mathrm{pH}(\mathrm{p}<0.01)$, also after exclusion of the patients treated with acid inhibitors.

Relating the H.pylori status to mucosal findings, in DU patients the presence of H.pylori correlated with the presence of chronic and active gastritis in antrum and in GU patients with the presence of chronic gastritis in corpus and active gastritis in antrum. In all patients, H.pylori was significantly less frequently found in the presence of intestinal metaplasia and mucosal atrophy $(p<0.05)$. Furthermore, in both DU and GU patients the H.pylori density in corpus was significantly higher when mucosal atrophy or intestinal metaplasia was present in the antrum $(\mathrm{p}<0.05)$.

\section{Histological findings in duodenal bulb and the relation to Helicobacter pylori}

Chronic and active inflammation were found in the duodenal bulb of $56.3 \%$ and $18.8 \%$ of DU and $42.2 \%$ and $11.1 \%$ of GU patients, respectively (Table V.1). H.pylori was detected in the duodenal bulb of eight DU (16.7\%) and of nine GU patients (20.0\%). In DU patients, H.pylori was found in combination with chronic inflammation in all eight patients and in combination with activity in only two patients. No association of $H$.pylori with chronic active inflammation was found in GU patients.

Table V.3: Presence of gastric metaplasia (grade $1,2,3$ ) in duodenal bulb biopsies of DU and GU patients

\begin{tabular}{llcccc}
\hline & n & positive & grade 1 & grade 2 & grade 3 \\
\hline DU & 45 & $18(40.0 \%)$ & $7(38.9 \%)$ & $5(27.8 \%)$ & $6(33.3 \%)$ \\
GU & 43 & $14(32.6 \%)$ & $9(64.3 \%)$ & $4(28.6 \%)$ & $1(7.1 \%)$ \\
\hline
\end{tabular}


No significant differences were found in either the prevalence or the degree of gastric metaplasia in both $\mathbb{D U}$ and $\mathrm{GU}$ patients, although the latter appeared slightly higher in DU patients (Table V.3). Furthermore, no correlation could be found between the presence of gastric metaplasia and the presence of chronic or active inflammation or between gastric metaplasia and the intragastric $\mathrm{pH}$ in both patient groups. Gastric metaplasia was present in 5 of 8 H.pylori positive DU patients and in 3 of 9 H.pylori positive GU patients (Figure V.2).

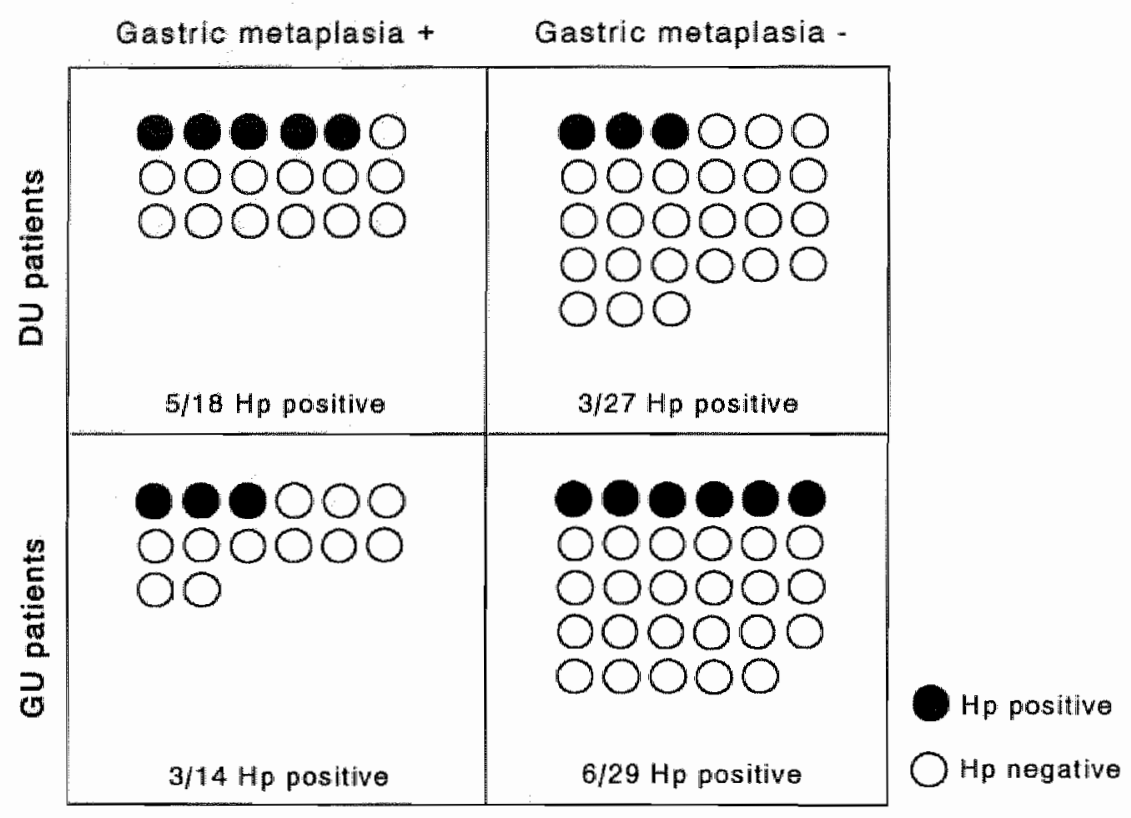

Figure V.2: Presence of H.pylori and gastric metaplasia in duodenal biopsies of DU and GU patients

\section{Helicobacter pylori negative patients}

Of the nine H.pylori negative DU patients, one patient used NSAID, and one paracetamol, but seven had not used any medication within three months prior to the gastroscopy. Of the eight H.pylori negative GU patients, one patient used omeprazole before endoscopy, two used NSAID, and five patients did not use any medication.

In 2 of 9 H.pylori negative DU patients intestinal metaplasia was found in the 
antrum, once in combination with mucosal atrophy in the antrum. In 4 of $8 \mathrm{GU}$ patients intestinal metaplasia was found in both antrum and corpus: once with mucosal atrophy in the corpus and once with mucosal atrophy in the antrum also.

\section{Discussion}

In this study H.pylori infection occurs with a similar frequency in DU and GU patients in both antrum and corpus as described by Madsen et al. ${ }^{21}$, whereas Louw et al. ${ }^{4}$ find a higher H.pylori frequency in antrum of the DU patients. In line with the latter and with other reports ${ }^{5.23}$, in DU patients a higher density of H.pylori in antrum compared to corpus was observed and a higher density in corpus of GU than DU patients. In line with these findings a predominantly antral gastritis was found in DU patients ${ }^{4,21.24,25}$ and a more widespread intragastric inflammatory response $^{4,25}$ with higher prevalences of mucosal atrophy and intestinal metaplasia was seen in GU patients. Finally, comparably low prevalences of H.pylori and gastric metaplasia were present in the duodenal bulb of both DU and GU patients.

To our knowledge this is the first study in which gastroduodenal bacterial flora of DU and GU patients was studied simultaneously with the histochemical MG stain and a H.pylori specific immunohistachemical stain. In peptic ulcer disease, there seems to be a good correlation between both stains. In this study, a non-H.pylori bacterial flora was only found in few ulcer patients. In the five DU patients, no association was found between the presence of non-H.pylori flora and mucosal atrophy or intestinal metaplasia. In GU patients, the non- $H$.pylori bacteria were present in 6 of 8 patients in combination with intestinal metaplasia and/or atrophy, found in the antrum only of 2 patients, in antrum and corpus of 3 patients and in corpus only of 1 patient. This indicates that especially in the GU patients these precancerous lesions create an environment where non-H.pylori bacterial flora can colonize.

The prevalence of H.pylori in DU and GU patients observed by us are in line with findings of others ${ }^{6}$, although the prevalence in DU patients is in the lower range. The absence of H.pylori in 9 DU patients cannot fully be explained by the use of medication prior to gastroscopy or by the presence of atrophy and intestinal metaplasia. Previously, also others have described a similar proportion of H.pylori negative PUD patients ${ }^{26,27}$.

Severall host or environmental factors may contribute to the differences between DU and GU in prevalence and density of $H$.pylori and inflammation in antrum and corpus. First, a higher density may reflect the duration or chronicity of the H.pylori infection ${ }^{6}$ : GU patients were older at time of diagnosis and the density 
in corpus biopsies was higher than in DU patients. This could advocate for an ascension of the infection with increasing age. Secondly, there may be a difference in affinity of H.pylori to the mucosa or in adherence factors with possible differences over antrum and corpus ${ }^{4}$. The availability of nutrients for H.pylori in antrum or corpus may differ between patients groups ${ }^{4}$. Madsen et al. ${ }^{21}$ and Bayerdörffer et al. ${ }^{24}$ also mention differences in mucosal reactivity towards H.pylori between antrum and corpus.

Furthermore the intragastric $\mathrm{pH}$ and precancerous lesions can influence the H.pylori status. H.pylori is generally more frequently found in the non-acid secreting antrum ${ }^{524}$. The lower gastric acidity present in GU compared to DU patients may promote the infection with H.pylori of the more proximal parts of the stomach ${ }^{28}$.

Finally, the density of H.pylori can be influenced by the presence of mucosal atrophy and intestinal metaplasia ${ }^{29.31}$ : indeed in this study, the prevalence of H.pylori was negatively associated with the presence of both histological lesions. However, from a transversal study like this, it cannot be concluded whether the latter two factors are a cause or a consequence of differences in density of H.pylori.

Although mucosal atrophy and intestinal metaplasia were found in both DU and GU patients, they were most frequently seen in GU patients as reported by Louw et al. ${ }^{4}$. Both mucosal atrophy and intestinal metaplasia are associated with an increased risk of gastric cancer, especially of the intestinal type ${ }^{32-35}$. This supports the reports of Correa et al. ${ }^{36}$ and Hansson et al. ${ }^{37}$, indicating that GU patients are at higher risk to develop gastric cancer compared with DU patients.

Gastric metaplasia is reported in $50-100 \%$ of DU patients ${ }^{5,38-40}$. In GU patients, a lower frequency is reported of $19 \%{ }^{39}$. Some authors have described that H.pylori is only present in duodenal areas with gastric metaplasia ${ }^{5.17 .38 .43}$ and that subsequent duodenal inflammation and ulceration leads to mucosal damage. A second hypothesis suggests that H.pylori infection of the gastric antrum increases the gastric acid production, leading to a greater duodenal acidity ${ }^{17}$ which induces gastric metaplasia and duodenal damage independent from each other.

In this study the overall frequency of gastric metaplasia was low in both DU and GU, although at least two duodenal biopsies of the first part of the duodenum were evaluated as recommended by Wyatt et al. ${ }^{18}$. Furthermore, the prevalence of gastric metaplasia was similar in GU patients who did not have duodenal lesions. Therefore gastric metaplasia cannot be a prerequisite for DU formation.

Several studies have shown that there was no concordance between the presence of gastric metaplasia and H.pylori ${ }^{25,40}$ : in many specimens with gastric metaplasia no H.pylori could be detected. This is in agreement with our findings 
and advocates against a close pathogenetic link between gastric metaplasia in the duodenal bulb, H.pylori infection and initiation of DU. In his review Kozol et al. ${ }^{2}$ come to the same conclusion because only low duodenal frequencies of H.pylori are reported in the literature. They suggest that the release of inflammatory mediators into the gastric لumen that washdown to the duodenum may play a role.

In conclusion, there is a different pattern of $\boldsymbol{H}$.pylori colonization and mucosal inflammation, intestinal metaplasia and mucosal atrophy in the both subtypes of peptic ulcer disease. However, our study does not allow to draw conclusions as to whether the differences of H.pylori colonization are a cause of these different histological patterns or a consequence of predetermined changes in the gastric mucosal lining. Longitudinal study of bacterial factors and host factors will hopefully elucidate the role of H.pylori in the differential pathogenesis of GU and DU. However, gastric metaplasia in the duodenum with or without H.pylori infection seems not to play a major part in DU pathogenesis. The higher degree of mucosal atrophy and of intestinal metaplasia found in GU patients support the finding of a higher risk for gastric cancer in these patients as it is previously described by Hansson et al. ${ }^{37}$. 


\section{References}

1 Marshall BJ, Warren JR. Unidentified curved bacilli in the stomach of patients with gastritis and peptic ulceration. Lancet 1984; 1: 1311-1314.

2 Kozoll RA, Dekhne N. Helicobacter pylori and the pathogenesis of duodenal ulcer. I Lab Clin Med 1994; 124:623-625.

3 Vorobjova $T$, Maaroos $H-I$, Uibo $R$, Wadström $T$, Wood WG, Sipponen $P$. Helicobacter pylori: histological and serological study on gastric and duodenal ulcer patients in Estonia. Scand J Gastroenterol 1991; 26 (suppl 186): 84-89.

4 Louw JA, Falck V, van Rensburg C, Zak J, Adams G, Marks IN. Distribution of Helicobacter pylori colonisation and associated gastric inflammatory changes: difference between patients with duodenal and gastric ulcers. J Clin Pathol 1993; 46: 754-756.

5 Khulusi S, Mendall MA, Patel P, Levy J, Badve S, Northfield TC. Helicobacter pylori infection density and gastric inflammation in duodenal ulcer and non-ulcer subjects. Gut 1995; 37: 319-324.

6 Kuipers EJ, Thijs JC, Festen HPM. The prevalence of Helicobacter pylori in peptic ulcer disease. Aliment Pharmacol Ther 1995; 9: 59-69.

7 Buck GE, Gourley WK, Lee WK, Subramanyam K, Latimer JM, DiNuzzo AR. Relation of Campylobacter pyloridis to gastritis and peptic ulcer. I Inf Dis 1986; 153: 664-669.

8 Hentschel $E$, Brandstätter $G$, Dragosics $B$ et al. Effect of ranitidine and amoxycillin plus metronidazole on the eradication of Helicobacter pylori and the recurrence of duodenal ulcer. New Engl J Med 1993; 5: 308-312.

9 Bayerdörffer E, Miehlke S, Mannes GA et al. Double-blind trial of omeprazole and amoxycillin to cure Helicobacter pylori infection in patients with duodenal ulcers. Gastroenterol 1995; 108: 1412-1417.

10 Labenz J, Börsch G. Evidence for the essential role of Helicobacter pylori in gastric ulcer disease. Gut 1994; 35:19-22.

11 Seppälä K, Pikkarainen P, Sipponen P, Rivilaakso E, Gormsen $\mathrm{MH}$, and the Finnish Gastric Ulcer Study Group. Cure of peptic gastric ulcer associated with eradication of Helicobacter pylori. Gut 1995; 36: 834-837.

12 Sung JJU, Chung SCS, Ling TKW et al. Antibacterial treatment of gastric ulcers associated with Helicobacter pylori. New Engl J Med 1995; 332: 139-142.

13 Graham DY. Campylobacter pylori as a pathogenetic factor in duodenal ulcer: the case for. Scand J Gastroenterol 1989; 24 (suppl 160): 46-52.

14 Alam K, Schubert TT, Bologna SD, Ma CK. Increased density of Helicobacter pylori on antral biopsy is associated with severity of acute and chronic inflammation and likelihood of duodenal ulceration. Am J Gastroenterol 1992; 87: 424-428.

15 Levi S, Beardshall K, Haddad G, Playford R, Ghosh P, Calan J. Campylobacter pylori and duodenal ulcers: the gastrin link. Lancet 1989; i: 1167-1168. 
16 Mossi S, Meyer-Weiss $\mathrm{B}$, Renner EL, Merki HS, Gamboni G, Beglinger $\mathrm{C}$. Influence of Helicobacter pylori, sex, and age on serum gastrin and pepsinogen concentrations in subjects without and patients with duodenal ulcers. Gut 1993; 34: $752-756$.

17 El-Omar EM, Penman ID, Ardill JES, Chittajallu RS, Howie C, McColl KEL. Helicobacter pylori infection and abnormalities of acid secretion in patients with duodenal ulcer disease. Gastroenterol 1995; 109: 681-691.

18 Wyatt I, Rathbone BJ, Sobala GM, Shallcross T, Heatley RV, Axon ATR, Dixon MF. Gastric epithelium in the duodenum: its association with Helicobacter pylori and inflammation. J Clin Pathol 1990; 43: 981-986.

19 Gray SF, Wyatt JL, Rathbone BJ. Simplified techniques for identifying Campylobacter pyloridis. J Clin Pathol 1986; $39: 1279$.

20 Jonkers $D$, Houben $G$, Stobberingh E, Stockbrügger R. Ongoing gastric acid inhibition is a confounding factor in Helicobacter pylori diagnosis. Eur $\mathrm{J}$ Gastroenterol Hepatol 1997; 9: 49-53.

21 Madsen JE, Vetvik K, Aase S. Helicobacter pylori and chronic active inflammation of the duodenum and stomach in duodenal ulcer patients treated with ranitidine, misoprostol, or an acid-neutralizing agent. Scand J Gastroenterol 1991; 26: 465-470.

22 Dixon MF, Genta RM, Yardley JH, Correa P, and the Participants, Classification. and grading of gastritis. The updated Sydney system. Am J Surg Pathol 1996; 20: 1161-1181.

23 Satoh $\mathbb{K}$, Kimura K, Yoshida $Y$, Kasano T, Kihira K, Taniguchi $Y$. A topographical relationship between Helicobacter pylori and gastritis: Quantitative assessment of Helicobacter pylori in the gastric mucosa. Am J Gastroenterol 1991; 86; 285-291.

24 Bayerdörffer $\mathrm{E}$, Lehn $\mathrm{N}_{*}$ Hatz $\mathbb{R}$ et al. Difference in expression of Helicobacter pylori gastritis in antrum and body. Gastroenterol 1992; 102: 1575-1582.

25 Saïta H, Murakami M, Yoo JK et al. Link between Helicobacter pylori-associated gastritis and duodenal ulcer. Dig Dis Sc 1993; 38: 112-122.

26 Wulffen von $\mathrm{H}$, Heesemann $\mathrm{J}$, Bützow GH et al. Detection of Campylabacter pyloridis and associated IgG and IgA antibody responses in patients undergoing upper gastrointestinal endoscopy. J Clin Microbiol 1986; 24: 716-720.

27 Blaser MJ. Gastric Campylobacter-like organisms, gastritis, and peptic ulcer disease. Gastroenterol 1987; 93: 371-383.

28 Ruiz B, Correa P, Fontham TH, Ramakrishnan T. Antral atrophy, Helicobacter pylori colonization, and gastric pH. Am J Clin Pathol 1996; 105: 96-101.

29 Siurala M, Sipponen P, Kekki M. Campylobacter pylori in a sample of Finnish population: relations to morphology and functions of the gastric mucosa. Gut 1988; 29: $909-915$. 
30 Maaroos H-I, Kekki M, Villako K, Sipponen P, Tamm A, Sadeniemi L. The occurrence and extent of Helicobacter pylori colonization and antral and body gastritis profiles in an Estonian population sample. Scand J Gastroenterol 1990; 25 : 1010-1017.

31 Kekki M, Maaroos H-I, Sipponen P et al. Grade of Helicobacter pylori colonization in relation to gastritis: a six-year population-based follow-up study. Scand J Gastroenterol 1991; 21 (suppl 186): 142-150.

32 Sipponen $P$. Helicobacter pylori infection - a common worldwide environmental risk factor for gastric cancer? Endoscopy 1992; 24: 424-427.

33 Fuchs CS, Mayer RJ. Review article: gastric carcinoma. N Engl J Med 1995; 333: 3241 .

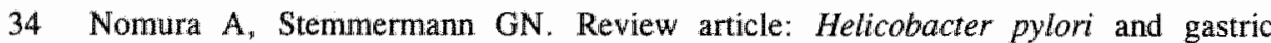
cancer. J Gastroenterol Hepatol 1993; 8: 294-303.

35 Parsonnet $\mathbf{J}$. Helicobacter pylori in the stomach - a paradox unmasked. N Engl $\mathrm{J}$ Med 1996; 335: 278-280.

36 Correa P, Schmidt BA. The relationship between gastric cancer frequency and the ratio of gastric to duodenal ulcer. Aliment Pharmacol Ther 1995; 9 (suppl 2): 13-19.

37 Hansson L-E, Nyrén O, Hsing AW et al. The risk of stomach cancer in patients with gastric or duodenal ulcer disease. N Engl J Med 1996; 335: 242-249.

38 Caselli M, Trevisani L, Aleotti A, Bovolenta MR, Stabellini G. Gastric metaplasia in duodenal bulb and Campylobacter-like organisms in development of duodenal ulcer. Dig Dis Sci 1989; 34: 1374-1378.

39 Offerhaus GJA, Noydas M, Hoedemaeker PJ. Helicobacter pylori infection of gastric mucin cell metaplasia: the duodenum revisited. I Pathol 1990; 162: 239-243.

40 Satoh K, Kimura K, Yoshida $Y$, Kasano T, Kihira K, Taniguchi Y. Relationship between Helicobacter pylori colonization and acute inflammation of the duodenal mucosa. Am J Gastroenterol 1993; 88: 360-363.

41 Wyatt I, Rathbone BJ, Dixon MF, Heatley RV. Campylobacter pyloridis and acid induced gastric metaplasia in the pathogenesis of duodenititis. J Clin Pathol 1987; 40: $841-848$.

42 Price AB. Histological aspects of Campylobacter pylori colonization and infection of gastric and duodenal mucosa. Scand J Gastroenterol 1988; 23 (suppl 142): 21-24.

43 Johnston BJ, Reed PI, Ali MH. Prevalence of Campylobacter pylori in duodenal and gastric mucosa - relationship to inflammation. Scand J Gastroenterol 1988; 23 (suppl 142): $69-75$. 


\section{Chapter VI}

Helicobacter pylori and nonHelicobacter pylori bacterial flora in gastric mucosal and tumour specimens of patients with primary gastric lymphoma

D Jonkers, I Gisbertz, A de Bruine, F. Bot, JW Arends, E Stobberingh, H Schouten, R Stockbrügger 


\section{Summary}

There is an association of Helicobacter pylori (H.pylori) with gastric mucosa-associated lymphoid tissue (MAIT) and MALT-lymphoma. Histologically, mainly non-specific stains are used to detect H.pylori, such as Haematoxylin-Eosin (HE) or modified Giemsa (MG).

In this study both a $\mathrm{MG}$ and a specific immunohistochemical stain (IMM) for H.pylori (DAKO B471) were performed on sequential slides of resection material containing tumour and non-tumorous gastric mucosa from patients with primary gastric lymphoma $(n=52)$. Special attention was paid to the presence of non-H.pylori bacterial flora diagnosed by a positive MG (according to form and localisation) and a subsequently negative IMM. On all slides bacterial density was scored semi-quantitatively (grades $0,1,2,3)$.

In total $32(61.5 \%)$ patients were H.pylori-positive by IMM and $34(65.4 \%)$ were non- $H$.pylori positive by MG. In 24 of the 34 patients the non-H.pylori flora consisted mainly of cocci, in combination with rods in 15 patients " mostly in minor quantities; in another ten patients high numbers of both cocci and different types of rods were present. Most non- $H$.pylori bacteria were localized superficially, although in 22 patients minor quantities of non-H.pylori were seen in the glandular lumina also. Analysing all patients, no differences in density of H.pylori and of non-H.pylori flora were found. Only when comparing patients with a small to those with a large cell lymphoma, a significantly higher density of $H$.pylori was found in the corpus mucosa of large cell lymphomas and a higher prevalence of non-H.pylori was found in tumour, in antrum or corpus, of patients with large cell lymphomas.

In conclusion, using joint evaluation by modified Giemsa and a H.pylori-specific immunohistochemical stain, the proportion of H.pylori positive gastric lymphoma patients was lower than in most previous publications and other bacteria were found in a relatively high proportion. The role of the non-H.pylori intragastric bacterial flora identified in this study has to be further elucidated with respect to the aetio-pathogenesis of primary gastric lymphoma. 


\section{Introduction}

Helicobacter pylori (H.pylori) has been found in the gastric non-tumorous mucosa of $50 \%$ to more than $90 \%$ of patients with primary gastric lymphoma ${ }^{1-4}$. A serological study of Parsonnet ${ }^{5}$ has shown that patients with gastric lymphoma have a significantly increased prevalence of previous H.pylori infection compared to matched controls. Furthermore, first results on eradication of H.pylori have demonstrated regression or disappearance of primary low grade gastric MALT lymphoma ${ }^{6-8}$.

In patients with gastric cancer an increased intragastric $\mathrm{pH}$ with an increased risk of bacterial overgrowth has been observed ${ }^{9-11}$. Metabolic products of bacteria such as $\mathrm{N}$-nitroso compounds, may contribute to the pathogenesis of the malignant process. It might be possible that a similar situation of reduced acidity and bacterial overgrowth occurs in patients with primary gastric lymphoma.

In histological studies of patients with primary gastric (MALT) lymphoma generally non-specific staining methods were used for the detection of H.pylori such as the Haematoxylin-Eosin or modified Giemsa stains ${ }^{1,3,4}$. In a previous study, we found a high specificity and sensitivity of an immunohistochemical stain for H.pylori ${ }^{12}$, which has been confirmed by others ${ }^{13}$.

In this study we wanted to assess the presence and distribution of the bacterial flora in gastric tissue specimens of patients with primary gastric lymphoma by microscopy using a modified Giemsa stain for the total bacterial flora (i.e. H.pylori and non-H.pylori bacterial flora), combined with a specific immunohistochemical stain for the detection of H.pylori.

\section{Material and methods}

\section{Patients and specimens}

Fifty-two patients (mean age 62.4 years; 31 male and 21 female) from ten hospitals in the provinces of Limburg and Brabant in the Netherlands with a documented primary gastric B-cell lymphoma were included in the study. For inclusion in this study, both tumour tissue and non-tumorous gastric mucosa had to be present in the surgically resected specimens $(n=50)$ or endoscopic biopsies $(n=2)$.

\section{Histology}

Serial sections of $4 \mu \mathrm{m}$ from formalin fixed and paraffin embedded specimens were cut for Haematoxylin-Eosin stain (HE), modified Giemsa stain (MG) and an 
immunohistochemical stain (IMM), respectively. HE stained sections were revised for the classification of the primary gastric lymphoma and to assess the anatomical tissue type (i.e. antral or corpus type) of the mucosa present in the specimens, which were used for the assessment of H.pylori and other bacteria. MG was performed as described by Gray et al. ${ }^{14}$ to discover intragastric bacteria. For the IMM, a purified polyclonal antibody against H.pylori (DAKO B471, ITK Diagnostics BV, Uithoorn, The Netherlands) was applied. The antiserum was used in a 1:500 dilution. Further staining was performed with biotin-conjugated swineanti-rabbit-antibodies (1:1000) (DAKO E431) as a second layer, followed by streptABC-HRP (1:1000) (DAKO K377). Sections were then stained with diaminobenzidine with $10 \%$ imidazol to intensify the reaction and were counterstained with haematoxylin.

In the MG stain, the presence of H.pylori was scored according to the S-shaped form and the localisation on or within the mucus layer as well as within the crypts. The presence of H.pylori was only accepted if IMM on consecutive slides was posilive. The presence of non-H.pylori flora was suspected in the MG stain by form and localisation of the bacteria and confirmed by negativity in the IMM.

All slides were examined completely at $400 \mathrm{x}$ magnification. If necessary a 1000x magnification was used. Both H.pylori and non-H.pylori were scored semiquantitatively and graded as follows: no bacteria found, grade 0; occasionally bacteria found, grade 1; scattered bacteria found in many high power fields, grade 2 ; and numerous bacteria found in most high power fields, grade $3^{15}$.

\section{Analysis}

Prevalence and density of $H . p y l o r i$ and non-H.pylori were compared in total and accorcling to their presence in tumour tissue or non-tumorous antral or corpus type mucosa. Differences in prevalence were analyzed using a Chi-Square test with Fisher's Exact test when necessary. Differences in density of H.pylori or nonH.pylori positive specimens were analyzed with a Mann-Whitney $U$ test. The prevalence and density of $H$.pylori and non-H.pylori in antrum compared to corpus and in tumour tissue compared to mucosa within the patients, were analyzed by paired non-parametrical tests as well.

Differences in the sex distribution and lymphoma type (small cell versus large cell gastric lymphoma) between different patient subgroups were analyzed with the Chi-Square test. Differences in age between the different groups were compared using the Mann-Whitney $U$ test or Kruskall-Wallis one-way Anova, depending on the number of groups to be compared.

A p-value of less than 0.05 was considered to be significant. 


\section{Results}

Of 52 patients included, 17 had a small cell and 35 a large cell primary gastric lymphoma according to the criteria given by Isaacson ${ }^{16,17}$. The diagnosis of MALT could be confirmed in 43 of 52 patients. The remaining nine large cell lymphomas could not further be classified as being from MALT origin because of the absence of a small cell component. Besides tumour tissue, normal appearing antral or corpus mucosa, or both types of mucosa were present for 9,8 , and 35 patients, respectively.

\section{Prevalence of Helicobacter pylori and non-Helicobacter pylori per patient}

H.pylori could be detected by IMM in 32 of the $52(61.5 \%)$ patients. Using MG 36 of $52(69.2 \%)$ patients were scored H.pylori positive. Non-H.pylori flora was detected in 34 of $52(65.4 \%)$ patients by MG. H.pylori and non-H.pylori were present simultaneously in 19 of $52(36.5 \%)$ patients, H.pylori only in $13(25.0 \%)$ and non- H.pylori flora only in 15 patients $(28.8 \%$ ). In five $(9.6 \%)$ patients no bacteria were found in any of the tissue specimens. H.pylori was only detected in the non-tumorous gastric mucosa present in the specimens, in contrast to nonH.pylori flora which was found on and within superficial tumour tissue as well as in the surrounding gastric mucosa.

For further analysis as to the prevalence and density of H.pylori, IMM results were considered as the standard for the detection of H.pylori because of the proven high specificity and sensitivity of $\mathrm{IMM}^{12,13}$.

\section{Description of non-Helicobacter pylori flora}

In 24 of 34 patients the non-H.pylori flora consisted mainly of cocci, 15 times in combination with rods. The density of cocci was higher than that of rods in nine of them. In the other ten patients, massive numbers of both cocci (grade 3) and of different types of rods (grade 3) were found. When several resection specimens were available from one patient, the bacterial forms observed were similar for each patient.

In tumour tissue the non-H.pylori flora was localised on the surface of and within the superficial layer of the tumour. When non-H.pylori flora was observed in the gastric mucosa, it was mainly localised superficially (in strains of mucus overlying the mucosa), although in 22 patients minor numbers were also seen on or within the mucus layer of the glands. In four patients coccoid bacteria were also present between H.pylori bacteria in the mucus layer of the glands. This will be coccoid forms of H.pylori, as they were found to be IMM positive. 
In addition to the bacteria observed, in 16 and 9 patients, respectively, yeast cells (median density grade 2) and mycelium and/or pseudo-mycelium threads (median density grade 3) (confirmed by Grocott stain) were seen, predominantly in the tumour area.

\section{Prevalence and density of Helicobacter pylori and non-Helicobacter pylori in antrum and corpus}

In Table VI. 1 the prevalence of H.pylori (by IMM) and non-H.pylori (by MG) in antrum and corpus specimens is given for all patients. Figure VI.1 shows the frequency of grade 1,2, and 3 as percentage of H.pylori or non-H.pylori positive specimens per anatomical site. Per patient the median gradation per anatomical site was used for the analyses of the density, if more than one specimen was available. When the median value was lower than the $75^{\text {th }}$ percentile of the gradation, we have chosen a "worst case" approach and used the $75^{\text {th }}$ percentile.

Table VI.I" Prevalences of H.pylori and non-H.pylori in antral and corpus specimens

\begin{tabular}{lllll}
\hline \multicolumn{1}{l}{ Anatomical site } & $\mathbf{n}$ & H.pylori pos & non-H.pylori pos \\
\hline Antrum & mucosa & 44 & $20(45.5 \%)$ & $24(54.5 \%)$ \\
& tumour & 36 & - & $19(52.8 \%)$ \\
\multirow{2}{*}{ Corpus } & mucosa & 43 & $27(62.8 \%)$ & $21(48.8 \%)$ \\
& tumour & 35 & - & $18(51.4 \%)$ \\
\hline
\end{tabular}

A tendency $(\mathrm{p}=0.06)$ was observed concerning a higher prevalence of H.pylori in corpus $(62.8 \%)$ compared to antral type mucosa $(43.2 \%)$. No significant differences were found in the density of H.pylori positive antrum or corpus specimens.

Non-H.pylori flora was found in antral mucosa of 24 of 44 patients $(54.5 \%)$ and in corpus type mucosa of 21 of 43 patients $(48.8 \%)$. No significant differences were found in either the prevalence or the density of this non-H.pylori flora in antral or corpus type mucosa. Moreover, both the prevalence and density of nonH.pylori flora were similar on or within tumour tissue in antrum $(50.0 \%)$ or corpus $(51.4 \%)$ compared to the normal appearing antral $(54.5 \%)$ or corpus $(48.8 \%)$ mucosa, respectively.

Comparing the presence of H.pylori with that of non-H.pylori in antrum or corpus, both types of flora were found with a similar frequency and density.

Among the patients with primary gastric lymphoma, four groups can be 
distinguished according to the bacterial floras detected: those with H.pylori only (group 1, $\mathrm{n}=13$ ), with non-H.pylori only (group 2, $\mathrm{n}=15$ ), with both H.pylori and non-H.pylori (group 3, $\mathrm{n}=19$ ) and those where no bacteria could be detected in any of the specimens (group $4, n=5$ ).

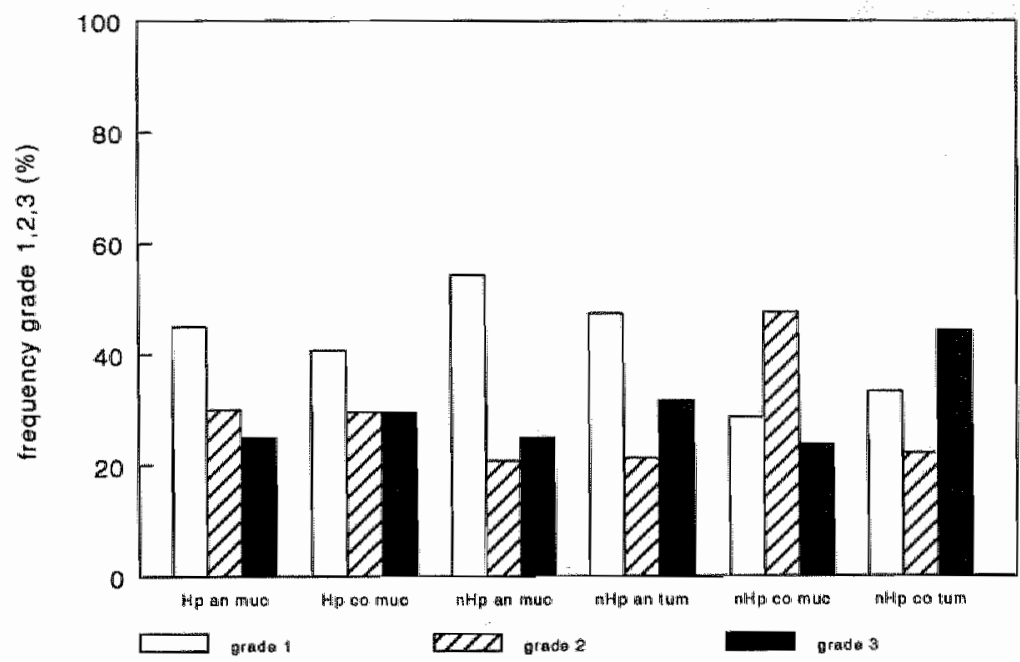

Figure VI.II: Density of H.pylori and non-H.pylori flora in antrum and corpus mucosa or tumour lissue (Percentage of grade 1,2,3 of total number of positives)

Table VI.2: Sex distribution, age and lymphoma type (small/large cell Iymphoma) of patients according to the presence of H.pylori (Hp) and/or non-H.pylori (nIllp) bacterial flora

\begin{tabular}{lllll}
\hline & $\begin{array}{l}\text { Hp only } \\
\text { gr } 1, \mathrm{n}=13\end{array}$ & $\begin{array}{l}\mathrm{nHP} \text { only } \\
\text { gr } 2, \mathrm{n}=15\end{array}$ & $\begin{array}{l}\text { both Hp/nHp } \\
\text { gr 3, } \mathrm{n}=19\end{array}$ & $\begin{array}{l}\text { no flora } \\
\text { gr 4, } \mathbf{n}=5\end{array}$ \\
\hline $\begin{array}{l}\text { Age } \\
\text { median (range) }\end{array}$ & $56(26-79)^{1}$ & $60(50-92)$ & $64(35-83)$ & $72(61-87)^{1}$ \\
$\begin{array}{l}\text { Sex } \\
\text { male/female }\end{array}$ & $10 / 3^{2}$ & $6 / 9^{2}$ & $12 / 7$ & $3 / 2$ \\
$\begin{array}{l}\text { Lymphoma type } \\
\text { small/large ceil }\end{array}$ & $7 / 6$ & $3 / 12$ & $6 / 13$ & $1 / 4$ \\
\hline
\end{tabular}

'Sign. higher age in groups 4 versus group 1 (Mann-Whitney, $p=<0.05$ )

${ }^{2} \mathrm{Sign}$ more fernales in group 2 wersus group 1 (Chi-Square, $p<0.05$ ) 
No statistical differences were observed in the distribution of small cell versus large cell gastric lymphoma between the four groups, although a trend was found for a higher number of large cell lymphomas to be present in group $2(p=0.07)$ and group $3(p=0.07)$ compared with group 1. The age of patients in group 4 was significantly higher than of group $2(p=0.04)$ and in group 2 significantly more females were present compared with group $1(p=0.048)$. No further differences concerning gender and age between the four groups were found (Table VI.2). Comparing the presence of H.pylori in group 1 with group 3, or the presence of non-H.pylori in group 2 with group 3, no significant differences were found in the prevalence or density of H.pylori or non-H.pylori in antrum or corpus. Also within each group no differences were observed comparing antrum with corpus and comparing H.pylori with non-H.pylori (Table VI.3, Figure VI.2).

Table VI.3: Prevalence of H.pylori and non-H.pylori flora in antrum and corpus of patients with H.pylori only, non-H.pylori only or both types of flora

\begin{tabular}{|c|c|c|c|c|}
\hline & & $\begin{array}{l}\text { Hp only } \\
\text { posin }(\%)\end{array}$ & $\begin{array}{l}\text { nHp only } \\
\text { pos/n (\%) }\end{array}$ & $\begin{array}{c}\text { both Hp/nHp } \\
\text { pos/n }(\%)\end{array}$ \\
\hline \multicolumn{5}{|c|}{ H.pylori } \\
\hline $\begin{array}{l}\text { corpus } \\
\text { non- } H_{4},\end{array}$ & $\begin{array}{l}\text { mucosa } \\
\text { lori }\end{array}$ & $11 / 12(91.7)$ & $\cdots$ & $16 / 17(94.1)$ \\
\hline \multirow[t]{2}{*}{ antrum } & mucosa & $\cdots$ & $11 / 14(78.6)$ & $13 / 15(86.7)$ \\
\hline & tumour & $\cdots$ & $10 / 12(83.3)$ & $9 / 13(69.2)$ \\
\hline \multirow[t]{2}{*}{ corpus } & mucosa & $\ldots$ & $6 / 11(54.5)$ & $15 / 17(88.2)$ \\
\hline & tumour & $\ldots$ & $7 / 8(87.5)$ & $11 / 16(68.8)$ \\
\hline
\end{tabular}



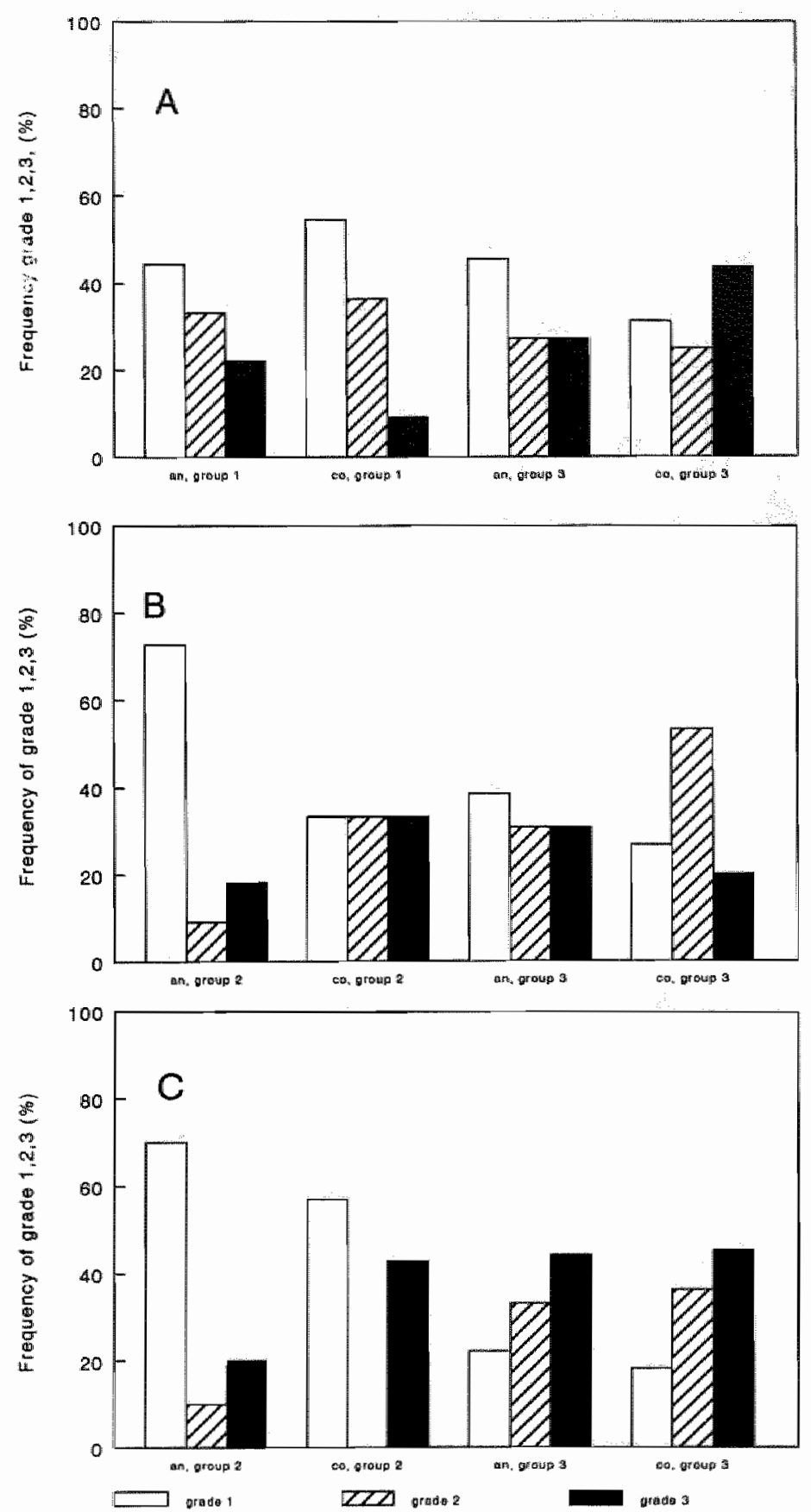

Figure VI.2: Density of H.pylori (A) or non-H.pylori in gastric mucosa (B) and tumour tissue (C) of patients with only H.pylori (group 1) or only non-H.pylori (group 2) compared with patients with both H.pylori and non-H.pylori (group 3) 


\section{Helicobacter pylori and non-Helicobacter pylori flora in small versus large cell gastric Iymphoma}

In total 17 patients had a small (10 male/7 female, median age 55 (26-83) years), and 35 patients had a large cell gastric lymphoma ( $21 \mathrm{male} / 14$ female, median age 67 (35-92) years). No significant differences were found in the distribution of males and females in both groups. However, patients with a large cell lymphoma were significantly older (Mann-Whitney, $p=0.03$ ) than those with a small cell lymphoma.

Table V1.4: Prevalente (\%) of Hpylori (by IMM) and non-H.pylon (by MG) in patients with smal] or large cell primary gastric lymphoma

\begin{tabular}{lcc}
\hline & $\begin{array}{c}\text { Small cell }(\mathbf{n}=17) \\
\text { pos/n }(\%)\end{array}$ & $\begin{array}{c}\text { Large cell }(\mathbf{n}=35) \\
\text { pos/n }(\%)\end{array}$ \\
\hline Hp antrum mucosa & $7 / 14(50.0 \%)$ & $13 / 30(43.3 \%)$ \\
Hp corpus mucosa & $12 / 16(75.0 \%)$ & $15 / 27(55.0 \%)$ \\
nHp antrum mucosa & $6 / 14(42.9 \%)$ & $18 / 30(60.0 \%)$ \\
nHp antrum tumour & $3 / 12(25.0 \%)$ & $16 / 24(66.7 \%)$ \\
nHp corpus mucosa & $7 / 16(43.8 \%)$ & $14 / 27(51.9 \%)$ \\
nHp corpus tumour ${ }^{2}$ & $4 / 14(28.6 \%)$ & $14 / 21(66.7 \%)$ \\
\hline
\end{tabular}

"Chi-Square, $p=0.02 ;{ }^{2}$ Chi-Square, $p=0.03$

The prevalence of H.pylori was similar in antrum and corpus mucosa of patients with small cell versus patients with large cell lymphomas (Table VI.4). The density of H.pylori was significantly higher $(\mathrm{p}=0.009)$ in corpus mucosa of patients with a large cell compared with those with a small cell lymphoma (Figure VI.3).

Regarding the non-H.pylori flora, the prevalence was higher in tumour of antrum or corpus in patients with a large compared to those with a small cell lymphoma (Table VI.4) (antrum, $p=0.02$; corpus, $p=0.03$ ). Further differences in the prevalence or density of non-H.pylori were not found. 

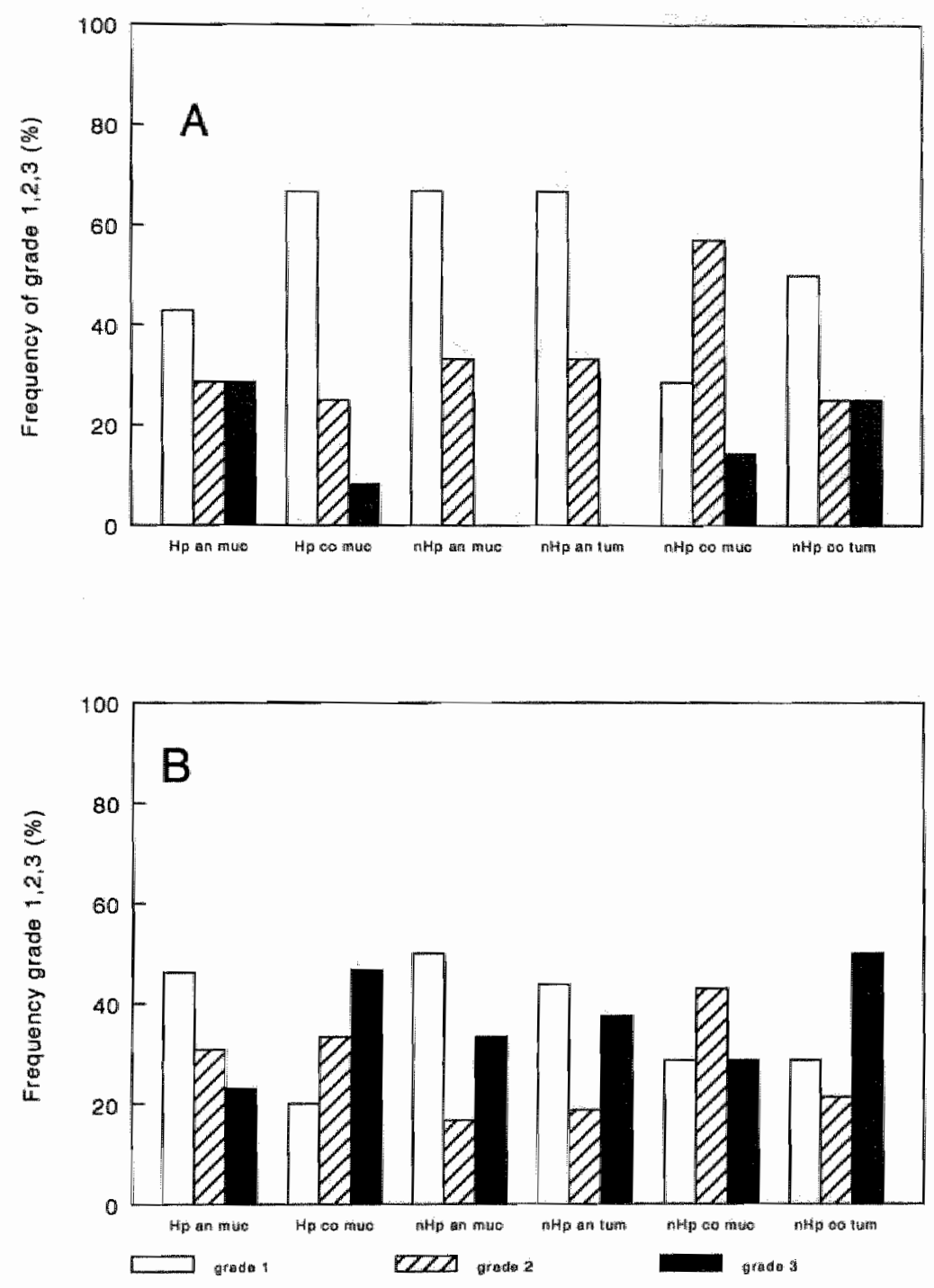

Figure VI.3: Density of H.pylori and non-H.pylori nora in antrum and corpus of patients with a small cell (A) or large cell primary gastric lymphoma (B) (Percentage of grade 1,2,3 of total number of positives:) 


\section{Discussion}

Using a joint evaluation with the non-specific MG stain for the total intragastric bacterial flora and a specific immunohistochemical stain for the detection of H.pylori, non-H.pylori flora was detected in $67.3 \%$ and H.pylori in $61.5 \%$ of patients with primary gastric lymphoma. Both types of bacterial flora were simultaneously present in $36.5 \%$ of patients. H.pylori was only found in nontumorous gastric mucosa, whereas non-H.pylori flora was present in antrum and corpus mucosa as well as on and within the surface of the lymphomas.

In this study using a specific immunohistochemical stain, fewer patients with primary gastric lymphoma were found to be H.pylori-positive compared to other studies ${ }^{1,3,18}$. An explanation for this discrepancy could be that the use of MG and HE has overestimated the H.pylori frequency in comparison with the H.pylori specific IMM stain as used in this study. Secondly, it cannot be excluded that real differences in the prevalence of H.pylori exist between different geographical regions as clescribed by Doglioni et al. ${ }^{19}$. Furthermore, it is possible that H.pylorinegative patients at present have previously been positive, as it has been described in patients with lymphocytic gastritis ${ }^{20.21}$. Earlier H.pylori-positivity can theoretically be controlled for by serology. Unfortunately, it was not possible to assess seropositivity for H.pylori in this study as we performed a retrospective study on histological material only derived from ten different hospitals.

As the archival material of this study was obtained before 1992, H.pylori eradication therapy was unlikely to be generally applied. Eradication is therefore not the cause of the low H.pylori prevalence found in this study. Relatively low H.pylori prevalences in patients with primary gastric lymphoma have recently also been described by others ${ }^{2,4}$. The prevalence of intragastric H.pylori-positivity in this study is not much different from that found in patients with non-ulcer dyspepsia or in healthy blood donors of the same geographical region of a similar age, where H.pylori was present in $49.6 \%$ and $58.3 \%$, respectively, using serology $y^{22}$. This has to be taken into account for the discussion of the aetiological role of H.pylori in gastric lymphoma.

To our knowledge, this is the first study to focus on the presence of nonH.pylori flora besides H.pylori in primary gastric lymphoma. Non-H.pylori flora occurred in a surprisingly high proportion of patients with a primary gastric lymphoma. Several explanations for this phenomenon can be put forward:

- Colonization with non-H.pylori flora can be a consequence of a decreased gastric acid secretion due to atrophic gastritis. Mucosal atrophy of the gastric body has been described in lymphocytic gastritis which is common in patients with primary gastric lymphoma ${ }^{21,23}$. 
- The tumour itself can cause decreased acid secretion by involvement of acid secreting gastric mucosa, and altered gastric motility as a consequence of tumour infiltration can lead to a stagnant loop syndrome with bacterial overgrowth. Theoretically, the non-H.pylori flora found in non-tumorous gastric mucosa could be spreading out from the tumour area.

- Finally, patients with primary gastric lymphoma might have gastrointestinal complaints and may have been treated with gastric acid inhibitors, resulting in an increased intragastric $\mathrm{pH}$ and bacterial overgrowth ${ }^{24,25}$.

Hitherto, little attention has been paid to the distribution of H.pylori and other bacteria in the stomach of gastric lymphoma patients. In this patient group the prevalence of H.pylori was somewhat higher in corpus than in antral type mucosa (although not significant). A similar situation is found during acid inhibitory treatment for H.pylori associated peptic disorders, where a displacement of H.pylori from antrum towards corpus can occur ${ }^{26.27}$. The finding of a trend of a greater number of H.pylori positive corpus- than antrum-specimens in patients with primary gastric lymphomas can support the presence of a reduced intragastric acidity in the present study population. The H.pylori density in corpus mucosa of patients with large cell lymphomas is significantly higher than in patients with small cell lymphomas. This may indicate that there can be a more prolonged or stronger reduction in gastric acidity in the former group of patients. In addition, this patient group is significantly older than those with a small cell lymphoma and therefore a longer duration of the H.pylori infection with subsequent atrophy may exist.

For non-H.pylori bacteria no difference in distribution was found between antrum and corpus or between tumour tissue and gastric mucosa analysing all patients. This homogeneous distribution of non-H.pylori flora in the stomach supports the presence of hypochlorhydria or achlorhydria in the stomach as an explanation for the presence of these microorganisms. However, a significantly higher prevalence of non- $H$.pylori was found in tumour tissue of patients with a large cell compared with small cell lymphoma.

H.pylori and non-H.pylori bacterial flora were both found with a similar frequency, density and distribution. No differences were found in the subgroups of patients with H.pylori only, non-H.pylori only, and the joint occurrence of H.pylori and non-H.pylori. This suggests that there is no direct relation between the two types of flora and that they may be independent from each other.

The role of the non-H.pylori bacteria in relation to primary gastric lymphoma is not clear yet. To our knowledge only the study of Blackburn et al ${ }^{28}$ has some relation to this subject; in that study an increased mortality from both gastric cancer and leukaemia was found in patients with pernicious anaemia, a condition 
known to be associated with intragastric bacterial overgrowth ${ }^{29,30}$.

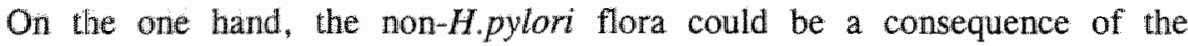
functional situation in gastric lymphoma patients, resulting from the stagnant loop situation and/or reduced gastric acidity. On the other hand, this flora may also play a role in the development of the lymphomas by being an antigenic stimulus for an inflammatory response. In parallel to gastric cancer, this bacteria could also be responsible for the production of toxic or carcinogenic metabolites, such as $\mathrm{N}$-nitroso-compounds $\mathrm{s}^{11}$. The higher prevalence of non-H.pylori flora in tumour tissue of large cell compared with small cell lymphomas may be a consequence of differences in tumour mass and/or gastric acidity between both groups as well as the higher age of the former group of patients. However, it cannot be excluded that the non-H.pylori flora contributes to the development of a large cell lymphoma. Further studies on the role of the non-H.pylori flora in the development and progression of small and large cell primary gastric lymphoma are therefore required.

Independent of the possible pathogenetic role of the non-H.pylori flora found in gastric lymphoma, the high frequency and concentrations of this flora in patients with primary gastric lymphoma may interfere with the detection of H.pylori and possibly lead to overestimation of H.pylori ${ }^{12}$. We therefore recommend the use of a H.pylori-specific immunohistochemical staining for H.pylori for further studies on the role of this bacterium in the pathogenesis and therapy of gastric MALTlymphomas. 


\section{References}

1 Wotherspoon AC, Ortiz-Hidalgo C, Falzon MR, Isaacson PG. Helicobacter pylon" associated gastritis and primary B-cell gastric lymphoma. Lancet 1991; 338: 1175-1176.

2 Fischbach W, Kolve ME, Dragosics $B$ and the German-Austrian Gastrointestinal Study Group. Prevalence of Helicobacter pylori infection in primary gastric lymphoma of the MALT: There is a difference between low grade and high grade lymphoma. Gut 1995; 37(suppl 2): A75.

3 Muller AF, Maloney A, Jenkens D et al. Primary gastric lymphoma in clinical practice 1973-1992. Gut 1995; 36: 679-683.

4 Karat D, O'Hanlon DM, Hayes N, Scott D, Rames SA, Griffin SM. Prospective study of Helicobacter pylori infection in primary gastric lymphoma. Br J Surg 1995; 82: $1369-1370$.

5 Parsonnet J, Hansen S, Rodriguez et al. Helicobacter pylori infection and gastric lymphoma. N Engl J Med 1994; 330: 1267-1271.

6 Wotherspoon AC, Doglioni C, Diss TC, Pan L, Moschini A, de Boni $M$. Regression of primary low-grade B-cell gastric lymphoma of mucosa-associated lymphoid tissue type after eradication of Helicobacter pylori. Lancet 1993; 342: 575-577.

7 Weber DM, Dimopoulos MA, Anandu DP, Pugh WC, Steinbach G. Regression of gastric lymphoma of mucosa-associated lymphoid tissue with antibiotic therapy for Helicobacter pylori. Gastroenterol 1994; 107: 1835-1838.

8 Roggero E, Zucca E, Pinotti G et al. Eradication of Helicobacter pylori infection in primary low-grade gastric lymphoma of mucosa-associated lymphoid tissue. Ann Intern Med 1995; 122: 767-769.

9 Kuster G, Remine W, Dockerty M. Gastric cancer in pernicious anemia and in patients with and without achlorhydria. Ann Surg 1972; 175: 783-789.

10 Muscroft TJ, Deane SP, Youngs D, Burdon DW, Keighley MRB. The microflora of the postoperative stomach. Br J Surg 1981; 86:560-564.

11 Houben GMP, Stockbrügger RW. Bacteria in the aetio-pathogenesis of gastric cancer: A review. Scand J Gastroenterol 1995; 30 (suppl 212): $13-18$.

12 Jonkers $\mathrm{D}$, Houben $\mathrm{P}$, Stobberingh $\mathrm{E}$, Stockbrügger $\mathbb{R}$. Ongoing gastric acid imhibition is a confounding factor in Helicobacter pylori diagnosis. Eur J Gastroenterol Hepatol 1997: 9: 49-53.

13 Few MJ, Codd J, Marker AJ. Grading Helicobacter pylorl infection in gastric biopsies. J Pathol 1996; 178(suppl): 16A.

14 Gray SF, Wyatt JL, Rathbone BJ. Simplified techniques for identifying Campylobacter pyloridis. J Clin Pathol 1986; 39: 1279.

15 Marshall BJ, Warren JR. Unidentified curved bacilli in the stomach of patients with gastritis and peptic ulceration. Lancet 1984; i: 1311-1314. 
16 Isaacson PG, Spencer J. Malignant lymphoma of mucosa-associated lymphoid tissue. Histopathol 1987; 11: 445-462.

17 Isaacson PG. Lymphomas of mucosa-associated lymphoid tissue (MALT). Histopathol 1990; 16: 617-619.

18 Eidt S, Stolte M. Evidence of a malignant cycle in early gastric lymphoma. Endoscopy 1994; 26: 299-302.

19 Doglioni $\mathrm{C}$, Wotherspoon $\mathrm{AC}$, Moschini $\mathrm{A}$, de Boni $\mathrm{M}$, Isaacson $\mathrm{PG}$. High incidence of primary gastric lymphoma in northeastern Italy. Lancet 1992; 339: 834-835.

20 Karnes WE, Samloff IM, Siurala $M$ et al. Positive serum antibody and negative tissue staining for Helicobacter pylori in subjects with atrophic body gastritis. Gastroenterol 1991; 101: 167-174.

21 Niemelä S, Karttunen T, Kerola T, Karttunen R. Ten year follow up study of lymphocytic gastritis: further evidence on Helicobacter pylori as a cause of lymphocytic gastritis and corpus gastritis. J Clin Pathol 1995; 48: 1111-1116.

22 Loffeld RJLF, Stobberingh E, Van Spreeuwel JP, Flendrig JA, Arends JW. The prevalence of anti-Helicobacter (Campylobacter) antibodies in patients and healthy blood donors. I Med Microbiol 1990; 32: 105-109.

23 Miettinen, A, Kartunen TJ, Alavaikko M. Lymphocytic gastritis and Helicobacter pylorl infection in gastric lymphoma. Gut 1995; 37: 471-474.

24 Stockbrügger RW, Cotton PB, Eugenides N, Bartholomew BA, Hill MJ, Walters $\mathrm{CL}$. Intragastric nitrites, nitrosamines, and bacterial overgrowth during cimetidine treatment. Gut 1982; 23: 1048-1054.

25 Verdu E, Viani $F$, Armstrong $D$ et al. Effect of omeprazole on intragastric bacterial counts, nitrates, nitrites, and $\mathrm{N}$-nitroso compounds. Gut 1994; 35: 455-460.

26 Kuipers EJ, Uyterlinde AM, Pena AS et al. Increase of Helicobacter pyloriassociated corpus gastritis during acid suppressive therapy: Implications for longterm safety. Am J Gastroenterol 1995; 90: 1401-1406.

27 Lôgan RPH, Walker MM, Misiewicz Jj, Gummett PA, Karim QN, Baron JH. Changes in the intragastric distribution of Helicobacter pylori during treatment with omeprazole. Gut 1995; 36: 12-16.

28 Blackburn EK, Callender SI, Dacie JV et al. Possible association between pernicious andemia: a prospective study of 1625 patients with a note on the very high incidence of stomaclh cancer. Int J Cancer 1968; 3: 163-170.

29 Dolby JM, Webster ADB, Borriello SP, Barclay FE, Bartholomew BA, Hill MJ. Bacterial colonization and nitrite concentration in the achlorhydric stomachs of patients with primary hypogammaglobulinaemia or classical pernicious anaemia. Scand J Gastroenterol 1984; 19: 105-110.

30 Stockbrigger $\mathrm{RW}$, Cotton $\mathrm{PB}$, Menon $\mathrm{GG}$ et al. Pernicious anaemia, intragastric bacterial overgrowth and possible consequences. Scand J Gastroenterol 1984; 19: $355-364$. 


\section{Chapter VII}

\section{The role of Helicobacter pylori and non-Helicobacter pylori intragastric bacterial flora in gastric cancer: a study in 39 newly diagnosed patients}

D Jonkers, G Houben, W Hameeteman, E Stobberingh, A de Bruine, JW Arends, I Biemond, R Stockbrügger 


\section{Summary}

Helicobacter pylori (H.pylori) is associated with gastric cancer as it may initiate a cascade towards gastric cancer. In achlorhydric atrophic gastritis, H.pylori is rarely found, but non-H,pylori bacterial flora is frequently occurring.

In 39 consecutive patients with gastric cancer, antral and corpus biopsies were obtained for the histological classicification of H.pylori by immunohistochemistry (IMM) and non-H.pylori bacterial flora by the modified Giemsa (MG) (according to form, location and negative IMM). In 21 patients, biopsies and/or gastric juice were also taken for culture of non-H.pylori flora. Current and previous H.pylori infection was screened for by $\operatorname{lgG}$ and IgA Elisa, and Western blotting. In addition, fasting serum gastrin levels were determined using radioimmunoassays.

H.pylori was detected by IMM in $21(53.8 \%)$, by IgG in $22(56.4 \%)$, by IgA in 13 (33.3\%), and by Western blotting in $29(74.4 \%)$ of 39 patients. All IgG, IgA and IMM positive patients were also Western blotting positive. Eight patients $(20.5 \%)$ were serologically H.pylori positive without current histological H.pylori infection and ten patients $(25.6 \%)$ were negative by both histology and serology. Non-H.pylori flora was deteced by $\mathrm{MG}$ in 27 of $39(69.2 \%)$ and by culture in 14 of $21(66.7 \%)$ patients. NonH.pylori flora occurred with a simillar frequency in Western blotting positive as in Western blotting negative patients. Elevated gastrin levels and antrum-sparing atrophic gastritis were more frequent in H.pylori negative than in H.pylori positive patients, indicating a possible role of atrophic gastritis of type A.

In about $25 \%$ of gastric cancer patients no prior or current H.pylori infection could be demonstrated. In another $20 \%$ only serological evidence of $H$.pylori was found, indicating a previous infection. Non-H.pylori was found in two-thirds of all patients regardless of the $H$.pylori status. The non- $H$.pylori flora may result from reduced intragastric acidity, partly due to type $\mathrm{A}$ atrophic gastritis and should be considered as a factor contributing to the development of gastric cancer, possibly via the formation of $\mathrm{N}$-nitroso compounds. 


\section{Introduction}

Presently there is little doubt about the association between Helicobacter pylori (H.pylori) infection and the risk of gastric cancer. In serological studies, the odds ratio of a H.pylori positive patient to develop gastric cancer appears to be 2.6 to 6.0 that of a H.pylori negative person ${ }^{1-5}$. An even higher odds ratio of 13.3 was found for gastric cancer patients under the age of 40 years $^{6}$. H.pylori is associated with chronic antral gastritis, which on long-term may progress towards chronic atrophic gastritis and intestinal metaplasia, ${ }^{7,8}$. Both of the latter conditions are related to an increased risk of gastric cancer, especially of the intestinal type $e^{7.9-11}$. However, mucosal atrophy and intestinal metaplasia are inversely related to an actual presence of H.pylori in the gastric mucosa. ${ }^{7.12,13}$; this means that H.pylori may initiate the pathogenetic sequence towards gastric cancer but must not necessarily play a role throughout the entire proces.

Only a small proportion of $H$.pylori-positive subjects will develop gastric cancer ${ }^{14}$. Therefore other factors - for example genetic and environmental - will also play a role in the aetio-pathogenesis of gastric cancer. A low vitamin C intake ${ }^{15-17}$, a high salt intake ${ }^{16,18,19}$ and food rich in nitrates and nitrites ${ }^{20-23}$ are associated with an increased risk of gastric cancer. Also high serum gastrin levels may play a role in the gastric carcinogenesis via induction of ECL-cell hyperplasia and subsequent carcinoid formation ${ }^{24,25}$.

Hypergastrinaemia is found in antrum-sparing atrophic gastritis with or without pernicious anaemia, so-called "type A" gastritis. High serum gastrin levels have been used to screen for atrophic type A gastritis ${ }^{26}$. Mucosal atrophy in both antrum and corpus gastritis A and B will be characterized by a low or normal serum gastrin ${ }^{27}$.

We have recently shown that non-H.pylori bacterial flora is present in the stomach of patients with primary gastric lymphoma in a high frequency and concentration $^{28}$. Intragastric bacterial overgrowth is also found in clinical situations which may precede the development of gastric cancer, such as atrophic gastritis and pernicious anaemia ${ }^{29,30}$. Intragastric bacteria may contribute to gastric carcinogenesis by formation of potentially carcinogenic $\mathrm{N}$-nitroso compounds from nitrates and nitrites ${ }^{29,30.32}$.

This was the reason to investigate the simultaneously the past and current presence of H.pylori and the current presence of non-H.pylori intragastric bacterial flora in a consecutive series of newly diagnosed gastric cancer patients by histology, microbiology, and serology. In addition, H.pylori positive and H.pylori negative patients were compared according to serum gastrin levels and the presence of antrum-sparing atrophic gastritis. 


\section{Material and methods}

\section{Patients}

From January 1992 to December 1994, in a prospective study, all patients suspected to have gastric cancer underwent upper gastrointestinal endoscopy. Of the 82 patients with a confirmed diagnosis of gastric adenocarcinoma, 39 had a complete set of serum samples and gastric biopsy specimens and were included in this study.

During endoscopy fasting intragastric $\mathrm{pH}$ of the patients was measured using pH-paper strips with grading steps of 0.5 from $\mathrm{pH} 0$ to $\mathrm{pH} 14$ (Schleicher \& Schüll GmbH; Dassel, Germany).

\section{Histological assessment of the intragastric bacterial flora}

Antrum and corpus mucosal biopsies were obtained during endoscopy, fixed in formalin and embedded in paraffin. Serial sections were cut for HaematoxylinEosin stain (HE), modified Giemsa stain (MG) ${ }^{33}$ and immunohistochemistry $(\mathrm{IMM})^{34}$. Adenocarcinoma were classified as intestinal or diffuse type on HE stained sections $^{35}$ and non-tumorous antrum and corpus biopsies were scored for the presence of mucosal atrophy according to the Sydney classification ${ }^{36}$.

For the detection and histological classification of the intragastric bacteria, the IMM and MG were used. IMM with a purified polyclonal antiserum (DAKO B471, ITK diagnostics BV, Uithoorn, The Netherlands) was used to detect H.pylori. MG was used to screen for the presence of bacteria, and for preliminary differentiation between $H$.pylori and non-H.pylori flora on the basis of morphology and location. In MG positive patients, presence of non-H.pylori bacteria were assumed when an IMM stain of an adjacent section was H.pylori-negative on that position.

\section{Microbiological assessment of the intragastric bacterial flora}

From a randomly selected subgroup of patients $(n=21)$ biopsies of antrum and/or corpus and gastric juice were also cultured. Biopsies were washed thrice in sterile saline to remove contaminating flora ${ }^{37}$ and transferred to agar plates with a sterile forceps. Blood agar plates to assess total aerobic bacterial growth were inoculated using the five segments method ${ }^{38}$. Oropharyngeal flora and Enterobacteriacea were identified using standard microbiological methods ${ }^{39}$. Oropharyngeal flora included Neisseria spp., Streptococci spp., and Corynebacterium spp. 


\section{Helicobacter pylori serology}

Shortly after endoscopy, blood samples were taken after an overnight fast. The samples were centrifuged and the sera were stored immediately at $-20^{\circ} \mathrm{C}$ until further analysis. IgG and IgA antibodies against H.pylori were detected with commercial Elisa assays (Pyloriset EIA-G, Pyloriset EIA-A) (Imphos BV, Zambon group, Amersfoort, The Netherlands). The assays used an extracted whole antigen preparation. All 39 samples were tested within one assay. The cut off values for positivity were used according to the manufacturers" instructions. Patients with a serum titer $\geq 300$ units for IgG and $\geq 250$ units for IgA were considered to be H.pylori positive.

Furthermore, a commercial Western blotting for IgG (Helicoblot 2.0, Imphos BV, Zambon Group, Amersfoort, The Netherlands) was performed in duplo with heat-inactivated serum samples. Bands were present for $19.5,26.5,30,35,89$ (vacA), and $116 \mathrm{kD}$ (cagA) proteins. When two bands of the $19.5,26.5$, or $30 \mathrm{kD}$ proteins, or any of the bands among the 35,89 , or $116 \mathrm{kD}$ proteins were positive, the patient was considered to be H.pylori positive (as indicated by the manufacturer). H.pylori positive and negative control sera were included each time the test was performed.

\section{Serum gastrin}

Serum gastrin was determined using a radioimmunoassay ${ }^{40}$. The reference value for normality was $<85 \mathrm{pg} / \mathrm{ml}$.

\section{Statistical analyses}

For the purpose of this study, the patient was considered to either be or to have been H.pylori-infected when one or several of the H.pylori-specific tests (IMM, IgG, IgA or Western blotting) were positive. Comparison of gender, tumour type and tumour site (i.e. antrum versus corpus), the presence of antrum-sparing atrophic gastritis and the prevalence of non-H.pylori bacteria in relation to the prevalence of H.pylori were analyzed by a Chi-Square test, if necessary with the Fisher's exact test. The intragastric $\mathrm{pH}$, age, and serum gastrin levels in H.pylori positive patients were compared with H.pylori negative patients using the MannWhitney U test. A p-value less than 0.05 was considered to be significant.

\section{Results}

Complete serological and histological data were available for 39 gastric cancer 
patients, 19 male and 20 female with a median age of 76 years (range 48 to 93 ). The fasting intragastric pH was measured at endoscopy in 28 patients. Median $\mathrm{pH}$ was 6.3 (range $1.0-8.0$ ). In 21 patients $(75.0 \%$ ), the $\mathrm{pH}$ was above 3.5 .

The tumour was located in the antrum of 10 , in the corpus/cardia of 23 , and in both antrum and corpus of 5 patients; one patient had a Billroth II stomach. Thircy patients had an intestinal type gastric adenocarcinoma and nine a diffuse rype. In Table VII.1 the distribution of the tumour site according to the tumour type is given. The intestinal type of gastric cancer was more frequently located in the corpus than the diffuse type of gastric cancer $(p<0.05)$.

\section{Histological assessment of intragastric bacteria}

At least two biopsy specimens of non-tumorous gastric mucosa were present per anatomical site in 37 patients. From two patients only one non-tumorous corpus biopsy was available.

Using IMM, H.pylori was found in antrum and/or corpus of $21(53.8 \%)$ patients. Non-H.pylori flora was identified in $27(69.2 \%)$ patients by the combined MG and IMM stains, H.pylori only, non-H.pylori bacteria only, or both types of flora were found in $7(17.9 \%), 13(33.3 \%)$, and $14(35.9 \%)$ patients, respectively. In the remaining five patients $(12.8 \%)$ no bacteria were detected by histology.

Table VII.1: The occurrence of the tumour sites according to the tumour type (intestinal versus diffuse)

\begin{tabular}{lcc}
\hline Tumour site & $\begin{array}{c}\text { Intestinal type } \mathbf{n}=\mathbf{3 0} \\
\mathbf{n}(\%)\end{array}$ & $\begin{array}{c}\text { Diffuse type } \mathbf{n}=\mathbf{9} \\
\mathbf{n}(\%)\end{array}$ \\
\hline corpus' & $21(70.0 \%)$ & $2(22.2 \%)$ \\
antrum & $5(16.7 \%)$ & $5(55.5 \%)$ \\
corpus/antrum & $3(10.0 \%)$ & $2(22.2 \%)$ \\
BII stomach & $1(3.3 \%)$ & $-(0.0 \%)$ \\
\hline
\end{tabular}

1 Intestinal type adenocarcinoma were significamtly more frequent in corpus than diffuse type: Chi-Square $p<0.05)$

\section{Microbiological assessment of the intragastric bacterial flora}

In 19 patients, biopsies were present for culture. In another two patients only gastric juice was obtained for culture. Gastric biopsy cultures were positive in 12 of $19(63.2 \%)$ patients: oropharyngeal flora only was found in nine patients; Enterobacteriaceae only were found in two patients (Klebsiella spp., Escherichia 
coli); in one patient both oropharyngeal flora and Klebsiella spp. were cultured. Of the two patients with gastric juice only, culture showed oropharyngeal flora in one; in the other patient both oropharyngeal and Escherichia coll were found.

In 10 of these 12 biopsy culture positive patients $(83.3 \%)$, non-H.pylori flora was also demonstrated in the MG stain. Two patients were culture positive but MG negative. Another four patients were culture negative, but MG positive for nonH.pylori flora.

\section{Helicobacter pylori serology}

Using Western blotting, 29 of 39 patients $(74.4 \%)$ were found to be H.pylori positive. In 26 of 29 Western blotting positive patients $(89.7 \%$ ), antibodies against the $116 \mathrm{kD}$ band for cagA were present. $\operatorname{IgG}$ and $\operatorname{IgA}$ antibodies were detected with Elisa assays in 22 patients $(56.4 \%)$ and 13 patients (33.3\%), respectively (Figure VII.1).

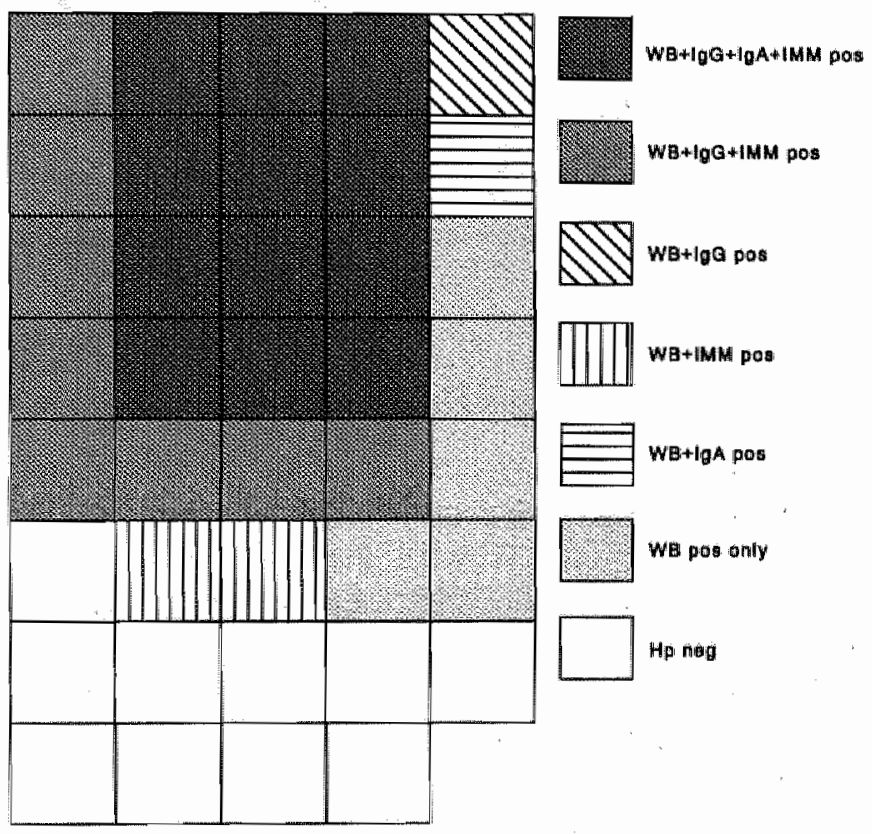

Figure VII.1: Presence of H.pylori by Western bloting, IgG, IgA, and immuniohistocliemistry for 39 gastric cancer patients 
No IgG-positive or IgA-positive patient were missed by Western blotting. Five patients were only Western blotting positive and negative with the IgG and IgA tests (Figure VII 1). An example of a H.pylori-positive and a H.pylori-negative Western blotting is shown in Figure VII. 2.

No IMM positive patients were missed by Western blotting, but two and nine IMM positive patients were IgG- and IgA-negative, respectively. Six Western blotting positive patients and three IgG positive patients were IMM negative (Figure VII.1).

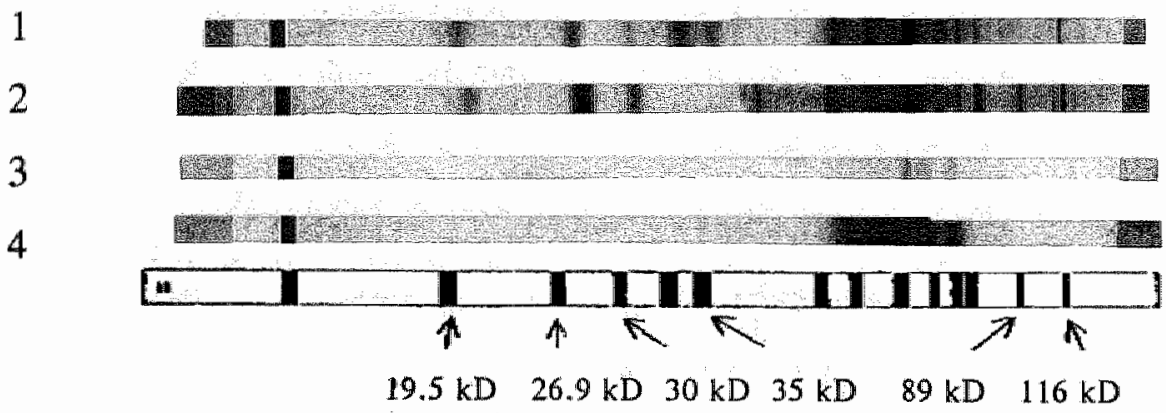

Figure VII.2: Examples of H.pylori positive (no. 1 and 2) and H.pylori negative results (no. 3 and 4) by Western blotting

\section{Helicobacter pylori positive versus Helicobacter pylori negative patients}

In total, 29 patients were H.pylori positive by one or several tests (always positive by Western blotting). Ten patients were H.pylori negative both by histology and by all serology tests. Comparing Western blotting-positive with Western blottingnegative patients (Table VII.2) no significant differences were found according to age, gender and fasting intragastric pH. However, H.pylori was found significantly more often in diffuse than intestinal type carcinoma patients $(\mathrm{p}<0.05)$. The presence of non-H.pylori flora was as frequently found in H.pylori-positive as H. pylori-negative patients.

Comparing gastric cancer patients according to the type and site of the tumour, a similar distribution of H.pylori and non-H.pylori flora was found in all groups. However, the tumour of patients with a cagA positive strain was significantly more often located in the antrum than in the corpus $(p<0.05)$. Furthermore, intestinal type patients tended to be older than diffuse ones $(p=0.06)$ 
and patients with a tumour in the corpus were older than those with a tumour in the antrum $(\mathrm{p}<0.05)$.

In ten $H$.pylori-negative patients, non-H.pylori bacteria were found in seven patients $(70.0 \%)$. Of the eight patients $H$.pylori-positive by serology only, nonH.pylori bacteria were present in six patients $(75.0 \%)$.

Table VII.2: Patient characteristics and presence of non-H.pylori bacterial flora in H.pylori-positive and H.pylori-negative patients (by Western blotting)

\begin{tabular}{|c|c|c|c|c|}
\hline \multirow[b]{2}{*}{ Age } & \multicolumn{2}{|c|}{$\begin{array}{l}\text { H.pylari positive } \\
\mathrm{m}=29\end{array}$} & \multicolumn{2}{|c|}{$\begin{array}{l}\text { H.pylori negative } \\
\mathrm{n}=10\end{array}$} \\
\hline & 75 & $(51-93)$ & 80 & $(48-90)$ \\
\hline $\begin{array}{l}\text { Sex } \\
\text { male/female }\end{array}$ & $14 / 15$ & & $5 / 5$ & \\
\hline $\begin{array}{l}\text { pH g.juice } \\
\text { median(range) }\end{array}$ & $\begin{array}{l}\mathrm{n}=20 \\
6.8\end{array}$ & $(1.5-8.0)$ & $\begin{array}{l}\mathrm{n}=8 \\
5.5\end{array}$ & $(1.0-7.0)$ \\
\hline $\begin{array}{l}\text { Tumour location } \\
\text { corpus } \\
\text { antrum } \\
\text { antrum/corpus } \\
\text { BII }\end{array}$ & $\begin{array}{l}14 \\
9 \\
5 \\
1\end{array}$ & $\begin{array}{l}(48.3 \%) \\
(31.0 \%) \\
(17.2 \%) \\
(3.4 \%)\end{array}$ & $\begin{array}{l}9 \\
1\end{array}$ & $\begin{array}{l}(90.0 \%) \\
(10.0 \%)\end{array}$ \\
\hline $\begin{array}{l}\text { Tumour type' } \\
\text { intestinal } \\
\text { diffuse }\end{array}$ & $\begin{array}{l}20 \\
9\end{array}$ & $\begin{array}{l}(69.0 \%) \\
(31.0 \%)\end{array}$ & $\begin{array}{l}10 \\
0\end{array}$ & $\begin{array}{l}(100.0 \%) \\
(0.0 \%)\end{array}$ \\
\hline MG non-H.pylori & $20 / 29$ & $(69.0 \%)$ & $7 / 10$ & $(70.0 \%)$ \\
\hline Culture non-H.pylori & $11 / 16$ & $(68.8 \%)$ & $3 / 5$ & $(60.0 \%)$ \\
\hline
\end{tabular}

' Higher H.pylori prevalence was found in diffuse than intestinal type adenocarcinoma patients: Chi-Square $p<0.05$

\section{Serum gastrin}

The median serum gastrin level of all patients was $116(12-5580) \mathrm{pg} / \mathrm{ml}$ with a gastrin value above the reference value in 25 of $39(64.1 \%)$ patients. Median gastrin values tended to be higher in H.pylori negative $(\mathrm{n}=10)$ than in H.pylori positive $(n=29)$ patients $(\mathrm{p}=0.07)$ (Figure VII.3). No association of serum gastrin levels was found with the histological prevalence of H.pylori (by IMM) or nonH.pylori bacterial flora (by MG minus IMM). 
Antrum-sparing atrophic gastritis was found in 5 of $10 \mathrm{H}$.pylori negative patients $(50.0 \%)$ and in 4 of 29 H.pylori positive patients $(13.3 \%)(\mathrm{p}<0.05)$. Furthermore, the presence of this type of gastritis corresponded with high gastrin levels in all five H.pylori negative patients but only in one of four H.pylori positive patients.

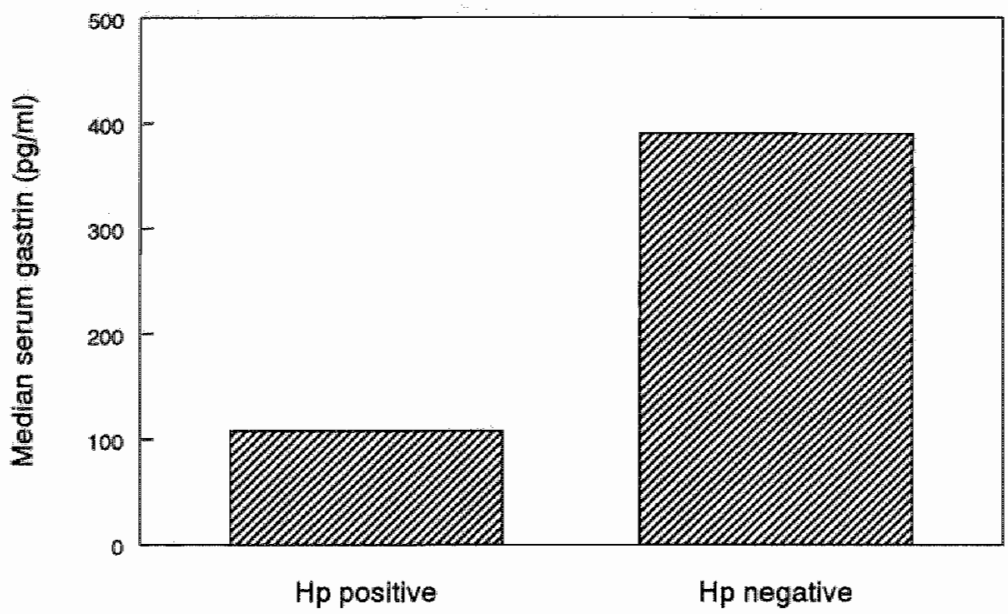

Figure VII.3: Median serum gastrin values in H.pylori positive $(\mathrm{n}=29)$ and H.pylori negative $(\mathrm{n}=10)$ gastric cancer patients (by Western blotting)

\section{Discussion}

In this prospective series of gastric cancer patients, in $25 \%$ there was no indication of previous or current H.pylori infection, whilst current H.pylori infection was found in $53.8 \%$ by immunohistochemistry and previous or current infection in $74.4 \%$ by serology, including Western blotting. Current infection with nonH.pylori intragastric bacterial flora was found histologically in $69.2 \%$ of gastric cancer patients to a comparable degree in H.pylori-positive and H.pylori-negative patients.

The serological H.pylori positivity of the patients is in line with those reported by others using either an IgG-Elisa assay or immunoblotting ${ }^{1,41-43}$. Histologically, higher H.pylori prevalences are reported in the literature; especially for the intestinal type of gastric cancer prevalences of $88-89 \%$ were found $d^{44,45}$, and even $94 \%$ using a combination of culture and histology ${ }^{46}$. However, also prevalences around $60 \%$ are described ${ }^{13,47}$. 
In most studies, $\mathrm{HE}$ and $\mathrm{MG}$, both non-specific staining methods, were applied for the histological detection of H.pylori. Use of a specific immunohistochemical stain for the detection of H.pylori may explain the lower prevalences found in this study. In addition, special attention was paid to the presence of non-H.pylori bacteria when using the $M G$, thereby excluding some falsely H.pylori-positive patients.

Serological tests are of great value in screening for H.pylori-positivity ${ }^{48,49}$. Both IgA and IgG Elisa assays used in this study ${ }^{50.51}$ appeared to be highly reproducible for the assessment of $H$.pylori-positivity or -negativity.

In this group of gastric cancer patients, Western blotting for the detection of IgG antibodies against H.pylori seemed to be the most sensitive method. No H.pylori positives diagnosed by IMM, IgG or IgA Elisa were missed by Western blotting. However, compared to IMM about $20 \%$ additional H.pylori positive patients were detected by Western blotting. The presence of H.pylori antibodies in this group of patients probably indicates a past H.pylori infection.

Using both serology and histology, $25 \%$ of the gastric cancer patients were negative for a past or present H.pylori infection. Although it cannot be excluded that disappearance of H.pylori on long term has resulted in a decrease or even disappearance of the antibody titers ${ }^{52}$, similar prevalences of H.pylori negative gastric cancer patient were found by Sipponen et al. ${ }^{53}$ also. We believe that one fourth of the patients has developed gastric cancer without a prior H.pylori infection and that other aetio-pathogenetic factors have to be considered in these.

Comparing H.pylori positive with H.pylori negative patients (taking Western blotting as discriminator), no significant differences were seen concerning age, gender, intragastric $\mathrm{pH}$, or tumour site. However, diffuse type adenocarcinoma were more frequently $H$.pylori positive than intestinal type carcinoma. This finding does therefore not support the hypothesis, that H.pylori is mainly involved in the pathogenesis of the intestinal type of cancer, a concept that has also been challenged by others ${ }^{43,45,53}$.

About $90 \%$ of H.pylori positive patients had antibodies against cagA, supporting the hypothesis that cagA positive strains may be associated with an increased risk of gastric cancer ${ }^{54}$. However, no differences were found between the prevalences of cagA in patients with an intestinal or diffuse type of gastric cancer.

In severe atrophic gastritis, a reduced or absent intragastric acidity is frequently found and is associated with intragastric bacterial overgrowth ${ }^{20.30 .55 .57}$ and an increased risk of gastric cancer ${ }^{58-60}$. In the gastric cancer patients of this study, non-H.pylori bacterial flora was found frequently and in high amounts in gastric biopsy specimens by MG as well as by culture. This seems to be a consequence of low gastric acid secretion. Unfortunately, stimulated acid secretion could not be 
determined in this patient population.

The intragastric concentration of non-H.pylori flora are not assumed to result from contamination only, as culture of biopsy specimens has confirmed the histological findings in most patients. Before culture all biopsies had been washed thrice in order to remove contaminating flora. Furthermore the non-H.pylori bacterial flora was found not only on the surface of the gastric mucosa but also within the gastric glands.

Two-thirds of the patients positive by histology or serology for H.pylori, were in addition positive for non-H.pylori bacterial flora. Also in $70 \%$ of H.pylori negative patients, non- $H$.pylori flora was found. This could mean that the presence of non-H.pylori flora in gastric cancer patients is independent of previous or current H.pylori infection. It also suggests that growth of non-H.pylori flora is not

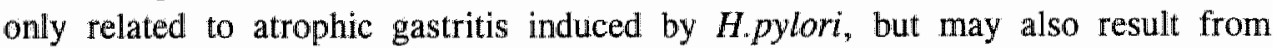
atrophic gastritis of other aetiology such as autoimmune.

The fact that eight patients with serological evidence of H.pylori infection, had no current infection but only evidence of non-H.pylori intragastric bacteria could support the hypothesis that H.pylori associated gastritis develops towards gastric atrophy with hypochlorhydria or achlorhydria, subsequent bacterial overgrowth and production of $\mathrm{N}$-nitroso compounds ${ }^{29,30,32}$. The $\mathrm{N}$-nitroso compounds may then play a role in the final development of gastric cancer. Another explanation for the association between intragastric bacterial overgrowth is a low intragastric vitamin $\mathrm{C}$ concentration ${ }^{16,17}$. Ascorbic acid acts as a scavenger of reactive oxygen and inhibits the $\mathrm{N}$-nitrosation reaction ${ }^{15}$. Partial deficiency of vitamin $\mathrm{C}$ as found in H.pylori positive gastritis ${ }^{61,62}$, and in situations with reduced intragastric acidity and bacterial overgrowth ${ }^{17.63}$. Furthermore, it can be hypothesized that non-H.pylori intragastric bacteria may contribute to the development of gastric cancer by acting as an antigenic trigger.

The elevated levels of serum gastrin with the presence of antrum-sparing atrophic gastritis found in this group of gastric cancer patients were predominantly present in the H.pylori negative patients. This finding might indicate that a type A atrophic gastritis is associated with gastric carcinogenesis in H.pylori negative patients.

In summary, in $25 \%$ of a consecutive series of gastric cancer patients, no evidence was found for current or previous H.pylori infection. Non-H.pylori bacterial flora was found in about two-thirds of all patients and has to be considered as a factor that may contribute to the development of gastric cancer. All diffuse cancers were H.pylori positive but only $67 \%$ of the intestinal type. Antrumsparing type A atrophic gastritis with elevated serum gastrin seems to be frequent in H.pylori negative patients with gastric cancer. 
It can be concluded that other factors than H.pylori may contribute to the aetio-pathogenesis of gastric cancer and that non-H.pylori flora may be one of those. 


\section{References}

1 Forman $D$, Newell $D G$, Fullerton $F$ et al. Association between infection with Helicobacter pylori and risk of gastric cancer: evidence from a prospective investigation. Br Med J 1991; 302: 1302-1305.

2 Nomura A Stemmermann GN, Chyou P-H, Kato I, Perez-Perez BI, Blaser MJ. Helicobacter pylori infection and gastric carcinoma among Japanese Americans in Hawaii. N Eng J Med 1991; 325: 1132-1136.

3 Parsonnet J, Friedman GD, Vandersteen DP et a1. Helicobacter pylori infection and the risk of gastric cancer. N Engl J Med 1991; 325: 1127-1131.

4 The Eurogast Study Group. An international association between Helicobacter pylori and gastric cancer. Lancet 1993; 341: 1359-1362.

5 Hansson L-E, Engstrand L, Nyrến $\mathrm{O}$ et al. Helicobacter pylori infection: independent risk indicator of gastric adenocarcinoma. Gastroenterol 1993; 105: 1098-1103.

6 Kikuchi $S$, Wada O, Nakajima $T$, Nishi $T$, Kobayashi $O$, Knoshi $T$, Inaba $Y$ and the Research Group on prevention of gastric carcinoma amoung young adults. Serum anti-Helicobacter pylori antibody and gastric carcinoma among young adults. Cancer 1995; 75: 2789-2793.

7 Fuchs CS, Mayer RJ. Review article: Gastric carcinoma. N Engl J Med 1995; 333: 32-41.

8 Fukao A, Komuatsu S, Tsubono $\mathrm{Y}$ et al. Helicobacter pylori infection and chronic atrophic gastritis among Japanese blooddonors: a cross-sectional study. Cancer Causes Control 1993; 4: 307-312.

9 Sipponen $\mathrm{P}$, Kekki M, Siurala M. Atrophic chronic gastritis and intestinal metaplasia in gastric carcinoma. Comparison with a representative population sample. Cancer 1983; 52: 1062-1068.

10 Sipponen P. Helicobacter pylori infection - a common worldwide environmental risk factor for gastric cancer? Endoscopy 1992; 24" 424-427.

11 Nomura A, Stemmermann GN. Review article: Helicobacter pylori and gastric cancer. J Gastroenterol Hepatol 1993; 8: 294-303.

12 Siurala M, Sipponen P, Kekki M. Campylobacter pylori in a sample of Finnish poplation: relations to morphology and functions of the gastric mucosa. Gut 1988; 29: 909-915.

13 Loffeld RJLF, Willmes I, Flendrig JA, Arends JW. Helicobacter pylori and gastric carcinoma. Histopathology 1990; 17: 537-541.

14 Houben GMP, Hooi J, Hameeteman W, Stockbrügger RW. The frequency of Helicobacter pylori associated peptic ulcer disease and of autoimmune associated conditions in gastric and renal cancer: a retrospective comparison in 267 patients. Eur J Cancer Prev 1994; 3(suppl 2): 75-79.

15 Mirvish SS, Effects of vitamins $\mathrm{C}$ and $\mathrm{E}$ on $\mathrm{N}$-nitroso compound formation, carcinogenesis and cancer. Cancer 1986; 58: 1842-1850. 
Hu J, Zhang S, Jia E et al. Diet and cancer of the stomach: a case-control study in China. Int J Cancer 1988; 41: $331-335$.

17 Sobala GM, Pignatelli B, Schorah $\mathrm{CJ}$ et al. Levels of nitrite, nitrate, N-nitroso compounds, ascorbic acid and total bile acids in gastric juice of patients with and without precancerous conditions of the stomach. Carcinogenesis 1991; 12:193-198.

Bjelke E. Epidemiological studies of cancer of the stomach, colon, and rectum with special emphasis on the role of diet. Scand J Gastroenterol 1974; 9 (suppl 31): $42-53$.

19 Buiatti E, Palli D, Decarli A et al. A case-control study of gastric cancer and diet in Italy. Int J Cancer $1989 ; 44: 611-616$.

20 Ruddel』 W, Bone E, Hill MJ, Blendis L, Walters C. Gastric juice nitrate: a risk factor for cancer in the hypochlorhydric stomach? Lancet 1976; ii: 1037-1039.

21 Jones S, Davies P, Savage A. Gastric juice nitrite and gastric cancer. Lancet 1978; i: 1355 .

22 Hall C, Cook A, Darken D et al. Evaluation of the nitrosamine hypothesis of gastric carcinogenesis in man. Clin Sci 1984; 66: 34-35P.

23 Forman D. Gastric cancer, diet and nitrate exposure. Br Med J 1987; 294: 528-529.

24 Waldum HL, Brenna E, Kleveland PM, Sandvik AK. Gastrin - physiological and pathophysiological role: clinical consequences. Dig Dis 1995; 13: 25-38.

25 Öberg K. Neuroendocrine gastrointestinal tumours. Review. Ann Oncol 1996; 7: 453-463.

26 Varis $\mathbb{K}$, Samloff $\mathbb{I M}$, Ihamäki $T$, Siurala $M$. An appraisal of tests for severe atrophic gastritis in relatives of patients with pernicious anemia. Dig Dis Sci 1979; 24: 187-191.

27 Varis K, Kekkï M, Härkönen M, Sipponen P, Samloff IM. Serum pepsinogen I and serum gastrin in the screeming of atrophic pangastritis with high risk of gastric cancer. Scand J Gastroenterol 1991; 26 (suppl 186): 117-123.

28 Gisbertz IAM, Jonkers DMAE, Arends JW et al. Specific detection of Helicobacter pylori and non-Helicobacter pylori flora in small and large cell primary gastric B-cell non-Hodgkin's lyphoma. Ann Oncol (in press).

29 Stockbrügger RW, Cotton PB, Menon GG el al. Pernicious anaenia, intragastric bacterial overgrowth and possible mechanisms. Scand IJ Gastroenteroll 1984; 19 : 355-364.

30 Forsythe SJ, Dolby JM, Webster ADB, Cole JA. Nitrate- and nitrite-reducing bacteria in the achlorhydric stomach. J Med Microbiol 1988; 25:253-259.

31 Ruddell WSJ, Bone ES, Hill MJ, Walters CL. Pathogenesis of gastric cancer in pernicious anaemia. Lancet 1978; i: 521-523.

32 Reed PI, Haines K, Smith PLR, House FR, Walters CL. Gastric juice N-nitrosamines in health and gastroduodenal disease. Lancet $1981 ; 2: 550-552$.

33 Gray SF, Wyatt JL, Rathbone BJ. Simplified techniques for identifying Campylobacter pyloridis. J Clin Pathol 1986; 39: 1279. 


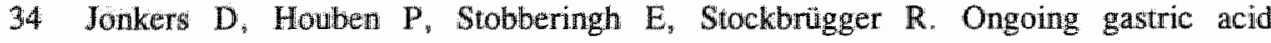
inhibition is a confounding factor in Helicobacter pylori diagnosis. Eur J Gastroenterol Hepatol 1997; 9: 49-53.

35 Lauren P. The two histological main types of gastric carcinoma. Diffuse and socalled intestinal type. Acta Pathol Microbiol Scand 1965; 64: 31-49.

36 Dixon MF, Genta RM, Yardley JA, Correa $P$ and the Participants of the International Workshop on the histopathology of gastritis. Classification and grading of gastritis. The Updated Sydney System. Am J Surg Pathol 1996; 20: 1161-1181.

37 Jonkers $D_{\text {; }}$ Stobberingh $\mathrm{E}$, Stockbrúgger $\mathrm{R}$. Influence of oropharyngeal flora and specimen pretreatment on the recovery of Helicobacter pylori. Eur J Clin Microbiol Infect Dis 1996; 15: 378-382.

38 Cruickshank $R$, Duguid JP, Marmion BP, Swain RHA. Medical Microbiology. Volume 2. The practice of medical microbiology. Churchill Livingstone, Edinburgh, 1975 .

39 Balows A, Hausler WJ, Herrmann KL: Manual of Clinical Microbiology. American Society for Microbiology, Washington, DC, 1991.

40 Jansen $J$, Lamers $C$. Effect of changes in serum calcium of secretin-stimulated gastrin in patients with Zollinger-Ellison syndrome. Gastroenterol 1982; 83: 173-178.

41 Crabtree JE, Wyatt JI, Sobala GM et al. Systemic and mucosal humoral responses to Helicobacter pylori in gastric cancer. Gut 1993; 34: 1339-1343.

42 Kuipers EJ, Gracia-Casanova M, Pena AS et al. Helicobacter pylori serology in patients with gastric carcinoma. Scand J Gastroenterol 1993; 28: 433-437.

43. Hansson L-E Engstrand L, Nyrén O, Lindgren A. Prevalence of Helicobacter pylori infection in subtypes of gastric cancer. Gastroenterol 1995; 109: 885-888.

44 Parsonnet J, Vandersteen D, Goates J, Sibley RK, Pritkin J, Chang Y. Helicobacter pylori infection in intestinal- and diffuse-type gastric adenocarcinoma. $J$ Nat Cancer Inst $1991 ; 83: 640-643$.

45 Buruk F, Berberoglu U, Pak I, Aksaz E, Celen O. Gastric cancer and Helicobacter pylori infection. Br J Surg 1993; 80: 378-379.

46 Nogueira AM, Ribero GM, Rodrigues MA et al. Prevalence of Helicobacter pylori in Brazilian patients with gastric carcinoma. Am J Clin Pathol 1993; 100: 236-239.

47 Wee A, Kang JY, Teh M. Helicabacter pylori and gastric cancer: correlation with gastritis, intestinal metaplasia and tumour histology. Gut 1992; 33: 1029-1032.

48 Pena AS, Endtz HPh, Offerhaus GJA et al. Value of serology (ELISA and immunoblotting) for the diagnosis of Campylobacter pylori infection. Digestion 1989; 44: 131-141.

49 Cutler AF, Havstad S, Ma CK, Blaser MJ, Perez-Perez GI, Schubert TT. Accuracy of invasive and noninvasive tests to diagnose Helicobacter pylori infection. Gastroenterol 1995; 109: 136-141. 
50 Riepponen $P$, Häivä V-M. Evaluation of three new Pyloriset ${ }^{\text {tM }}$ tests, EIA-G, EIA-A, and dry latex, for serological diagnosis of Hellcobacter pylori infection. Gut 1995; 37 (suppl 1): A12.

51 Wouw van de BAM, Boer de WA, Jansz AR, Roymans RTM, Staals APG. Comparison of three commercially available enzyme-linked immunosorbent assays and biopsy-dependent diagnosis for detecting Helicobacter pylori infection. J Clin Microbiol 1996; 34: 94-97.

52 Karnes WE, Samloff IM, Siurala $M$ et al. Positive serum antibodies and negative tissue staining for Helicobacter pylori in subjects with atrophic body gastritis. Gastroenterol 1991; 101: 167-174.

53 Sipponen $\mathbb{P}$, Kosunen TU, Valle J, Rihela M, Seppala $\mathbb{K}$. Helicobacter pylori infection and chronic gastritis in gastric cancer. J Clin Pathol 1992; 45:319-323.

54 Blaser MJ, Perez-Perez CI, Kleanthous $\mathrm{H}$ et al. Infection with Helicobacter pylori strains possessing cagA is associated with an increased risk of developing adenocarcinoma of the stomach. Cancer Res 1995; 55: 2111-2115.

55 Ruddell WSJ, Bone ES, Hill MJ, Blendes LM, Walters CL. Pathogenesis of gastric cancer in pernicious anaemia. Lancet 1978; i: 521-523.

56 Dolby JM, Webster ADB, Boriello SP, Barclay FE, Bartholomew BD, Hill MJ. Bacterial colonization and nitrite concentration in the achlorhydric stomachs of patients with primary hypogammaglobulinaemia or classical pernicious anaemia. Scand J Gastroenterol 1989; 19: 105-110.

57 Stockbrigger RW, Armbrecht U, Rode JW et al. The bacterial overgrowth syndrome is uncommon in pernicious anaemia: results of a follow-up study. Microbial Ecol Health Dis 1990; 3: 209-215.

58 Kuster G, Remine W, Dockerly M. Gastric cancer in pernicious anaemia and in patients with and without achlorhydria. Ann Surg 1972; 175: 783-789.

59 Stockbrügger RW, Menon GG, Beilby JD, Mason RR, Cotton PB. Gastroscopic screening in 80 patients with pernicious anaemia. Gut 1983; 24: 1141-1147.

60 Borch K. Epidemiologic, Clinicopathologic and economic aspects of gastroscopic screening of patients with pernicious anaemia. Scand J Gastroenterol 1986; 21 : 21-30.

61 Rokkas $T$, Papatheodorou G, Karamins A, Mavrogeorgis A, Kalogeropoulos $\mathbb{N}$, Giannikos N. Helicobacter pylori infection and gastric cancer juice vitamin $C$ levells. Impact of eradication. Dig Dis Sci 1.995; 40:615-621.

62 Waring AJ, Drake IM, Schorah CJ, White KLM, Lynch DAF, Axon ATR, Dixon MF. Ascorbic acid and total vitamin $C$ concentrations in plasma, gastric juice, and gastrointestinal mucosa: effects of gastritis and oral supplementation. Gut 1996; 38 : 171-176.

63 Houben GM, Stockbrügger RW. Bacteria in the aetio-pathogenesis of gastric cancer: a review. Scand J Gastroenterol 1995; 212 (suppl): 13-18. 


\section{Chapter VIII}

\section{General discussion}




\section{Introduction}

In this thesis, the contribution of both $H$.pylori and non-H.pylori intragastric bacterial flora in patients with peptic ulcer disease, primary gastric lymphoma and gastric cancer has been studied. Therefore, culture procedures were optimalized and a specific immunohistochemical stain for the histological detection of $H$.pylori was applied in combination with the non-specific modified Giemsa stain to assess the total intragastric bacterial flora.

\section{Detection of Helicobacter pylori by culture}

The sensitivity of culture for the detection of H.pylori is often found to be moderate and is influenced by low counts of H.pylori, transport time and conditions and the presence of contaminating flora. In the literature, use of several selective media containing different combinations of antibiotics have been described to detect H.pylori in the presence of non-H.pylori flora. We further optimalized culture procedures to improve the detection of H.pylori by washing and grinding gastric biopsy specimens before inoculation, in addition to the use of selective media (Chapter II). Washing of the specimens reduced the amount of contaminating flora but not of $H$.pylori and thereby improved the detection of the latter. Also grinding of the specimens, as applied in this study, results in a higher bacterial yield of $H$.pylori. Furthermore, biopsies were kept at $4^{\circ} \mathrm{C}$ and cultured within four hours to prevent a decreased viability of the H.pylori microorganisms.

\section{Detection of Helicobacter pylori by histology}

For the histological detection of H.pylori, mostly non-specific staining methods are used with a moderate agreement between observers'. Especially in situations with a high intragastric $\mathrm{pH}$ and consequently bacterial overgrowth in the stomach, a sensitive and specific staining method for the histological detection of H.pylori is required. A specific immunohistochemical stain employing a commercially available antiserum for the detection of H.pylori was evaluated in situations where H.pylori and/or non-H.pylori bacterial flora could be present (Chapter III and IV). Both a high sensitivity and specificity and the lowest inter-observer variation were found for the immunohistochemical stain compared to the modified Giemsa stain (lowest specificity) and the Warthin-Starry silver stain (lowest sensitivity).

The presence of non-H.pylori bacteria will result in false positive and false negative results, and a large inter-observer variation of $H$.pylori scores in the MG stain. This stain has to diagnose H.pylori on the basis of morphology and location only. These problems can be overcome by use of a specific immunohistochemical 
stain for the histological detection of H.pylori. Furthermore, coccoid forms of H.pylori can be missed using non-specific staining methods, but react positively in the immunohistochemical stain.

Also PCR will be a sensitive and specific method to detect $H$.pylori in the presence of other bacteria. H.pylori can $\mathbb{a l s o}$ be detected by non-invasive tests such as the urea breath test ${ }^{2}$. However, the sensitivity and specificity of this test can be influenced by treatment with antibiotics, gastric acid inhibitors, or other clinical conditions associated with a reduced gastric acid secretion.

When it is desirable to distinguish symptomatic from asymptomatic H.pylori infection, endoscopy is required ${ }^{3}$. Many studies still use culture, histology or a combination of both for the detection of H.pylori. Megraud ${ }^{4}$ concludes in a review on H.pylori diagnosis that both histology and culture give very good results when performed under optimal conditions, in addition to information about the status of the mucosa. The present study has contributed to the optimalisation of both culture and histology for the detection of H.pylori.

\section{Prevalence of Helicobacter pylori and non-Helicobacter pylori flora in peptic ulcer disease, primary gastric lymphoma and gastric cancer patients}

In the gastric disorders studied in this thesis, the prevalence of H.pylori was lower than found in the literature (Table). This may be due to the use of the specific immunohistochemical stain for the detection of H.pylori in our studies. Especially when other flora is present, use of the modified Giemsa or the Haematoxylin-Eosin stain may result in false positive scores. In all studies of this thesis, special attention was paid to the presence of non- $H$.pylori flora in the modified Giemsa stain. However, in mainly untreated DU and GU patients, hardly any non-H.pylori flora could be detected by the modified Giemsa and there was a good correlation between the modified Giemsa and the immunohistochemical stain. In patients with treated acid-related disorders, with gastric cancer, and with primary gastric lymphoma, high amounts of non-H.pylori were found. This can disturb the detection of $H$.pylori and will warrant the use of a specific immunohistochemical staining method for the histological detection of H.pylori. 
Prewalence of H.pylori (by immumohistochemical stain) and non-Hpylori flora (by modified Giemsia) in patients with peptic ulcer disease, prinary gastric lymphoma, and gastric caucer

\begin{tabular}{lcc}
\hline Clinical condition & H.pylori & non-H.pylori \\
\hline Duodenal ulcer & $81.6 \%$ & $10.2 \%$ \\
Gastric ulcer & $83.0 \%$ & $17.0 \%$ \\
Gastric lymphoma & $61.5 \%$ & $67.3 \%$ \\
Gastric cancer & $53.8 \%$ & $69.2 \%$ \\
\hline
\end{tabular}

\section{Duodenal versus gastric ulcer patients}

DU and GU patients were further compared to assess differences in the gastroduodenal distribution, prevalence and density of H.pylori as well as the histological changes which may contribute to a differential presentation of both forms of peptic ulcer disease. The H.pylori prevalence was found to be similar in antrum and corpus of both DU and GU patients. The H.pylori density was lower in corpus than antrum of DU and was higher in corpus of GU than of DU patients. Together with the antral-predominant gastritis in DU and the more wide-spread inflammatory changes in GU patients, these findings were in line with reports in the literature ${ }^{5-7}$.

Higher prevalences of the precancerous lesions atrophic gastritis and intestinal metaplasia in GU than DU patients support the hypothesis that GU patients are at higher risk to develop gastric cancer than DU patients ${ }^{8-10}$. From the presented study in this thesis it is not clear whether the histological differences between DU and GU patients result from or are the cause of the differences in H.pylori colonization.

One factor reported to be specifically associated with H.pylori and duodenal ulcer disease, is the presence of gastric metaplasia in the duodenal bulb. In contrast with findings in the literature ${ }^{11.12}$, we could not confirm a role of gastric metaplasia in the development of a duodenal ulcer as similarly low prevalences were found in both DU and GU patients. An alternative ulcerogenic mechanism may be the release of inflammatory mediators in the gastric lumen that subsequently enter the duodenum. However, a comparable prevalence of H.pylori and gastritis in antrum of DU and GU patients does not either support a role of this mechanism in the differential pathogenesis of DU and GU formation.

Several reviews ascribe a role to the altered gastric acid secretion and the age of acquisition of H.pylori infection in the differential pathogenesis of peptic ulcer disease: Acquisition of H.pylori infection early in life should increase the risk of developing gastric ulcer but not duodenal ulcer ${ }^{8}$, and DU patients have an increased 
acid secretion while GU patients are characterized by a normal or decreased acid secretion ${ }^{7.9 .13}$. In this context, an increased parietal cell mass, increased basal acid secretion, rapid gastric emptying and an increased duodenal acid load may predispose to $\mathrm{DU}$ formation ${ }^{14}$. A higher basal intragastric $\mathrm{pH}$ in $\mathrm{GU}$ than in $\mathrm{DU}$ patients was confirmed in our study.

\section{Gastric malignancies}

Non-H.pylori flora was found in a relatively high proportion of both patients with primary gastric lymphoma (Chapter VI) and patients with gastric cancer (Chapter VII), with a similar degree in H.pylori positive and H.pylori negative patients. Although the non-H.pylori flora might just be a consequence of the functional situation in both patient groups, it cannot be excluded that this flora significantly contributes to their pathogenesis: by being an antigenic stimulus for a chronic inflammatory response or by the production of toxic and/or carcinogenic metabolites, such as N-nitroso compounds. Finally, both H.pylori and non-H.pylori flora are associated with a low intragastric vitamin $\mathrm{C}$ level ${ }^{15,16}$. Vitamin $\mathrm{C}$ can protect against gastric cancer by preventing the formation of potentially carcinogenic $\mathrm{N}$-nitroso compounds and reactive oxygen metabolites. The known presence of non-H.pylori flora in gastric cancer precursor lesions or conditions supports a possible role of this flora in gastric carcinogenesis ${ }^{17}$.

Patients in whom no H.pylori is present in the stomach at the time of diagnosis, can previously have been infected by H.pylori without signs of a current infection. This can be controlled for by serology. Unfortunately, serum samples were not available for the patients with primary gastric lymphoma, but they were for the gastric cancer patients. In these patients, H.pylori was detected in $53.8 \%$ by immunohistochemistry and in $74.4 \%$ by serology (i.e. Western blotting). Using the same Western blotting technique, H.pylori was detected in $62.5 \%$ of healthy blood donors of the same age and the same area. One quarter of gastric cancer patients showed no evidence of a previous or current H.pylori infection and about $20 \%$ was positive by serology only. The latter indicates that $H$.pylori may in many patients play an initial role in gastric carcinogenesis as suggested by Correa ${ }^{18}$ : H.pylori associated gastritis can progress towards atrophic gastritis and intestinal metaplasia, both precancerous lesions for the intestinal type of gastric cancer. H.pylori colonization decreases and potentially disappears with increasing atrophic gastritis and intestinal metaplasia. H.pylori associated gastritis can also be the base for the diffuse type of gastric cancer by formation of hyperplasia through involvement of genes affecting cell-cell and cell-matrix junctional proteins ${ }^{19}$.

In this study about $90 \%$ of $H$.pylori positive gastric cancer patients were cagA positive. The presence of cagA positive H.pylori isolates may be associated 
with an increased risk of gastric cancer ${ }^{20}$. This is in line with findings of Kuipers et al. ${ }^{21}$, who reports an increased risk for patients infected with cag A positive strains to develop atrophic gastritis.

Although many studies describe an association of H.pylori with gastric cancer, this association is not always found to be as strong as reviewed by Crespi et al. ${ }^{22}$. In our study, the H.pylori prevalences both in patients with gastric cancer and with primary gastric lymphoma are not much different from that of the normal population of a similar age and at least in a quarter of the gastric cancer patients. Other factors than H.pylori have to be involved in the aetio-pathogenesis of gastric cancer. One of these factors may be the presence of type A autoimmune atrophic gastritis $^{23}$ : higher prevalence of antrum-sparing atrophic gastritis and higher serum gastric levels were found in H.pylori negative than H.pylori positive gastric cancer patients.

\section{General conclusions and recommendations}

The presence of gastric non-H.pylori flora, as found in patients with low acid secretions and gastric malignancies, will warrant the use of specific and sensitive methods for the detection of H.pylori, like a specific immunohistochemical stain, optimalized culture procedures, or the use of PCR.

The rather small differences in distribution of a H.pylori infection and of the frequency of gastric metaplasia between DU and GU patients indicate that H.pylori and gastric metaplasia of the duodenum are not the only factors responsible for the differential development of peptic ulcer disease. Other factors have to be studied in addition, including host factors, inflammatory mediators, H.pylori strains differences and environmental factors.

H.pylori prevalences found in patients with primary gastric lymphoma and gastric cancer are not much different form the normal population. Furthermore, high amounts of non-H.pylori flora have been found in both patients with primary gastric lymphoma and gastric cancer. It cannot be excluded that this flora plays a role in the initiation, development or progression of these gastric malignancies. The exact role of this flora has to be further investigated.

The Western blotting is the most sensitive serological detection method to assess a current or previous $H$.pylori infection and can give additional information on the presence of cagA positive strains. This is important as these strains seem to be 
related to the development of peptic ulcer disease, atrophic gastritis, and gastric cancer. Their role in primary gastric lymphoma needs further study.

In further studies the non-H.pylori bacterial flora of the stomach has to be further characterized to obtain more information on its potentially harmful effects. This can be done by culture of both aerobes and anaerobes and assessment of the presence of nitrate-reducing bacteria. Other options may be the use of PCR or immunohistochemistry to identify single bacterial species or a subgroup of bacteria. 


\section{References}

1 Santucci $R$, Amorosi A, Pileri S et al. Observer variation in histological assessment of Helicobacter pylori on gastric biopsiles. Gastroenterol 1994; 106 (suppl): A172.

2 Cutler AF, Havstad S, Ma CK, Blaser MJ; Perez-Perez GI, Schuber TI. Accuracy of invasive and noninvasive tests to diagnose Helicobacter pylori infection. Gastroenterol 1995; 109: 136-141.

3 Mion F. Diagnostic tests to document Helicobacter pylori eradication. Gastroenterol 1996; 110: 324-325.

4 Megraud F. Advantages and disadwantages of current diagnostic tests for the detection of Helicobacter pylori. Scand J Gastroenterol 1996; 31 (suppl 215): 57-62.

5 Sipponen $P$. Natural history of gastritis and its relationship to peptic ulcer disease. Digestion 1992; 51 (suppl 1): 70-75.

6 Louw JA, Falck V, van Rensburg C, Zak J, Adams G, Marks JN. Distribution of Helicobacter pylori colonisation and associated inflammatory changes: difference between patients with duodenal and gastric ulcers. J Clin Pathol 1993;46: 754-756.

7 Kuipers EJ, Thijs JE, Festen HPM. The prevalence of Helicobacter pylori in peptic ulcer disease. Aliment Pharmacol Ther 1995; 9: 59-69.

8 Blaser MJ, Chyou PH, Nomura A. Age at establishment of Helicobacter pylori infection and gastric carcinoma, gastric ulcer, and duodenal ulcer risk. Cancer Res $1995 ; 55: 562-565$.

9 Correa P, Schmidt BA. The relationship between gastric cancer frequency and the ratio of gastric to duodenal ulcer. Aliment Pharmacol Ther 1995; 9 (suppl 2): 13-19.

10 Hansson L-E, Nyrén $\mathrm{O}$, Hsing AW et al. The risk of stomach cancer in patients with gastric or duodenal ulcer disease. N Engl J Med 1996; 335: 242-249.

11 Caselli M, Threvisani L, Aleotti A, Bovolenta MR, Stabellini G. Gastric metaplasia in duodenal bulb and Campylobacter-like organisms in development of duodenal ulcer. Dig Dis Sc 1989; 34: 1374-1378.

12 Khulusi S, Mendall MA, Patel P, Levy J, Badve S, Northfield TC Helicobacter pylori infection density and gastric inflammation in duodenal ulcer and non-ulcer subjects. Gut 1995; 37: 319-324.

13 Tytgat GNJ, Noach LA, Rauws EAJ. Helicobacter pylori infection and duodenal ulcer disease. Gastroenterol Clin N Am 1993; 22: 127-139.

14 Graham DY. Campylobacter pylori as a pathogenic factor in duodenal ulcer: the case for. Scand J Gastroenterol 1989; 24 (suppl 160): 46-52.

15 Sobala GM, Crabtree JE, Dixon MF et al. Acute Helicobacter pylori infection: clinical features, local and systemic immune response "gastric mucosal histology and gastric juice ascorbic acid concentrations. Gut 1991; 32:1415-1418.

16 Sobala GM, Pignatelli B, Schorah CJ et al. Levels of nitrate, nitrite, N-nitroso compounds, ascorbic acid and total bile acid in gastric juice of patients with and without precancerous conditions of the stomach. Carcinogenesis $1991 ; 12: 193-198$. 
17 Stockbrigger RW, Cotton $\mathrm{PB}$, Menon GG at al. Pernicious anaemia, intragastric bacterial overgrowth and possible consequences. Scand J Gastroenterol 1984; 19 : 355-364.

18 Correa $\mathrm{P}$. The epidemiology of gastric cancer. World J Surg 1991; 15: 228-234.

19 Solcia $E$, Fiocca $\mathbb{R}_{*}$ Luinetti $O$ et al. Intestinal and diffuse gastric cancers arise in a different background of Helicobacter pylori gastritis through different gene involvement. Am J Surg Pathol 1996; 20 (suppl 1): S8-S22.

20 Blaser MJ, Perez-Perez GI, Kleanthous $\mathrm{H}$ et al. Infection with Helicobacter pylori strains possessing cagA is associated with an increased risk of developing adenocarcinoma of the stomach. Cancer Res 1995; 55: 2111-2115.

21 Kuipers EJ, Pérez-Pếrez GI, Meuwissen SGM, Blaser MJ. Helicobacter pylori and atrophic gastritis: importance of cagA status. J Natl Cancer Inst 1996; 88: 465-566.

22 Crespi M, Citara F. Current opinion. Helicobacter pylori and gastric cancer: an overestimated risk? Scand J Gastroenterol 1996; 31: 1041-1046.

23 Stockbrügger $R$, Angervall $\mathrm{L}$, Lundqvist G. Serum gastrin and atrophic gastritis in achllohydric patients with and without pernicious anaemia. Scand J Gastroenterol $1976 ; 11: 713-719$. 


\section{Chapter IX}

\section{Summary}




\section{Summary}

The presence of a Helicobacter pylori (H.pylori) infection is associated with duodenal and gastric ulcer disease, gastric cancer and primary gastric (mucosaassociated lymphoid tissue) lymphoma. If the intragastric $\mathrm{pH}$ increases, also nonH.pylori bacteria can colonize the stomach. The presence of non-H.pylori flora may disturb the detection of $H$.pylori both by culture and histology. In this thesis some methodological studies are described on an improved detection of H.pylori by culture and immunohistochemistry, especially when H.pylori and/or non-H.pylori bacterial flora can be present. These techniques are then applied in clinical situations associated with both types of flora.

Regarding the methodological findings of this study, the use of selective agar plates in addition to washing and grinding of the gastric biopsies prior to inoculation, improved the detection of H.pylori by culture. The rate of recovery of low amounts of H.pylori ( $\leq 10^{3} \mathrm{cfu} / \mathrm{ml}$ ) was low in the presence of high amounts of oropharyngeal flora ( $\geq 10^{4} \mathrm{cfu} / \mathrm{ml}$ ). Pretreatment of the specimens by washing of the biopsies improved the detection of H.pylori in 10 of 28 patients.

An immunohistochemical staining method using a purified polyclonal antiserum had a high sensitivity $(83.8 \%)$ and the highest specificity $(90.0 \%)$ for the detection of $H$.pylori compared with the modified Giemsa $(90.0 \%$ and $53.8 \%$, respectively) and the Warthin-Starry silver stain $(70.0 \%$ and $82.5 \%$, respectively). A non-H.pylori flora could for example be found after eradication therapy when patients were treated with gastric acid inhibitors until control endoscopy and can lead to both false positive and false negative results with a high inter-observer variation when non-specific histological staining methods are used.

Using an immunohistochemical stain, the H.pylori prevalences were $81.6 \%$ in duodenal ulcer, $83.0 \%$ in gastric ulcer, $61.5 \%$ in primary gastric lymphoma and $53.8 \%$ in gastric cancer patients. In all patients, special attention was also paid to the presence of non-H.pylori flora through assessment of form and location of microorganisms in the modified Giemsa stain in combination with absent immunoreactivity for H.pylori in the same area of a consecutive section. The distribution and density of both floras were studied and related to histological findings.

Non-H.pylori bacteria were found in $10.2 \%$ of duodenal ulcer and $17.0 \%$ of gastric ulcer patients. The immunohistochemical stain and the modified Giemsa stain were comparable for the detection of H.pylori: $98.0 \%$ concordance in duodenal ulcer and $89.4 \%$ concordance in gastric ulcer patients. H.pylori prevalences were similar in 
corpus, antrum and duodenum of both duodenal and gastric ulcer patients. Only the H.pylori density was higher in antrum than corpus of duodenal ulcer and in the corpus of gastric ulcer than of duodenal ulcer patients. The H.pylori density was in line with the presence of an antrum-predominant gastritis in duodenal ulcer patients and a more wide-spread gastric mucosal inflammation in gastric ulcer patients. A major role of gastric metaplasia of the duodenal bulb in the differential pathogenesis of duodenal and gastric ulcer could not be confirmed. Higher prevalences of precancerous lesions such as atrophic gastritis and intestinal metaplasia were found in gastric than duodenal ulcer patients, possibly associated with an increased risk to develop gastric cancer.

In patients with primary gastric lymphoma and gastric cancer, a similar frequency of H.pylori (61.5\% and $53.8 \%$, respectively) and non-H.pylori flora (65.4\% and $69.2 \%$, respectively) was found. The H.pylori prevalences found by immunohistochemistry were lower compared to findings reported in the literature, and were not much different from the normal population of a simillar age.

In patients with primary gastric lymphoma, the H.pylori prevalences tended to be higher in corpus $(62.8 \%)$ than antrum mucosa $(45.5 \%)$, with a higher density in corpus of large than of small cell lymphoma patients. Also in tumour tissue, the prevalence of non-H.pylori flora was higher in large than small cell lymphoma. Both observations can be a consequence of differences in tumour mass and/or intragastric acidity.

In gastric cancer patients no significant differences in the presence of H.pylori or non-H.pylori flora were found in relation to tumour type or tumour site. In these patients, a previous H.pylori infection was controlled for by serology: $20 \%$ were H.pylori positive by serology but not by histology supporting the hypothesis of an initial role of H.pylori in the gastric carcinogenesis. However, in a quarter of the gastric cancer patients H.pylori could not at all be detected either by serology or histology. In this group of patients other factors than H.pylori have to play a role in the pathogenesis of gastric cancer such as type A atrophic gastritis. This type of gastritis was found in 50\% of H.pylori negative gastric cancer patients. Another factor may be the presence of relatively high amounts of non-H.pylori bacteria found in both patient groups with primary gastric lymphoma and gastric cancer. The non-H.pylori may contribute to the development or progression of gastric malignancies by acting as an antigenic trigger or by the production of carcinogenic on toxic metabolites.

The role of the total bacterial flora, H.pylori and non-H.pylori, in the pathogenesis of gastric malignancies needs further study and will warrant the use of a specific 
immunohistochemical stain for the histological detection of H.pylori in combination with highly sensitive serology. 
Chapter X

Samenvatting 


\section{Samenvatting}

De aanwezigheid van Helicobacter pylori (H.pylori) in de maag is geassocieerd met het voorkomen van ulcus duodeni, ulcus ventriculi, maagkanker en primaire maaglymfomen. Een veel toegepaste therapie voor H.pylori eradicatie is een combinatie van twee antibiotica met een maagzuurremmend middel. Als de $\mathrm{pH}$ in de maag toeneemt, kunnen ook andere bacteriën, de zogenaamde non-H.pylori bacteriën, de maag koloniseren. De aanwezigheid van deze non-H.pylori flora kan de detectie van de H.pylori met behulp van kweek of histologie verstoren. Dit proefschrift beschrijft methodologische studies betreffende een verbeterde detectie van H.pylori met behulp van kweek en immunohistochemie, met name in die omstandigheden waarbij H.pylori en/of non-H.pylori bacteriën aanwezig kunnen zijn. Vervolgens zijn deze technieken toegepast in een aantal klinische situaties die geassocieerd zijn met het voorkomen van beide types flora.

Uit de methodologische studies is gebleken dat het gebruik van selectieve agar platen in combinatie met het wassen van de maagbiopten en deze vervolgens te vermalen vốr het enten, de detectie van H.pylori met behulp van kweek verbeteren. Met name het terugvinden van lage concentraties H.pylori $\left(\leq 10^{3} \mathrm{cfu} / \mathrm{ml}\right)$ werd bemoeilijkt in de aanwezigheid van relatief grote hoeveelheden orofaryngeale flora $\left(\geq 10^{4} \mathrm{cfu} / \mathrm{ml}\right)$. Wassen resulteerde voornamelijk in een afname van orofaryngeale flora en niet H.pylori wat leidde tot een verbeterde detectie van H.pylori in 10 van de 28 patiënten.

Immunohistochemie met gebruik van een gezuiverd polyklonaal antiserum tegen H.pylori, had een hoge sensitiviteit $(83.8 \%)$ en de hoogste specificiteit $(90.0 \%$ ) voor het aantonen van H.pylori in vergelijking met de gemodificeerde Giemsa kleuring (respectievelijk $90.0 \%$ en $53.8 \%$ ) en de Warthin-Starry zilver kleuring (respectievelijk 70.0 en $82.5 \%$ ). Non-H.pylori bacteriën konden onder andere worden aangetroffen na gebruik van maagzuurremmende middelen gericht op eradicatie van $H$.pylori. Indien niet-specifieke histologische kleuringsmethoden werden gebruikt voor het aantonen van H.pylori na maagzuurremmende therapie, kon de non- $H$.pylori flora leiden tot zowel vals-positieve als vals-negatieve resultaten. Ook tussen beoordelaars werd een grote variatie in beoordeling van de preparaten waargenomen bij gebruik van niet-specifieke kleuringen.

Met behulp van immunohistochemie werd H.pylori aangetoond in $81.6 \%$ van de ulcus duodeni patiënten, in $83.0 \%$ van de ulcus ventriculi patiënten, $61.5 \%$ van de patiënten met een primair maaglymfoom en $53.8 \%$ van de patiënten met maagkanker. Tevens werd gekeken naar de aanwezigheid van non-H.pylori 
bacteriën met behulp van de gemodificeerde Giemsa kleuring op basis van vorm en ligging van microörganismen én een negatieve uitslag van de immunohistochemische kleuring voor H.pylori op dezelfde locatie van een achtereenvolgende coupe. De verdeling en de dichtheid van H.pylori en nonH.pylori flora werden bestudeerd en gerelateerd aan de histologische bevindingen.

Non-H.pylori bacteriën werden slechts in $10.2 \%$ van ulcus duodeni en in $17.0 \%$ van ulcus ventriculi patiënten waargenomen. Er was een grote mate van overeenstemming wat betreft het aantonen van H.pylori tussen de immunohistochemie en de gemodificeerde Giemsa kleuring: $98.0 \%$ in ulcus duodeni en $89.4 \%$ in ulcus ventriculi patiënten. De prevalentie van $H$.pylori was gelijk in corpus, antrum en duodenum van ulcus duodeni en ulcus ventriculi patiënten. Echter bij ulcus duodeni patiënten was de dichtheid van H.pylori hoger in antrum dan in corpus en de dichtheid was hoger in het corpus van ulcus ventriculi patiẻnten ten opzichte van ulcus duodeni patiẻnten. De verdeling van de dichtheid van H.pylori over de maag kwam overeen met de aanwezigheid van gastritis die overheersend voorkwam in het antrum bij ulcus duodeni patiënten en een meer gelijkmatig verspreid aanwezig was in antrum en corpus bij ulcus ventriculi patiënten. In deze studie kon niet worden bevestigd dat de aanwezigheid van gastrische metaplasie in de bulbus duodeni een belangrijke rol speelt in de differentiële pathogenese die leidt tot een ulcus duodeni of een ulcus ventriculi. De prevalenties van precancereuze laesies zoals atrofische gastritis en intestinale metaplasie, waren hoger in ulcus ventriculi patiënten dan in ulcus duodeni patiënten. Dit is mogelijk gerelateerd aan het hogere risico bij ulcus ventriculi patiënten om maagkanker te ontwikkelen.

Bij patiënten met primaire maaglymfomen en patiënten met maagkanker werden gelijke frequenties van H.pylori (respectievelijk $61.5 \%$ en $53.8 \%$ ) en non-H.pylori flora (respectievelijk $65.4 \%$ en $69.2 \%$ ) gevonden. De prevalenties van H.pylori, gevonden met een immunohistochemische kleuring waren lager in vergelijking met de gegevens uit de literatuur en verschilden nauwelijks van de prevalentie in gezonde vrijwilligers van dezelfde leeftijd.

Bij patiënten met primaire maaglymfomen waren de prevalenties van H.pylori hoger, maar niet significant verschillend in de mucosa van het corpus $(62.8 \%)$ ten opzichte van het antrum $(45.5 \%)$. De dichtheid van H.pylori in het corpus van patiënten met een grootcellig maaglymfoom was hoger ten opzichte van patiënten met een kleincellige maaglymfoom evenals de prevalentie van non-H.pylori flora in tumorweefsel. Beide waarnemingen kunnen een gevolg zijn van verschillen in tumormassa en/of verschillen in de zuurgraad van de maag.

Bij de maagkanker patiënten werden geen significante verschillen gevonden 
betreffende de aanwezigheid van H.pylori of non-H.pylori flora in relatie tot het type tumor of de histologische locatie hiervan. Twintig procent van de patienten was positief voor H.pylori op basis van serologie maar negatief op basis van histologie. Deze bevinding ondersteunt de hypothese dat H.pylori een initiẻle rol zou kunnen spelen bij de ontwikkeling van maagkanker. Bij een kwart van de patiënten met maagkanker kon H.pylori niet worden aangetoond met behulp van immunohistochemie of serologie. In deze groep patiënten spelen andere factoren dan de aanwezigheid van H.pylori waarschijnlijk een rol in de pathogenese van maagkanker zoals de aanwezigheid van type $\mathrm{A}$ atrofische gastritis: dit type gastritis werd in 50\% van de H.pylori negatieve maagkanker patiënten gevonden. Ook de aanwezigheid van relatief grote hoeveelheden non-H.pylori bacteriën, zoals aangetroffen bij mensen met maagkanker en bij mensen met een primair maaglymfoom, kunnen een rol spelen. Deze non-H.pylori flora zou kunnen bijdragen aan de ontwikkeling of progressie van maligniteiten in de maag door als antigene trigger te fungeren of door de produktie van carcinogene of toxische metabolieten.

De rol van de totale bacteriële flora, H.pylori en non-H.pylori, in de pathogenese van gastrische maligniteiten vereist nader onderzoek. Hierbij is het gebruik van specifieke immunohistochemische kleuringen voor de histologische detectie van $H . p y l o r i$ in combinatie met een sensitieve serologische test noodzakelijk. 


\section{Dankwoord}




\section{Dankwoord}

Graag wil ik iedereen bedanken die op enigerlei wijze heeft bijgedragen aan de totstandkoming wan dit proefschrift. Een aantal personen wil ik hierbij met name noemen.

Allereerst wil ik alle patiënten bedanken van wiens materiaal ik gebruik kon maken. Zonder hen was dit proefschrift nooit tot stand gekomen.

Prof. Stockbrügger, mijn promotor, wil ik bedanken voor de mogelijkheid die ik heb gekregen om dit promotieonderzoek uit te voeren en zijn sterke betrokkenheid, enthousiasme en kritische blik waarmee hij mij begeleid heeft.

Ellen Stobberingh, jij was mijn dagelijkse aanspreekpunt. Ik wil je bedanken voor de goede begeleiding (ondanks dat je het altijd druk had). Alhoewel de gastroenterologische en microbiologische visie niet altijd op eén lijn lagen, heeft dit in positieve zin bijgedragen tot de interpretatie van de resultaten. Daarnaast heb ik het zeer gewaardeerd dat je ook altijd belangstelling toonde voor de gewone dingen en dat een bespreking vaak uitmondde in zomaar even wat praten.

Al die biopten hadden niet verzameld kunnen worden zonder de hulp van alle artsen en arts-assistenten van Gastroenterologie en het personeel van de Endoscopie-afdeling. Hartelijk bedankt voor all die keren dat ik 's morgens met mijn potjes en buisjes kwam en ze daarna weer gevuld mee terug kon nemen.

$\mathrm{Na}$ het verzamelen moest alles natuurlijk verwerkt worden op het lab.

Allereerst wil ik Sandra van der Veeke bedanken, de analiste die mij 2,5 jaar met heel veel werk heeft geholpen en mij de beginselen van de bacteriologie heeft bijgebracht. Toen ik na de eerste dag naar huis ging kon ik mij niet voorstellen dat ik ooit zou leren om al die "bolletjes" te onderscheiden als zijnde Gram-positief, Gram-negatief, coccen of staven.

Ook alle analisten van het "bac-lab" en Lieve Lemaitre bedankt voor jullie hulp.

Op de laboratoria histologie en immuunhistochemie van de afdeling pathologie kon ik altijd mijn coupes kleuren: bedankt voor jullie hulp en gezelligheid.

Adriaan de Bruïne en Prof. Arends bedankt voor al die preparaten die we samen bekeken hebben en bedankt voor de adviezen en opmerkingen bij de totstandkoming van de artikels. Adriaan, ook bedankt voor je hulp bij de laatste fase van het proefschrift vanuit Amerika.

Hoofdstuk VI kwam tot stand dankzij een samenwerking met de vakgroep haematologie/oncologie. Harrie Schouten bedankt voor je begeleiding hierbij en Ingrid Gisbertz bedankt voor de fijne samenwerking. 
Voorts waren er de collega's op het lab: Bryan, Christel, Han, Moniek, Ruud, alle excollega's en stagiaires. Allemaal bedankt voor de samenwerking, hulp en de leuke tijd.

Al mijn kamergenoten bedankt. Tussen het werk door was er altijd tijd voor advies, een luisterend oor of gewoon even gezellig kletsen. Met name Nancy bedankt dat je ne altijd met raad en daad bijstond en Els en Nico (vierkantjes, driehoekjes... of toch vierkantjes) bedankt voor jullie steun tijdens de laatste fase.

Peter Houben, wij hebben nauw samengewerkt en samen veel materiaal verzameld voor onze studies. Dit blijkt ook uit onze gezamenlijke promoties. Bedankt voor al je hulp, de prettige samenwerking en bedankt voor al die keren dat ik je lastig mocht vallen als we weer een patiënt of patiëntenmateriaal op moesten sporen.

Verder wil ik bedanken alle medewerkers van de afdeling Medische Microbiologie, het secretariaat van Medische Microbiologie en Gastroenterologie, de functiekamer, Dr. Biemond voor de gastrine bepalingen en Peter Terporten en Wil Mullers voor hun hulp met statistiek en computer, en Tiny voor de hulp bij de laatste afronding van dit proefschrift.

Al mijn familie en vrienden bedankt voor jullie belangstelling bij mijn onderzoek met "beestjes en stukjes weefsel".

Tenslotte niet te vergeten mijn ouders en Karel.

Pap en mam dank zij jullie kon ik gaan studeren. Jullie hebben mij altijd gesteund en gemotiveerd om te worden hoe ik nu ben. Bedankt voor alles.

Karel, jij stond voor $200 \%$ achter me. Als ik ooit twijfelde was jij er altijd van overtuigd dat ik het kon. En je had gelijk,... het is gelukt. Bedankt voor al je steun en begrip. 
Curriculum Vitae 


\section{Curriculum Vitae}

Daisy Jonkers werd geboren op 2 december 1968 te Nederweert. In 1987 behaalde zij het VWO-diploma an de Philips van Horne Scholengemeenschap te Weert. Aansluitend begon zij met de studie Gezondheidswetenschappen, richting Biologische Gezondheidskunde, aan de Universiteit van Maastricht. Zij haalde op 18 november 1992 haar doctoraal diploma en trad per 15 januari 1993 in dienst als assistente in opleiding bij de vakgroep Gastroenterologie van de Universiteit van Maastricht. In nauwe samenwerking met de vakgroepen Medische Microbiologie en Pathologie werkte ze aan het onderzoek dar beschreven is in dit proefschrift. 


\section{Publications}

- Jonkers DMAE, Verhagen $H$, van Poppel G, Willems MI, Leeman WR, de Vogel $N$, van Bladeren P. Effect of three weeks dietary intake of Brussels sprouts on repeatedly measured cytogenetic biomarkers in human lymphocytes. Mut Res 1993; 291: 247.

- Jonkers DM, Stobberingh EE, Houben P. Stockbrügger RW. The influence of longterm treatment with omeprazole on changes in faecal aerobic flora. Gastroenterol 1994; 106 (suppl 4): A101.

- Jonkers D, Stobberingh E, Stockbrügger R. Omeprazole inhibits growth of Grampositive and Gram-negative bacteria including Helicobacter pylori in vitro. I Antimicrob Chemother 1996; 37: 145-150.

- Jonkers D, Stobberingh E, Stockbrügger R. Influence of oropharyngeal flora and specimen pretreatment on the recovery of Helicabacter pylori. Eur J Clin Microbiol Infect Dis 1996; 15: 378-382.

- Jonkers D, Houben P, Stobberingh E, Stockbrügger R. Ongoing gastric acid inhibition is a confounding factor in Helicobacter pylori diagnosis. Eur J Gastroenterol Hepatol $1997 ; 9: 49-53$.

- Jonkers D, Stobberingh E, de Bruine A, Arends JW, Stockbrügger R. Evaluation of immunohistochemistry for the detection of Helicobacter pylori in gastric mucosal biopsies. I Infection (in press).

- Jonkers D, Houben P, de Bruine A, Stobberingh E, Stockbrügger R. Helicobacter pylori and non-Helicobacter pylori bacterial flora in patients with gastric cancer. Eur J Gastroenterol Hepatol 1996; 8: A6.

- Jonkers D, Houben P, Stobberingh E, Stockbrïgger R. The gastroduodenal distribution of Helicabacter pylori: a comparison of patients with duodenal orgastric ulcer. $\mathrm{Z}$ Gastroenterol 1996; 9: 592 .

- Jonkers D, Gisbertz I, Arends JW, Stobberingh E, Schouten H, Stockbrügger $\mathbb{R}$. Helicobacter pylori (Hp) and non-Helicobacter pylori (non-Hp) bacterial flora in patients with gastric MALT-lymphoma. Z Gastroenterol 1996; 9: 608.

- Gisbertz IAM, Jonkers DMAE, Arends JW, Bot FJ, Stockbrügger RW, Vrints LW, Schouten HC. Specific detection of Helicobacter pylori flora in small and large cell primary gastric B-cell non-Hodgkin's lymphoma. Ann Oncol (in press). 